Public Interest Energy Research (PIER) Program FINAL PROJECT REPORT

\title{
CHARACTERIZING COSTS, SAVINGS AND BENEFITS OF A SELECTION OF ENERGY EFFICIENT EMERGING TECHNOLOGIES IN THE UNITED STATES
}

Prepared for: California Energy Commission

Prepared by: Lawrence Berkeley National Laboratory

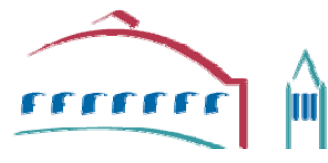




\title{
Prepared by:
}

\author{
Primary Author(s): \\ Tengfang Xu \\ Jan Willem Slaa \\ Jayant Sathaye \\ Lawrence Berkeley National Laboratory \\ 1 Cyclotron Road \\ Berkeley, CA 94720 \\ http://www.lbl.gov
}

Contract Number: BOA-99-205-P

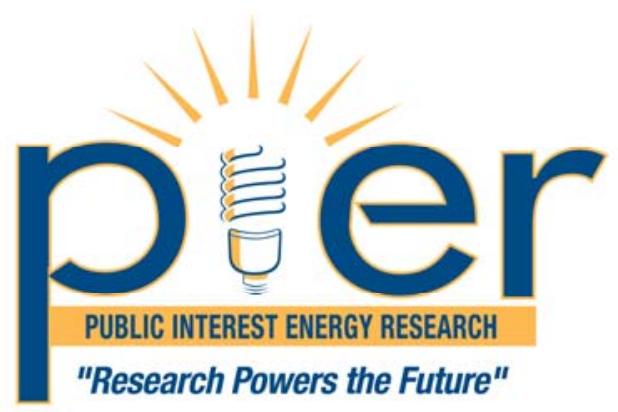

\section{Prepared for:}

\section{California Energy Commission}

Anish Gautam

Contract Manager

Pramod Kulkarni

Project Manager

Virginia Lew

Office Manager

\section{Energy Efficiency Research Office}

Laurie Ten Hope

Deputy Director

Energy Research, Development and Demonstration Division

Melissa Jones

Executive Director

\section{DISCLAIMER}

This report was prepared as the result of work sponsored by the California Energy Commission. It does not necessarily represent the views of the Energy Commission, its employees or the State of California. The Energy Commission, the State of California, its employees, contractors and subcontractors make no warrant, express or implied, and assume no legal liability for the information in this report; nor does any party represent that the uses of this information will not infringe upon privately owned rights. This report has not been approved or disapproved by the California Energy Commission nor has the California Energy Commission passed upon the accuracy or adequacy of the information in this report. 


\section{ACKNOWLEDGEMENTS}

This study is sponsored by the California Energy Commission's Public Interest Energy Research (PIER) program, and managed by CIEE, under the Contract No. DE-AC02-05CH11231 with the U.S. Department of Energy. This report benefits from the guidance and recommendations provided by Anish Gautam and Promod Kulkarni of California Energy Commission's PIER program. We would like to thank Barbara Adams for her assistance in publication of this report. 


\section{PREFACE}

The California Energy Commission's Public Interest Energy Research (PIER) Program supports public interest energy research and development that will help improve the quality of life in California by bringing environmentally safe, affordable, and reliable energy services and products to the marketplace.

The PIER Program conducts public interest research, development, and demonstration (RD\&D) projects to benefit California.

The PIER Program strives to conduct the most promising public interest energy research by partnering with RD\&D entities, including individuals, businesses, utilities, and public or private research institutions.

- PIER funding efforts are focused on the following RD\&D program areas:

- Buildings End - Use Energy Efficiency

- Energy Innovations Small Grants

- Energy - Related Environmental Research

- Energy Systems Integration

- Environmentally Preferred Advanced Generation

- Industrial/Agricultural/Water End - Use Energy Efficiency

- Renewable Energy Technologies

- Transportation

Characterizing Costs, Savings and Benefits of a Selection of Energy Efficient Emerging Technologies in the United States is the report for the Industrial/Agricultural/Water End - Use Energy Efficiency project (contract number BOA-99-205-P, grant number LBL9005398) conducted by Lawrence Berkeley National Laboratory. The information from this project contributes to PIER's Industrial/Agricultural/Water End - Use Energy Efficiency Program.

For more information about the PIER Program, please visit the Energy Commission's website at www.energy.ca.gov/research/ or contact the Energy Commission at $916-654-4878$. 


\begin{abstract}
Adoption of energy-efficient technologies and practices as one of the most important strategies to reduce energy consumption while maintaining economic growth. This report presents the project outcomes from performing re-assessments of all of the 33 emerging energy-efficient industrial technologies selected for this study, including re-evaluation of the 26 technologies that were previously identified by Martin et al. (2000) and their potential significance to energy use in the industries, and new evaluation of additional seven technologies. The re-assessments were updated with recent information that we searched and collected from literature to the extent possible. The progress of the selected technologies as they diffused into the marketplace from 2000 to 2010 was then discussed in this report. The report also includes updated detailed characterizations of 15 technologies studied in 2000, with comparisons noted.
\end{abstract}

Please use the following citation for this report:

$\mathrm{Xu}$, Tengfang, Slaa, Jan Willem, Sathaye, Jayant. (Lawrence Berkeley National Laboratory). 2010. Characterizing Costs, Savings and Benefits of a Selection of Energy Efficient Emerging Technologies in the United States. California Energy Commission. Publication number: BOA-99-205-P. 


\section{TABLE OF CONTENTS}

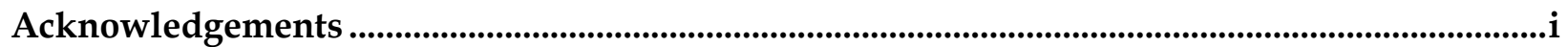

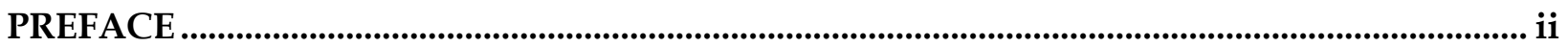

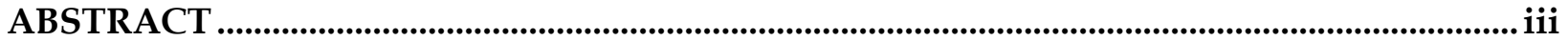

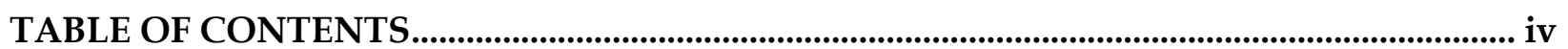

Executive Summary .........................................................................................................................................

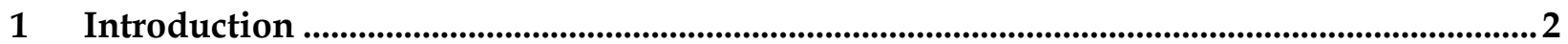

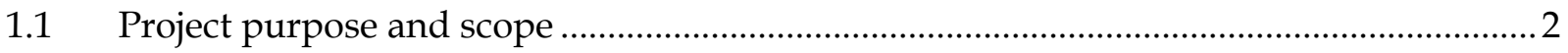

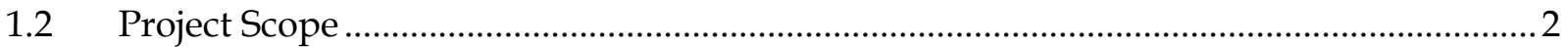

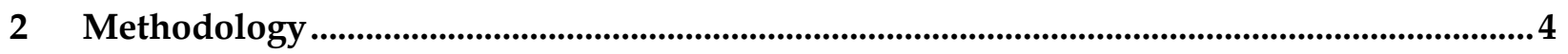

2.1 Assessment on Significance of Technologies …................................................................. 4

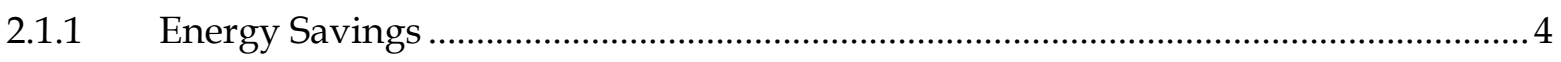

2.1.2 Cost of emerging technologies …...............................................................................

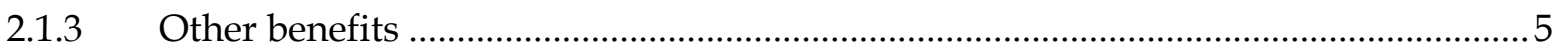

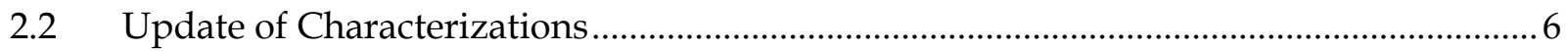

2.2.1 Market information, new technology and reference technology ............................. 6

2.2.2 Analyses of energy savings, cost, other benefits ................................................... 7

3 Assessment on Significance of the Selected Emerging Technology .........................................8

$4 \quad$ Updated Characterizations ....................................................................................................................... 10

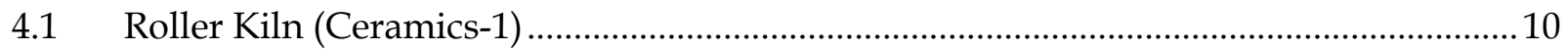

4.2 Advanced CHP Turbines (Utilities-1) ........................................................................ 14

$4.3 \quad$ Advanced Reciprocating Engines (Utilities-2) ........................................................... 18

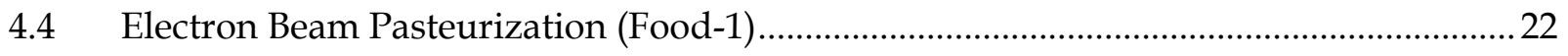

4.5 High-Efficiency/Low $\mathrm{NO}_{x}$-Burners (Other-2) …............................................................2 25

4.6 Pump System Efficiency Improvements (Motorsystems-6) ...........................................28

4.7 Semi-Continuous Melt Silicon Crystal Growth (Electron-1)........................................... 32

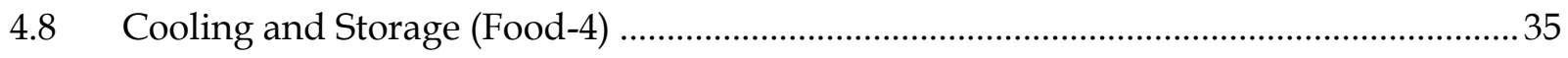

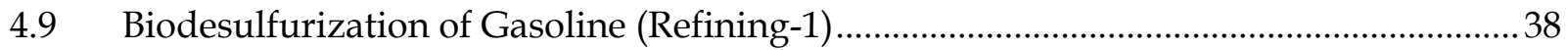

4.10 Fouling Minimization (Refining-2) ........................................................................... 41

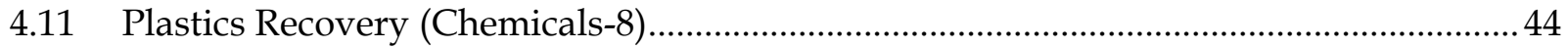




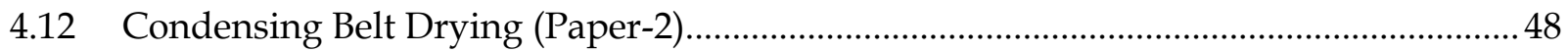

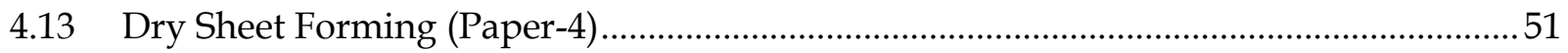

4.14 Heat Recovery Paper - Enclosing Hoods (Paper-5) ....................................................... 54

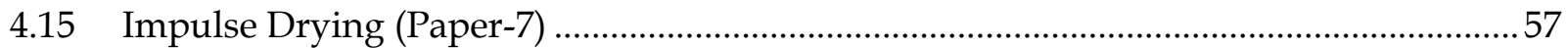




\title{
Characterizing Costs, Savings and Benefits of a Selection of Energy Efficient Emerging Technologies in the United States
}

\author{
Tengfang Xu \\ Jan Willem Slaa \\ Jayant Sathaye \\ Lawrence Berkeley National Laboratory \\ Environmental Energy Division \\ Lawrence Berkeley National Laboratory \\ Berkeley, CA \\ LBNL Final Report \\ to \\ California Energy Commission (CEC) and \\ California Institute for Energy and Environment (CIEE) \\ December 2010
}




\section{EXECUTIVE SUMMARY}

Implementation and adoption of efficient end-use technologies have proven to be one of the key measures for reducing greenhouse gas (GHG) emissions throughout the industries. In many cases, implementing energy efficiency measures is among one of the most cost effective investments that the industry could make in improving efficiency and productivity while reducing $\mathrm{CO}_{2}$ emissions. Over the years, there have been incentives to use resources and energy in a cleaner and more efficient way to create industries that are sustainable and more productive. With the working of energy programs and policies on GHG inventory and regulation, understanding and managing the costs associated with mitigation measures for GHG reductions is very important for the industry and policy makers around the world. Successful implementation of emerging technologies not only can help advance productivities and competitiveness but also can play a significant role in mitigation efforts by saving energy. Providing evaluation and estimation of the costs and energy savings potential of emerging technologies is the focus of our work in this project.

The overall goal of the project is to identify and select emerging and under-utilized energy-efficient technologies and practices as they are important to reduce energy consumption in industry while maintaining economic growth. This report contains the results from performing Task 2 "Technology evaluation" for the project titled "Research Opportunities in Emerging and Under-Utilized Energy-Efficient Industrial Technologies," which was sponsored by California Energy Commission and managed by CIEE. The project purpose is to analyze market status, market potential, and economic viability of selected technologies applicable to the U.S. In this report, LBNL first performed re-assessments of all of the 33 emerging energy-efficient industrial technologies, including re-evaluation of the 26 technologies that were previously identified by Martin et al. (2000) and their potential significance to energy use in the industries, and new evaluation of additional seven technologies. The re-assessments were essentially updated with recent information that we searched and collected from literature to the extent possible. The progress of selected technologies as they diffused into the marketplace from 2000 to 2010 was then discussed in this report. The report also includes updated detailed characterizations of 15 technologies studied in 2000, with comparisons noted. 


\section{Introduction}

The U.S. economy used 100 quadrillion Btu (106 EJ) of primary energy in 2008. The U.S. industries accounted for 32 percent of total domestic primary energy use that served the entire commercial, residential, industrial and transportation sectors.

Implementation and adoption of efficient end-use technologies have proven to be one of the key measures for reducing greenhouse gas (GHG) emissions throughout the industries. In many cases, implementing energy efficiency measures is among one of the most cost effective investments that the industry could make in improving efficiency and productivity while reducing carbon dioxide $\left(\mathrm{CO}_{2}\right)$ emissions. Over the years, there have been incentives to use resources and energy in a cleaner and more efficient way to create industries that are sustainable and more productive. With the working of energy programs and policies on GHG inventory and regulation, understanding and managing the costs associated with mitigation measures for GHG reductions is very important for the industry and policy makers around the world. Successful implementation of emerging technologies not only can help advance productivities and competitiveness but also can play a significant role in mitigation efforts by saving energy. Providing evaluation and estimation of the costs and energy savings potential of emerging technologies is the focus of our work in this project.

Based upon the agreement and previous coordination with American Council for an Energy-Efficient Economy (ACEEE), Lawrence Berkeley National Laboratory (LBNL) identified an initial list of 33 emerging and under-utilized energy-efficient technologies for screening study. Some of the identified technologies were considered to have good potential in future perspective but had not been readily commercialized or were having low market penetration in the industries. Among the 33 technologies that were identified, only 15 technologies were characterized with detailed information on cost and savings benefits in the study perform by Martin et al. (2000). There was very limited information on 13 technologies (out of 33) because of immaturity for adoption in the market in 2000, and virtually no information on five other technologies.

\subsection{Project purpose and scope}

The overall goal of the project is to identify and select emerging and under-utilized energy-efficient technologies and practices as they are important to reduce energy consumption in industry while maintaining economic growth. This report contains the results from performing Task 2 "Technology evaluation" for the project titled "Research Opportunities in Emerging and Under-Utilized Energy-Efficient Industrial Technologies," which was sponsored by California Energy Commission (CEC) and managed by California Institute for Energy and Environment (CIEE). The project purpose is to analyze energy savings, technology costs, market potential, and economic viability of selected technologies applicable to the U.S.

\subsection{Project Scope}

In this report, LBNL will first perform re-assessments of all of the 33 emerging energyefficient industrial technologies, including re-evaluation of the 26 technologies that were 
previously identified by Martin et al. (2000) and their potential significance to energy use in the U.S. industries, and new evaluation of additional seven technologies. The reassessments will be updated with recent information to be searched and collected from literature to the extent possible. The progress of selected technologies as they diffused into the marketplace from 2000 to 2010 will be discussed in this report. In addition, The report will also include updated detailed characterizations of 15 technologies studied in 2000, with comparisons noted. 


\section{Methodology}

Based upon the agreement and previous coordination with ACEEE, LBNL identified an initial list of 33 emerging and under-utilized energy-efficient technologies for screening study. We then performed literature reviews to collect relevant and updated information on energy efficiency, energy savings, market adoption, and costs of the selected emerging technologies applicable to various industries; followed by an evaluation of the potential significance in energy savings from each of the 33 technologies. The evaluations included 26 technologies and compared them with their previous outcomes from the earlier study performed by Martin et al. (2000).

Because only 15 emerging technologies were characterized and published in the previous report (Martin et al. 2000), we updated the characterizations of 15 emerging technologies based upon available and updated information, which was obtained from the literature research and further technology reviews performed in this study.

In summary, we searched and used updated information to evaluate the significance of the 33 selected emerging or underutilized technologies in industries, and then characterized all of the 15 technologies that were previously profiled, using the updated information on costs and savings that were gathered from new literature reviews performed in the current study.

\subsection{Assessment on Significance of Technologies}

For the screening evaluation, significance of technologies was assessed using the following criteria: energy savings, first costs, and other benefits, all being compared to existing technologies using a rating system adopted in the previous study.

The three levels of significance are defined to be "low, medium, or high," while in the case of "other benefits," an additional rating category, "none," is included. Each level of significance corresponds to a pre-defined criteria score as shown in Table 1. In the following, we describe how the criteria scores are defined and developed.

\subsubsection{Energy Savings}

First, the potential energy savings were identified by calculating the specific energy savings of an emerging technology when compared to that of the dominating technology (business as usual). Then, we extrapolated the difference to the total (potential) market size. The total potential energy savings percentage in the U.S. industries can then be obtained by dividing this energy savings by the total U.S. industrial primary energy use in 2006 (15,657 TBtu or 16,516 Peta Joule-PJ).

There are various ways to obtain this percentage depending on the source of data and information available, based upon our literature research. For example, the savings can be quantified as an average saving in percentage (e.g. new method saves $20 \%$ energy), an average saving per product (e.g. $0.1 \mathrm{MBtu}$ per short ton), or expected total savings for the whole sector in TBtu. In the first two scenarios mentioned, scaling up was then done by either looking at the total sector primary energy use, or the total production, respectively. 
In this study, we evaluated the significance of energy savings potential for each emerging technology by its total potential energy savings percentage, which is defined as energy savings divided by the total U.S. industrial primary energy use in 2006.

Based upon the comparison with the total U.S. industrial primary energy in 2006, a total potential energy savings percentage above 0.1 percent for one technology is considered to have a "high" potential with a score of 40 points (shown in column 2 of Table 1 ), while a value lower than 0.01 percent is considered to have "low" potential, with a score of 10 points. A total potential energy savings percentage ranging between 0.01 and 0.1 percent is then considered to have medium potential, corresponding to a score of 20 points. Overall, a higher savings score means greater significance.

Table 1. . Significance ranking for each emerging technology by three criteria (i.e., energy

\begin{tabular}{l|c|c|c}
\multicolumn{1}{c|}{ savings, cost, other benefit) } & Other Benefits \\
\hline High & Energy Savings & Cost & 30 \\
Medium & 40 & 10 & 20 \\
Low & 20 & 20 & 10 \\
None & 10 & 30 & 0
\end{tabular}

\subsubsection{Cost of emerging technologies}

Capital cost estimates of emerging technologies were based on descriptive information obtained from literature, mostly online sources, as actual costs are commonly unavailable in public domains.

As shown in column 3 of Table 1, an emerging technology is considered to have a "high" capital cost, corresponding to a score of 10 points, if its first cost is assessed as expensive as over 1.5 times the average cost of the conventional technology. On the other hand, a technology is considered to have a "low" capital cost, corresponding to a score of 30 points, if it is assessed to be significantly cheaper than the average cost of the conventional technology. If the technology first costs were comparable to a conventional technology or unclear, it would be assumed to be "medium," corresponding to a score of 20 points. Overall, a higher cost score means a lower cost.

\subsubsection{Other benefits}

Other benefits of emerging technologies, which are not directly related to energy savings or first costs, are also important factors affecting the market adoption of the emerging technologies. In the assessments, we considered four different types of other benefits: productivity improvement, product quality improvement, safety improvement benefits, and environmental benefits.

As shown in column 4 of Table 1, if any of these "other benefits" becomes the compelling driver for the technology's adoption in the market, we would assign a high score (compelling benefits, 30 points). Otherwise, the other benefits could either be deemed 'significant' (medium score, 20 points), or 'somewhat significant' (low score, 10 points). No point was given when there were no "other benefits" identified in this study. A higher benefit score means greater significance. 
For each technology, we then summed the scores from each of the three criteria. The summed score can in turn yield a final score that indicates the overall significance of the technology. By definitions shown in Table 1, the final score of an emerging technology could range from as low as 20 (low energy savings, high cost, no other benefit) up to 100 points (high energy savings, low cost, compelling other benefits).

According to the total individual score calculated for each technology, we then ranked the 33 emerging technologies selected in this study, with a higher total individual score indicating a higher level of significance.

In addition, we also compared the individual scores with the previous screening results, when available, which were included in the previous study by Martin et al. 2000. Such comparisons can show improvement or deterioration in the levels of significance for all technologies selected in this study.

\subsection{Update of Characterizations}

For the 15 technologies, we performed updated characterization, each with a one- to two-page summary of the technology profiles, including a complementary data table. In the data table, the following information is included:

- Market information

- Reference technology information

- New technology information

- Energy savings analysis

- Cost analysis

- Key non-energy factors

- Evaluation

- Data source information

\subsubsection{Market information, new technology and reference technology}

In the profile table, market information includes types of technology application and energy used, and the industries to which the new technology is applicable. It also includes the estimated base-case in formation of the market in year 2015, such as production or the energy consumed in the relevant industries. Year 2015 was the same year used in the previous report for the sake of uniformity and the lack of proper forecasting tools. The reference technology information includes the reference technology application, throughput or production unit, and final and primary energy consumption per time (year, or hour), which provides a base case for the comparison with the new technology information. New technology information includes description of the new measure, electricity use, fuel use, and primary energy use. It also includes information on current status of market implementation, date of commercialization, and estimated life time of the new measure. 


\subsubsection{Analyses of energy savings, cost, other benefits}

The energy savings analysis is based upon the comparison of the new technology with its reference case. Estimates were made based on compiled source data from active literature research and technology information gathered in this study.

Normally, technology cost is quantified using either the cost of equipment installation or replacement, or incremental cost per energy unit compared to that of the reference technology. Sometimes, there was a lack of data for analyzing costs in which case no reasonable assessment could be made. In those cases, it will be notes as "N/A."

The other benefits (non-energy) are evaluated using results from the screening assessments and promotion information on implementing the new technology.

Most of the updated information comes from online literature research and reviews. Specifically, we used the Google search engine to gather information and data for the technologies and the industries in which they are applicable. In addition, scientific literature was searched by using ISI Web of Knowledge. In these searches, particular emphasis was placed on available information from manufacturers and research institutes that addressed implementation issues instead of academic issues. Information was also obtained from governmental websites (e.g. U.S. Department of Energy, U.S. Environmental Protection Agency) and the specific industry's professional associations. Finally, information from newspaper and magazine articles was used to understand other benefits of relevant technologies in screening assessments. 


\section{Assessment on Significance of the Selected Emerging Technology}

In this study, a total of 33 technologies were assessed using the criteria described in the "Methodology" section. As stated, only 26 out of the 33 technologies were assessed in the previous study (Martin et al., 2000). Based upon the updated information gathered for this study, we develop new criteria scores for each of the technologies, and compared the criteria scores of each of the 26 technologies with those of the same technologies. Based upon comparisons from the screening assessment, we identified changes in the levels of significance.

Table 2 includes the updated screening assessment results - criteria ranking and scores for each technology, with indications of the changes in its significance (improvement or deterioration as distinguished by different colors).

Table 2 shows that for nine out of 26 technologies, the total individual score for each technology remained the same in 2010 as its counterpart in 2000. The total individual score of another nine technologies went down from 2000 to 2010, while total individual score for eight other technologies went up instead. Overall, the criteria scores for the majority of the individual technologies (i.e., 22 out of 26) had changed in at least one of the criteria (e.g., savings, cost, or other benefits), i.e., only four technologies had not changed in any criteria scores. 
Table 2. Updated screening assessment of 33 emerging energy-efficient industrial technologies, compared to that of previous report by Martin et al. 2000

\begin{tabular}{|c|c|c|c|c|c|c|}
\hline Measure / Technology & Sector & $\begin{array}{c}\text { Potential for } \\
\text { Energy Savings }\end{array}$ & $\begin{array}{c}\text { Costs compared } \\
\text { to standard }\end{array}$ & $\begin{array}{c}\text { Other } \\
\text { Benefits }\end{array}$ & $\begin{array}{l}\text { Significance of } \\
\text { Other Benefits }\end{array}$ & \begin{tabular}{|c|} 
Total Initia \\
Scoring \\
\end{tabular} \\
\hline Super Boiler & Combustion & high & medium & $\mathrm{P}, \mathrm{E}$ & significant & 80 \\
\hline \multirow{3}{*}{$\begin{array}{l}\text { High-efficiency welding } \\
\text { Pump efficiency improvement } \\
\text { Continuous melt silicon crystal growth }\end{array}$} & \multirow{3}{*}{$\begin{array}{l}\text { cross-cutting } \\
\text { cross-cutting } \\
\text { Electronics }\end{array}$} & high & medium & \multirow{3}{*}{$\begin{array}{c}\mathrm{E}, \mathrm{S} \\
\mathrm{P} \\
\mathrm{Q}\end{array}$} & significant & 80 \\
\hline & & high & medium & & significant & 80 \\
\hline & & high & medium & & significant & 80 \\
\hline Submerged Combustion Melting (SCM) & Glass & high & low & $\mathrm{P}, \mathrm{Q}$ & somewhat & 80 \\
\hline \multirow{5}{*}{$\begin{array}{l}\text { Fouling minimization } \\
\text { Impulse drying } \\
\text { Advanced reciprocating engines } \\
\text { Energy management systems } \\
\text { High efficiency/low NOx burners }\end{array}$} & \multirow{5}{*}{$\begin{array}{c}\text { petroleum refining } \\
\text { pulp and paper } \\
\text { cross-cutting } \\
\text { cross-cutting } \\
\text { cross-cutting }\end{array}$} & high & medium & \multirow{5}{*}{$\begin{array}{l}\mathrm{P} \\
\mathrm{P} \\
\mathrm{P} \\
\mathrm{P}, \mathrm{S} \\
\mathrm{E}\end{array}$} & significant & 80 \\
\hline & & high & medium & & significant & 80 \\
\hline & & high & medium & & somewhat & 70 \\
\hline & & high & medium & & somewhat & 70 \\
\hline & & high & medium & & somewhat & 70 \\
\hline Carbon dioxide as a refrigerant & food processing & medium & medium & E,S & compelling & 70 \\
\hline \multirow{4}{*}{$\begin{array}{l}\text { Heat recovery in sinter plants } \\
\text { Plastics recovery } \\
\text { Condebelt drying } \\
\text { Cooling and storage }\end{array}$} & \multirow{4}{*}{$\begin{array}{l}\text { iron and steel } \\
\text { plastics } \\
\text { pulp and paper } \\
\text { food processing }\end{array}$} & medium & low & \multirow{4}{*}{$\begin{array}{l}\mathrm{E} \\
\mathrm{E} \\
\mathrm{P} \\
\mathrm{E}\end{array}$} & significant & 70 \\
\hline & & medium & low & & significant & 70 \\
\hline & & high & medium & & somewhat & 70 \\
\hline & & medium & medium & & significant & 60 \\
\hline Pulsed fluid-bed drying & food processing & medium & medium & $\mathrm{P}, \mathrm{Q}$ & significant & 60 \\
\hline \multirow{2}{*}{$\begin{array}{l}\text { Ammonia absorption refrigeration unit } \\
\text { Biodesulfurization }\end{array}$} & \multirow{3}{*}{$\begin{array}{c}\text { petroleum refining } \\
\text { petroleum refining } \\
\text { pulp and paper }\end{array}$} & medium & high & \multirow{2}{*}{$\begin{array}{l}\mathrm{P}, \mathrm{E} \\
\mathrm{E}, \mathrm{S}\end{array}$} & compelling & 60 \\
\hline & & medium & medium & & significant & 60 \\
\hline \multirow{5}{*}{$\begin{array}{l}\text { Dry sheet forming } \\
\text { Advanced CHP turbine systems } \\
\text { Heat pumps } \\
\text { Heat recovery for cogeneration } \\
\text { Roller kiln }\end{array}$} & & medium & medium & $\mathrm{P}, \mathrm{Q}$ & significant & 60 \\
\hline & \multirow{4}{*}{$\begin{array}{l}\text { cross-cutting } \\
\text { cross-cutting } \\
\text { cement } \\
\text { ceramics }\end{array}$} & high & high & $\mathrm{E}$ & somewhat & 60 \\
\hline & & high & high & $\mathrm{Q}$ & somewhat & 60 \\
\hline & & medium & medium & $\mathrm{E}$ & somewhat & 50 \\
\hline & & medium & medium & $\mathrm{E}$ & somewhat & 50 \\
\hline pulsed electric field pasteurization & food processing & low & medium & Q & significant & 50 \\
\hline \multirow{2}{*}{$\begin{array}{l}\text { High levels of pulverized coal injection } \\
\text { Electron Beam Pasteurization }\end{array}$} & \multirow{2}{*}{$\begin{array}{l}\text { iron and steel } \\
\text { cross-cutting }\end{array}$} & medium & medium & \multirow{3}{*}{$\begin{array}{l}\mathrm{Q} \\
\mathrm{Q} \\
\mathrm{P}\end{array}$} & somewhat & 50 \\
\hline & & low & high & & significant & 40 \\
\hline Advanced polysilicon production & electronics & low & medium & & somewhat & 40 \\
\hline High Intensity Plasma Melting & glass & medium & high & Q & somewhat & 40 \\
\hline Heat recovery - paper & pulp and paper & medium & medium & & insignificant & 40 \\
\hline \multirow{3}{*}{$\begin{array}{l}\text { Low friction working fluids } \\
\text { advanced rotary burners } \\
\text { New glass melting technologies }\end{array}$} & \multirow{3}{*}{$\begin{array}{l}\text { cross-cutting } \\
\text { cross-cutting } \\
\text { glass }\end{array}$} & low & medium & & insignificant & 30 \\
\hline & & low & medium & \multirow[b]{3}{*}{ Q } & insignificant & 30 \\
\hline & & low & medium & & insignificant & 30 \\
\hline Hydrogen purification improvements & petroleum refining & low & medium & & insignificant & 30 \\
\hline
\end{tabular}

deterioration
improvement
no recent data/unclear technology.
new technology: no comparison

While not necessarily a statistically robust observation, this finding shows that approximately one-third of the 26 emerging technologies seemed to be gaining significance in the total individual scores - indicating a higher degree of likelihood that fewer market barriers exist (e.g., decreased measure cost, improved other benefits) for these technologies within the last ten years; whereas approximately two-third of the 26 emerging technologies may have been experiencing headwinds in adoption, commercialization or implementation in the market within the last ten years. 


\section{Updated Characterizations}

In this project, in order to track the performance of the selected emerging technologies, we performed detailed update for the characterizations of the 15 technologies, which were profiled in the previous report. New market penetration and energy performance data, when available, is included in this update.

For the 15 technologies, we first searched and reviewed new data to update the input of the data table. Then we gathered information on the development of the technology since 2000 by searching and studying recent information (within the last five years) and going through the names and companies that were using the technologies. From the tracking and comparisons, we could then understand whether or not the technology had been further developed or implemented; and if so, to what extent it had penetrated into the market. Also, base-case information on industry production and energy use was updated to the more recent data that is available.

The following enlists the names of actual technologies included in this study, followed by new characterizations (profiles) for each of the technologies.

- Roller kiln

- Advanced CHP turbine systems

- Advanced reciprocating engines

- Electron Beam Pasteurization

- High efficiency/low NOx burners

- Pump efficiency improvement

- Semi-continuous melt silicon crystal growth

- Cooling and storage

- Bio-desulfurization

- Fouling minimization

- Plastics recovery

- Condensing belt drying

- Dry sheet forming

- Heat recovery - paper

- Impulse drying

\subsection{Roller Kiln (Ceramics-1)}

Roller kilns (i.e. roller hearth kilns) can be used for manufacturing structural clay products and ceramics. In the U.S., approximately 13.5 million short tons (12.3 Mt) of clay are consumed annually for the production of structural clay products. These are mainly building bricks, which account for 96 percent of clay consumption. Roof tiles, sewer pipes, wall tiles and floor tiles are manufactured out of clay (Virta, 2007). In 2007, about 7.12 billion bricks were produced with production concentrated in Alabama, North Carolina, Texas, Georgia, Ohio, South Carolina, Arkansas, Wyoming, Tennessee and Virginia. Ceramic production in the U.S. is concentrated mainly in the production of tiles (36 percent). Tile production in 2007 is estimated at 157 million $\mathrm{m}^{2}$ (Virta, 2007). 
Total clay consumption for ceramic production was 2.33 million short tons (2.12 Mt) in 2007 (Virta, 2007). In the past decade there has been a decline in clay consumption from 15.1 to 13.5 million short tons (Virta, 1998, 2007).

Bricks, tiles and other ceramics are baked from clay. The clay is formed, dried and then baked. Previously flame and ring-kilns were used with long production cycles (up to 14 days). Today, the most common process is the tunnel kiln. Tunnel kilns have a relatively short production cycle of 75-140 hours. The firing process in the tunnel kiln is automated, and consists of three zones through which the bricks travel: preheating, baking and cooling.

In our reviews, we have found no statistical information on energy use for production of ceramics and structural clay products. However, a survey of ceramic industry kilns showed that energy use for tunnel kilns varied between 2.52 and $3.82 \mathrm{MBtu} /$ short ton brick (2.93-4.44 GJ/t), while intermittent kilns used between 2.91 and $8.46 \mathrm{MBtu} /$ short ton (3.38-10.4 GJ/t) (Whittemore, 1999). A more recent study calculated specific thermal energy consumption by wood fuelled kilns in Brazil. The authors found energy use of $2.64 \mathrm{MBtu} /$ short ton $(3.07 \mathrm{GJ} / \mathrm{t}$ ) for non-continuous kilns, 1.64 MBtu/short ton (1.91 $\mathrm{GJ} / \mathrm{t})$ for semi-continuous kilns and $1.15 \mathrm{MBtu} /$ short ton $(1.34 \mathrm{GJ} / \mathrm{t})$ for continuous kilns (Schwob, Henriques Jr, \& Szklo, 2009). However, these figures might be on the lower side because the calculations apply a low energy content value for the wood they used (2.4 MBtu/short ton wood; $2.8 \mathrm{GJ} / \mathrm{t}$ ). Therefore, we use a higher average specific fuel consumption of $4.5 \mathrm{MBtu} /$ short ton brick (5.2 GJ/t) in our calculations, which was also used in the previous report (Martin et al., 2000). Natural gas is probably the main fuel used, although there are kilns that use other fuels (e.g. oil, and even wood chips for example at a plant in Mississippi), while sawdust is added to the bricks and partially combusted in the baking process.

A technology which has developed over the last decades is the rapid firing technology for bricks and tiles, called the roller kiln (or roller-hearth). In the rapid firing process, clay is prepared dry with appropriate additives to maintain the forming and baking characteristics required. The amount of water is thus reduced to 6-8 percent (compared to $18-20$ percent in the current process). The fired products are transported on refractory rollers, rather than on Lorries. A roller kiln makes it possible to reduce the heating time to approximately 8-9 hours (Tomasseti, 1995) and use shorter firing curves. The flue gas volumes in the roller kilns are lower, compared to the tunnel kiln, reducing the heat losses (Elmi, 1993). This reduces not only the heat demand, but also the power consumption for air circulation. Roller kilns are the state-of-the-art for the production of sanitary ware and wall and floor-tiles. They can be found in modern facilities across the world, and also in the U.S. (e.g., in Ohio and Texas). In recent years, roller hearth kilns have replaced many tunnel kilns on the market (Marvin, 2009).

In The Netherlands, a roller kiln was demonstrated for sanitary ware ([CADDET], 1993a). The kiln reduced energy intensity by 60 percent relative to the previously used tunnel kiln - reducing the specific energy consumption to $4.2 \mathrm{MBtu} /$ ton product (3.8 $\mathrm{GJ} / \mathrm{t})$ ([CADDET], 1993a), compared to $9.3 \mathrm{MBtu} /$ ton $(10.8 \mathrm{GJ} / \mathrm{t})(\mathrm{LHV})$. The performance can be even further improved by heat recovery from the flue gases. The technology is under investigation for more massive products like tiles and bricks. In 
Italy, a new plant produces 50,000 lightened and specially shaped bricks per day using the rapid firing technology. In 1996, two roller kilns for bricks were in operation in Europe (Italy and Germany) while two were under construction in Indonesia and Mexico. The plant in Italy was designed to consume 1.2 MBtu/ton $(1.4 \mathrm{GJ} / \mathrm{t})(\mathrm{LHV})$ (Tomasseti, 1995). Initially, it consumed 1.4 MBtu/ton (1.6 GJ/t) (LHV) (Tomasseti, 1995).

In a more recent tile-producing roller kiln brochure of an Italian machine manufacturer, energy consumption is estimated to be about $1.44 \mathrm{MBtu} /$ ton dry product $(1.68 \mathrm{GJ} / \mathrm{t})$ on average (SACMI, 2008). We use this value for the average energy consumption for a future roller kiln in the U.S, which is $0.41 \mathrm{MBtu}$ lower than the value previously used in the previous Emerging Technologies report (Martin et al., 2000).

To shorten the firing time in the kiln, heat distribution needs to be optimal, and the temperature needs to be distributed evenly among all materials travelling through the kiln. Earlier roller kilns have a single layer of products, while new designs have a double layer. This is well suited for ceramic products. However, it less suited for the larger capacity brick kilns. Developers such as Italian firm Mori (the main developer of the roller kiln for ceramics) have been trying to develop multi-layer kilns. Other suppliers actually did develop multi-layer roller kilns: SACMI (Italy) and Eissenmann (Germany) for example.

Investment costs for a tunnel kiln with a capacity of 110,000 tons/year (100,000 t/year) were estimated at $\$ 2.1$ million (Tomasseti, 1995), equivalent to approximately $\$ 19 /$ toncapacity (\$21/t-capacity). Tomasseti (1995) expects roller kilns to be less expensive than a tunnel kiln. Kilns for sanitary ware have a lower capacity and higher typical investment costs. The roller kiln for ceramics as described in the demonstration project in The Netherlands had higher investment costs of $\$ 38 /$ ton-capacity $(\$ 41 / t)$, with a payback period of 2 to 2.5 years with Dutch gas prices of $\$ 3.00 / \mathrm{MBtu}(\$ 2.80 / \mathrm{GJ})$ ([CADDET], 1993a). The 1994 natural gas price for the stone, clay and glass industries in the U.S. was $\$ 2.83 / \mathrm{MBtu}(\$ 2.68 / \mathrm{GJ})$, which would give an average U.S. payback period of 2.7 years. For this study we will assume that the investments of a roller kiln are equal to that of a tunnel kiln, both for bricks and other ceramic products. The maintenance costs are lower or equal compared to that of a conventional tunnel kiln. 
Table 3. Roller Kiln Data Table 2010

\begin{tabular}{|c|c|c|c|}
\hline & Units & & Notes \\
\hline \multicolumn{4}{|l|}{ Roller Kiln } \\
\hline \multicolumn{4}{|l|}{ Ceramics-1 } \\
\hline \multicolumn{4}{|l|}{ Energy-efficient roller kiln replacing tunnel kiln } \\
\hline \multicolumn{4}{|l|}{ Market Information: } \\
\hline Industries & & Clay Products & SIC 325, 326 \\
\hline End-use(s) & & Process Heating & \\
\hline Energy types & & Natural Gas & \\
\hline Market segment & & New & \\
\hline 2015 basecase use & Mton & 13.0 & Based on slow growth (2010: $12.3 \mathrm{Mt})$ \\
\hline \multicolumn{4}{|l|}{ Reference technology } \\
\hline Description & Tunnel Kiln & & \\
\hline Throughput or annual op. hrs. & & 100,000 tpy & \\
\hline Electricity use & $\mathrm{kWh}$ & 0 & \\
\hline Fuel use & MBtu/ton & 4.5 & \\
\hline Primary energy use & MBtu/ton & 4.5 & \\
\hline \multicolumn{4}{|l|}{ New Measure Information: } \\
\hline Description & Roller Kiln & & \\
\hline Electricity use & kWh & 0 & \\
\hline Fuel use & MBtu/ton & 1.4 & Sacmi FBS (tile production) \\
\hline Primary Energy use & MBtu/ton & 1.4 & Sacmi FBS (tile production) \\
\hline Current status & & Commercial & Commercial for ceramics and became commercial for bricks in last decade \\
\hline Date of commercialization & & 1993 & \\
\hline Est. avg. measure life & Years & 30 & \\
\hline \multicolumn{4}{|l|}{ Savings Information: } \\
\hline Electricity savings & $\mathrm{kWh} / \%$ & $0 \%$ & \\
\hline Fuel savings & MBtu/\% & $68 \%$ & \\
\hline Primary energy savings & MBtu/\% & 3.1 & \\
\hline Penetration rate & & Medium & Competition of improved tunnel kilns \\
\hline Feasible applications & $\%$ & $15 \%$ & Half of kiln turnover will use roller kiln technology \\
\hline \multicolumn{4}{|l|}{ Other key assumptions } \\
\hline Elec svgs potential in 2015 & GWh & 0 & \\
\hline Fuel svgs potential in 2015 & TBtu & 6.0 & \\
\hline Primary energy svgs potential in 2015 & TBtu & 6.0 & \\
\hline \multicolumn{4}{|l|}{ Cost Effectiveness } \\
\hline Investment cost & $\$$ & 10 & Estimated investment costs are $10 \$ /$ ton annual capacity over a tunnel kiln \\
\hline Type of cost & & incremental & Incremental costs over that of a tunnel kiln \\
\hline Change in other costs & $\$$ & 0 & \\
\hline Cost of saved energy (elec) & $\$ / k W h$ & N/A & \\
\hline Cost of saved energy (fuel) & $\$ /$ Mbtu & 0.50 & \\
\hline Cost of saved energy (primary) & $\$ /$ Mbtu & 0.50 & \\
\hline Simple payback period & Years & 1.6 & \\
\hline Internal rate of return & $\%$ & N/A & \\
\hline \multicolumn{4}{|l|}{ Key non energy factors } \\
\hline Productivity benefits & & Somewhat & Higher production per surface area when using double-layer roller kiln \\
\hline Product quality benefits & & Somewhat & \\
\hline Environmental benefits & & Significant & Reduced NOx \\
\hline \multicolumn{4}{|l|}{ Other benefits } \\
\hline Current promotional activity & $\mathrm{H}, \mathrm{M}, \mathrm{L}$ & Low & \\
\hline \multicolumn{4}{|l|}{ Evaluation } \\
\hline Major market barriers & & Competition tunnel kilns & \\
\hline Likelihood of success & $\mathrm{H}, \mathrm{M}, \mathrm{L}$ & Medium & \\
\hline Recommended next steps & & Further market analysis & \\
\hline Data quality assessment & $E, G, F, P$ & Fair & \\
\hline \multicolumn{4}{|l|}{ Sources: } \\
\hline 2015 basecase & & & Virta 2007 \\
\hline Basecase energy use & & & Author's estimate on basis of Whittemore (1999) \\
\hline New measure energy savings & & & SACMI 2008; Tomassetti 1995; CADDET 1993c \\
\hline Lifetime & & & Author's estimate \\
\hline Feasible applications & & & Tomassetti 1995; Elmi 1993 \\
\hline Costs & & & Tomassetti 1995; CADDET 1993c \\
\hline Key non energy factors & & & Author's estimate \\
\hline \multicolumn{4}{|l|}{ Principal contacts } \\
\hline Additional notes and sources & & & \\
\hline
\end{tabular}

Notes: Yellow cells represent updated information from Martin et al. report (2000). 
Roller kilns will likely be implemented when the conventional tunnel kilns need to be replaced, or when an existing facility is expanding its capacity. Competing technologies will be more efficient tunnel kilns as developed in Europe and the U.S., or retrofitting existing facilities with improved insulation with low thermal mass materials (LTM), LTM-carts, and improved heat recovery. The DOE NICE3-program has sponsored the demonstration of a new kiln with LTM-insulation in Southern California, reducing energy use by half and reducing NOx emissions by 40 percent. In recent years, roller kilns have become wider to increase energy efficiency and decrease costs (Pöhlmann, 2009).

R\&D is needed to develop materials that can hold the heavy weight of tiles and bricks while withstanding the stresses of rapid heating and cooling. R\&D is also directed at the construction of a kiln with a good air circulation and at ensuring good brick quality. The applicability of the technology for different types of bricks should be demonstrated, before further implementation is feasible (Elmi, 1993). More recently, the issue of accurate temperature control systems has come up to decrease the number of cracked tiles and improve product quality in general (Wei et al., 2008).

Our update shows that roller (hearth) kilns have matured since reported by (Martin et al., 2000). It has penetrated the market to become a major technology in tile production; it has been applied to making other products such as sanitary ware. The technology has become more energy-efficient. Due to the decline in the U.S. ceramics market, its total potential for energy savings has not changed in absolute numbers (the current data table has total savings potential of $6.0 \mathrm{TBtu}$, compared to $5.8 \mathrm{TBtu}$ in the 2000 report).

Although there is competition from more energy-efficient tunnel kilns, the share of roller kilns in future ceramics production is likely to grow further.

\subsection{Advanced CHP Turbines (Utilities-1)}

Combined heat and power (CHP) systems generate electricity (and/or mechanical energy) and thermal energy in a single, integrated system. This contrasts with the more common practice where electricity is generated at a central power plant. Because CHP captures the heat that would otherwise be rejected in traditional separate generation of electric or mechanical energy, the total efficiency of these integrated systems can be much larger than from separate systems. Typically, on-site heating and cooling equipment is used to meet operation or process that requires non-electric energy.

$\mathrm{CHP}$ is an application of technologies to meet end-user needs for heating and/or cooling, and mechanical and/or electric power. Steam turbines, gas turbines, combined cycles, and reciprocating engines are the major current technologies used for power generation and CHP (Elliott \& Spurr, 1999). Collaborative research by government and industry has contributed significantly to the new generations of turbines and engines.

Conventional electricity generation is inherently inefficient, converting and transporting only about a third of a fuel's potential energy into usable energy. The significant increase in efficiency with $\mathrm{CHP}$ results in lower fuel consumption and reduced emissions compared with separate generation of heat and power. CHP can be an economically productive approach to reducing air pollutants through pollution prevention, whereas 
traditional pollution control achieved solely through flue gas treatment provides no profitable output and actually reduces efficiency and useful energy output.

The thermodynamic cycle associated with the majority of gas turbine systems is the Brayton cycle. In this cycle, atmospheric air is passed as the working fluid through the turbine. The thermodynamic steps of the Brayton cycle include compression of atmospheric air, introduction and ignition of fuel, and expansion of the heated combustion gases through the gas producing and power turbines. The developed power is used to drive the compressor and the electric generator.

Since there are two or more usable energy outputs from a CHP system, defining overall system efficiency is more complex than doing with simple systems. The system can be viewed as two subsystems - the power system and the heat recovery system. The efficiency of the overall system results from an interaction between the individual efficiencies of the power and heat recovery systems.

For the updated calculations, we have considered the example of a $5 \mathrm{MW}$ gas-fired $\mathrm{CHP}$ turbine operating with a 70 percent overall efficiency and a power-to-heat ratio of 0.66 . This system is compared to the example of purchased grid electricity with an on-site gas boiler. The electric grid is estimated to have an efficiency of 33.4 percent and the gas boiler has an efficiency of 68 percent. Installation costs for a $5 \mathrm{MW}$ combustion turbine currently cost about $\$ 1321 / \mathrm{kW}$ (ICF:EEA, 2008), compared to $\$ 1070 / \mathrm{kW}$ in 2000 (Onsite Sycom Energy Corporation, 2000). Operating and maintenance costs are currently $\$ 0.0074 / \mathrm{kWh}$ (ICF:EEA, 2008), which is also higher than O\&M costs in 2000 (\$ $0.0059 / \mathrm{kWh}$ ) (Onsite Sycom Energy Corporation, 2000). In general, CHP installations have become more expensive.

In the last decade, about 25,000 MW of industrial CHP capacity was installed, which yielded a total capacity of 75,000 MW in 2009 (Hedman, 2009). This market has increased by about $50 \%$ in size in the last ten years. The estimated technical potential for industrial CHP in the United States is approximately 125,000 MW (McKinsey, 2009), so there is 50,000 MW of industrial CHP potential remained to be realized. Since 2006 annual capacity additions have been less than 500 MW (Hedman, 2009). This was because there exist barriers for further development of CHP, such as capital constraints, uncertainties, lack of awareness and support, grid interconnection issues and environmental regulations (McKinsey, 2009). Environmental regulations can pose a problem because in spite of lower total emissions, local onsite emissions will increase and can be subject to local emission regulations.

A key uncertainty is the prices in natural gas and electricity, which affect the payback period of CHP installations significantly. This can be seen in figure 1, which shows the effect of varying the prices in the core data table. Payback periods will be over ten years with high natural gas and low electricity prices. In ten years, gas turbines are very likely to require a costly overhaul of $20 \%$ of the capital costs (Martin et al., 2000). In such a scenario, payback period would make them financially infeasible. As natural gas has become more expensive compared to electricity in the last decades, CHP investments became less desirable. Since the recession broke out in 2008, prices have become more favorable once again. In August 2010 the natural gas price in the U.S. was slightly higher 
than $\$ 4.00 / \mathrm{MBtu}$, while industrial electricity costs $\$ 0.065 / \mathrm{kWh}$. For this profiled data table, gas price of $\$ 7.00 / \mathrm{MBtu}$ is used with an unchanged electricity price. In the previous report, natural gas price of $\$ 3.38 / \mathrm{MBtu}$ and electricity price of $\$ 0.04 / \mathrm{kWh}$ was used for estimations in year 2015.

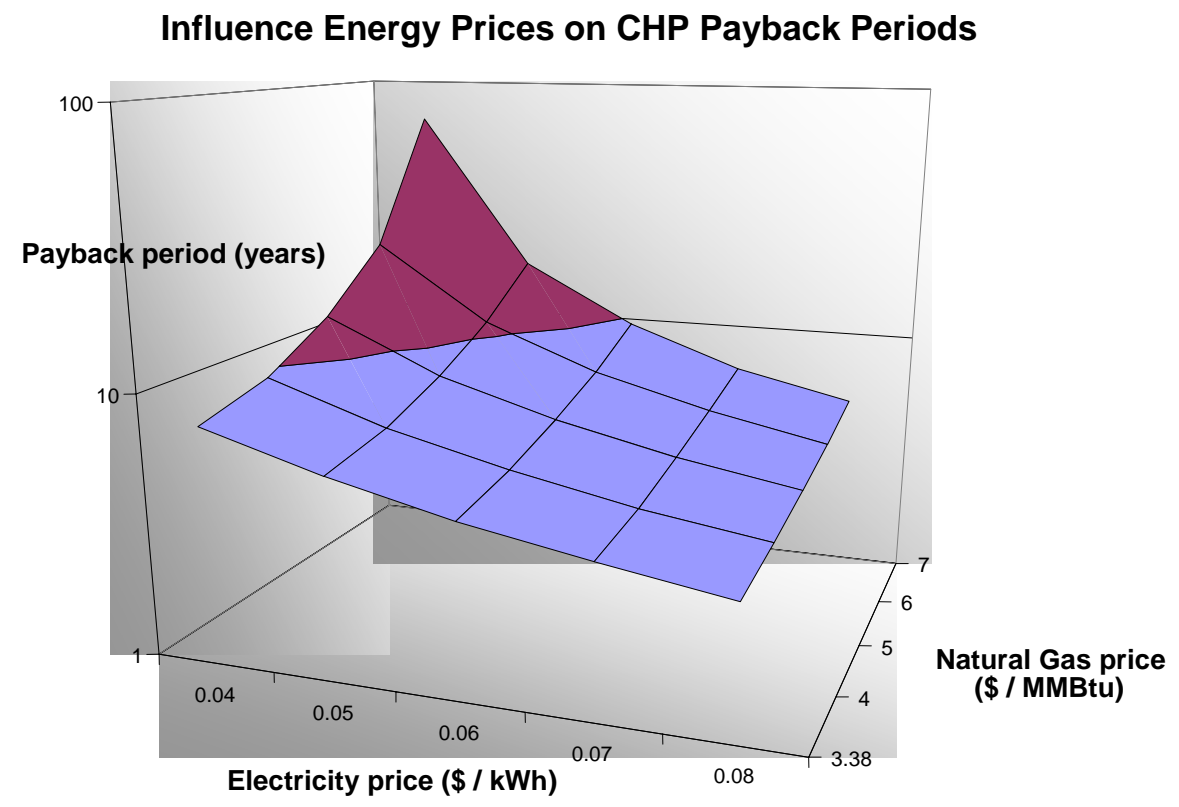

\begin{tabular}{|c|c|c|c|c|c|}
\hline Electricity & \multicolumn{5}{|c|}{ Natural Gas Price (\$ / MBtu): } \\
\cline { 2 - 6 } Price & $\mathbf{3 . 3 8}$ & $\mathbf{4}$ & $\mathbf{5}$ & $\mathbf{6}$ & $\mathbf{7}$ \\
\cline { 2 - 6 }$(\mathbf{S} / \mathrm{kWh})$ & \multicolumn{5}{|c|}{ Payback Period (years): } \\
$\mathbf{0 . 0 4}$ & 8 & 9.4 & 13.2 & 22.2 & 69.1 \\
$\mathbf{0 . 0 5}$ & 5.9 & 6.6 & 8.2 & 11 & 16.6 \\
$\mathbf{0 . 0 6}$ & 4.6 & 5.1 & 6 & 7.3 & 9.5 \\
$\mathbf{0 . 0 7}$ & 3.8 & 4.1 & 4.7 & 5.5 & 6.5 \\
$\mathbf{0 . 0 8}$ & 3.2 & 3.5 & 3.9 & 4.4 & 5.1 \\
\hline
\end{tabular}

Figure 1. The influence of energy prices on CHP payback periods is apparent. The payback period may be as short as three years with high electricity prices and low natural gas prices, while low electricity and high natural gas prices lead to longer payback periods.

In summary, industrial CHP capacity has grown by $50 \%$ since 2000 but appears to be slowing down or stagnant recently. This is because several conditions have become less favorable: while its costs have increased, the development of energy prices results in longer payback periods and the larger part of the total U.S. potential is already installed. Further CHP expansion is likely to occur when new incentives are provided, more awareness is created and grid interconnection issues are resolved (Kerr, 2008; McKinsey, 2009). Also, a rise in electricity prices compared to natural gas prices would make CHP investments more attractive. 
Table 4. Advanced CHP Turbines Data Table

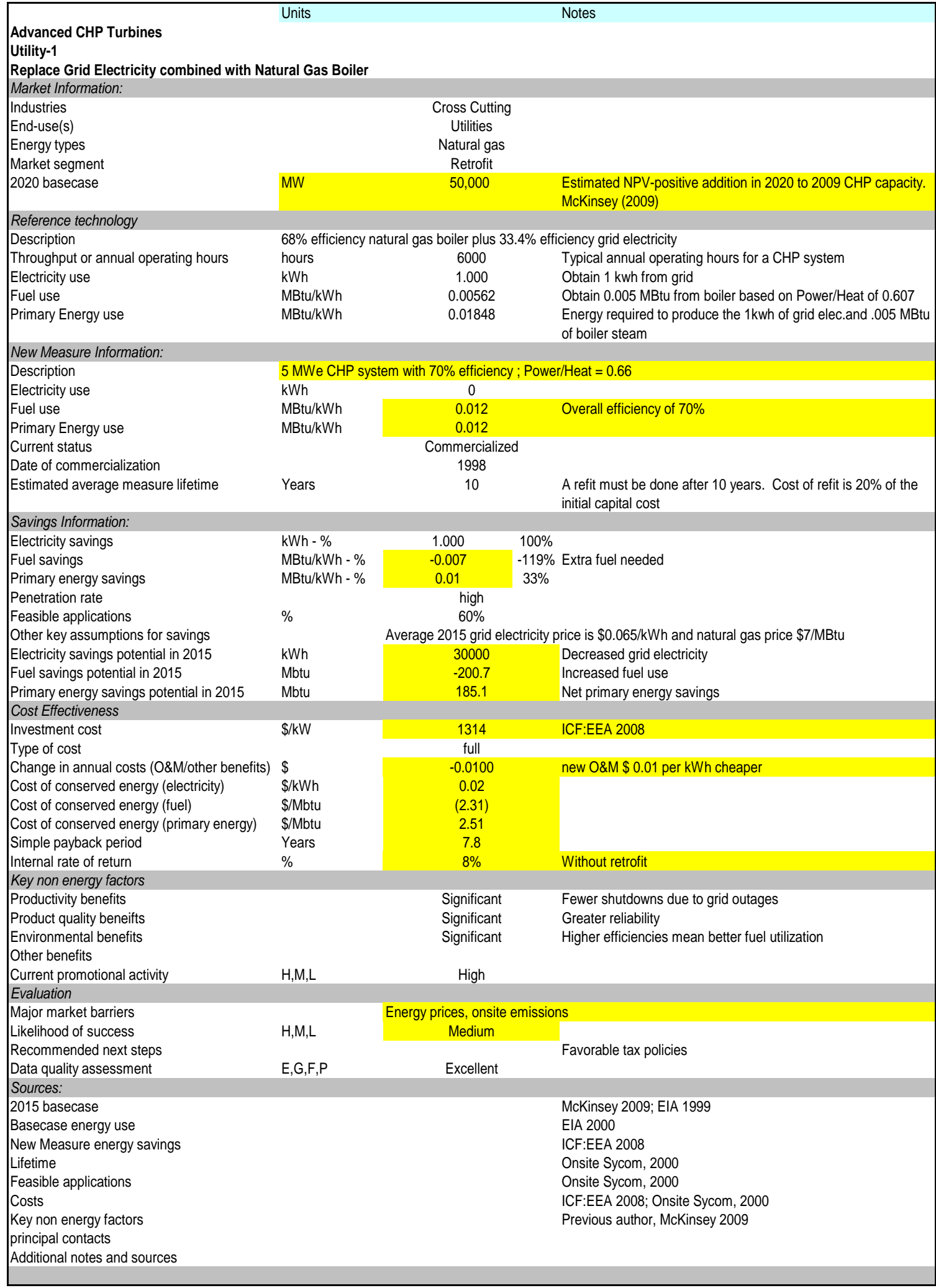




\subsection{Advanced Reciprocating Engines (Utilities-2)}

Reciprocating engines (e.g. diesel engines) can be used to generate a portion of a plant's electricity onsite, reduce demand during peak periods, or support premium power applications (e.g., microelectronics manufacturing) (Elliott \& Spurr, 1999). Such a reciprocating engine generator (also called genset) uses a combustion engine to convert fuel to shaft power, which then spins a generator. Diesel generators have long been used to generate small amounts of electricity at industrial, commercial, and institutional sites, either for continuous use or for backup in case of utility power failure. Developments in engine design have increased power efficiency (now approaching 50 percent) and reliability during the 90s, while dramatically reducing the emissions of these engines. These new designs can use a variety of liquid and gas fuels, including natural gas. For emissions reasons, natural gas-fired engines have become dominant for continuous operation applications (e.g., not emergency generators).

Reciprocating engines can be more energy efficient when operating as part of a CHP system, which can meet some of the facility's thermal requirements as well. Such a system might obtain an overall efficiency of 65 percent. However, reciprocating engines will have to compete with microturbines and fuel cells to gain a stronghold in this market. As with all CHP technologies, it will also need to compete with grid-supplied electricity, but the additional 'free' thermal energy can benefit local plants or sites.

Advanced reciprocating engines cost approximately \$ 850/kW (Onsite Sycom Energy Corporation, 2000), which makes their installation dependent on the grid electricity price. Still, reciprocating engines are the dominant independent generation technology for small installations, accounting for 47 percent of sites but only 2 percent of the power generation. In the industrial sector in 1995, reciprocating systems generated less than 1 percent of total cogenerated electricity but accounted for 5 percent of the installed systems with an average installed size of less than $1 \mathrm{MW}_{\mathrm{e}}$. This type of system is most commonly found in the food products industry (EIA, 1997). The total industrial reciprocating engine capacity for distributed generation was $362 \mathrm{MW}$ in 2000 (Gas Research Institute and National Renewable Energy Laboratory, 2003). In the years from 2006 to 2008, about 4000-5000 reciprocating engines were ordered in North America (Diesel \& Gas Turbine Worldwide, 2006, 2007, 2008, 2009). Virtually all of them had a capacity below $3 \mathrm{MW}$. Due to the recent recession, North American orders in 2009 dropped to 3000 engines (Diesel \& Gas Turbine Worldwide, 2010). It is not clear how many of these would serve for continuous power generation, or for back-up capacity. Main reciprocating engine manufacturers include Caterpillar, Cummins, Fairbanks Morse Engines, Wartsila, and Waukesha.

In 2001 reciprocating engines became popular for onsite generation in California, due to spiked energy prices (Mckinley, 2001). However, because of California's strict environmental regulations with regard to $\mathrm{NO}_{x}$ emissions, uncertainties remained in the extent to which reciprocating engines would be installed statewide. Lowering these emissions has remained an important barrier for actual installations. Similar to CHP technologies, remaining issues include capital constraints, uncertainties, lack of awareness and support and grid interconnection issues (McKinsey, 2009). In addition, energy price is one of the significant factors for deployment. Figure 1 shows electricity 
prices should be high enough to obtain reasonable payback periods, whereas natural gas prices in this example should stay relatively low.

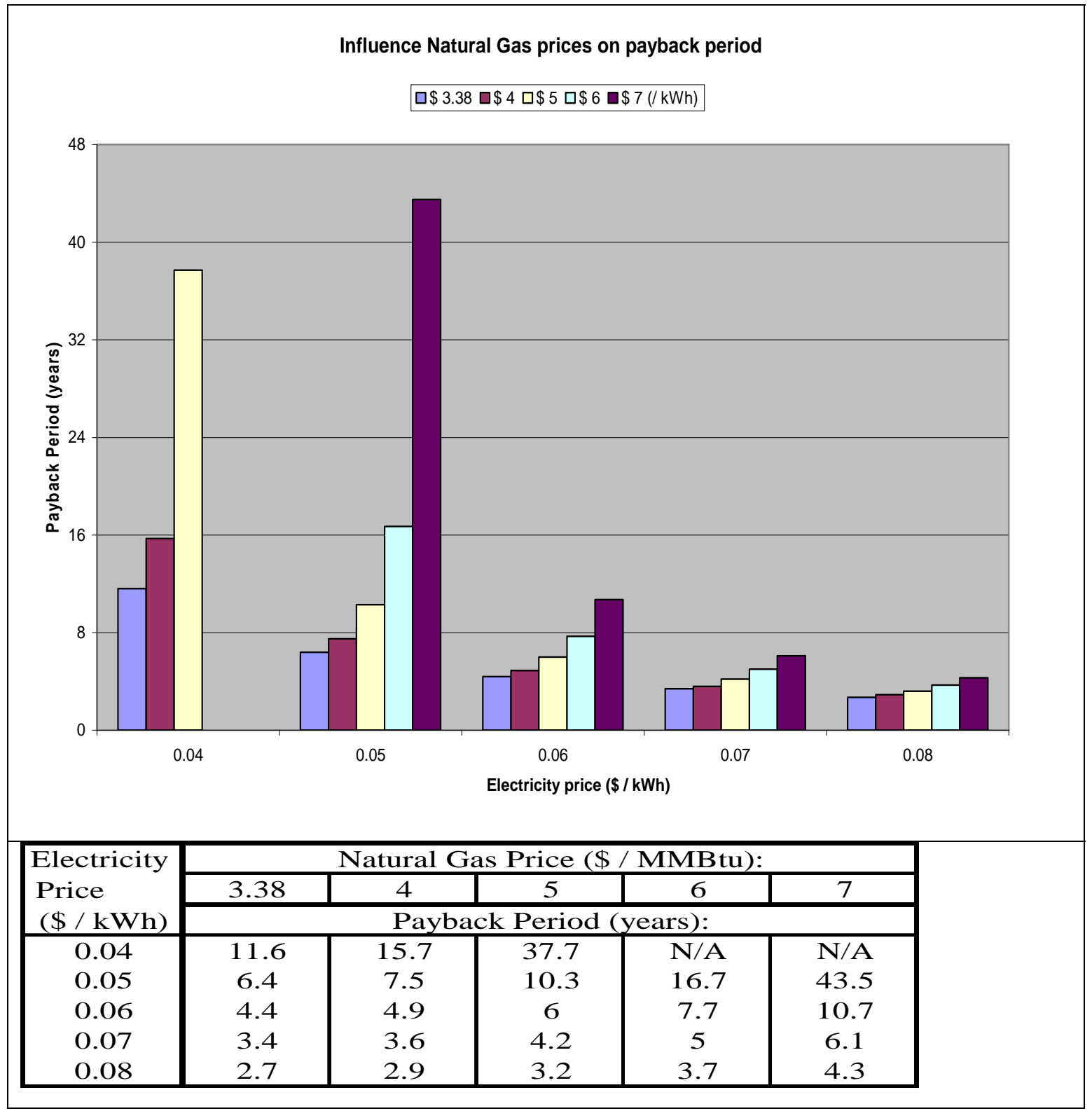

Figure 2. The influence of energy prices on the payback periods of advanced reciprocating engines is comparable with its influence on CHP payback periods. Investments pay off most with low natural gas and high electricity prices.

Two major energy programs have been installed in the last decade to deliver advanced reciprocating engines to the market: the Department of Energy's ARES (Advanced Reciprocating Engine Systems) program and the Advanced Reciprocating Internal Combustion Engine (ARICE) program of the California Energy Commission. It set out ambitious goals for the thermal energy efficiency (46-50\%) and NOx emissions (0.05-0.2 $\mathrm{g}$ NOx / kWh) of these engines for 2010 (Callahan, 2003). However, in the last two years 
no development on these programs has been reported online and the annual conferences have ceased.

This technology update shows that reciprocating engines have been advanced over the last decade, but might be out of fashion more recently. Another reason might be that market penetration is less visible due to the small size of installations, as it has been estimated that its key growth market segment is in installations between 0.8 and $3 \mathrm{MW}$ (Montgomery, 2006). However, the technology has become more expensive and $\mathrm{NO}_{\mathrm{x}}$ emissions remain worrisome, which makes the future of advanced reciprocating engines less promising than earlier thought. 
Table 5. Advanced Reciprocating Engines Data Table

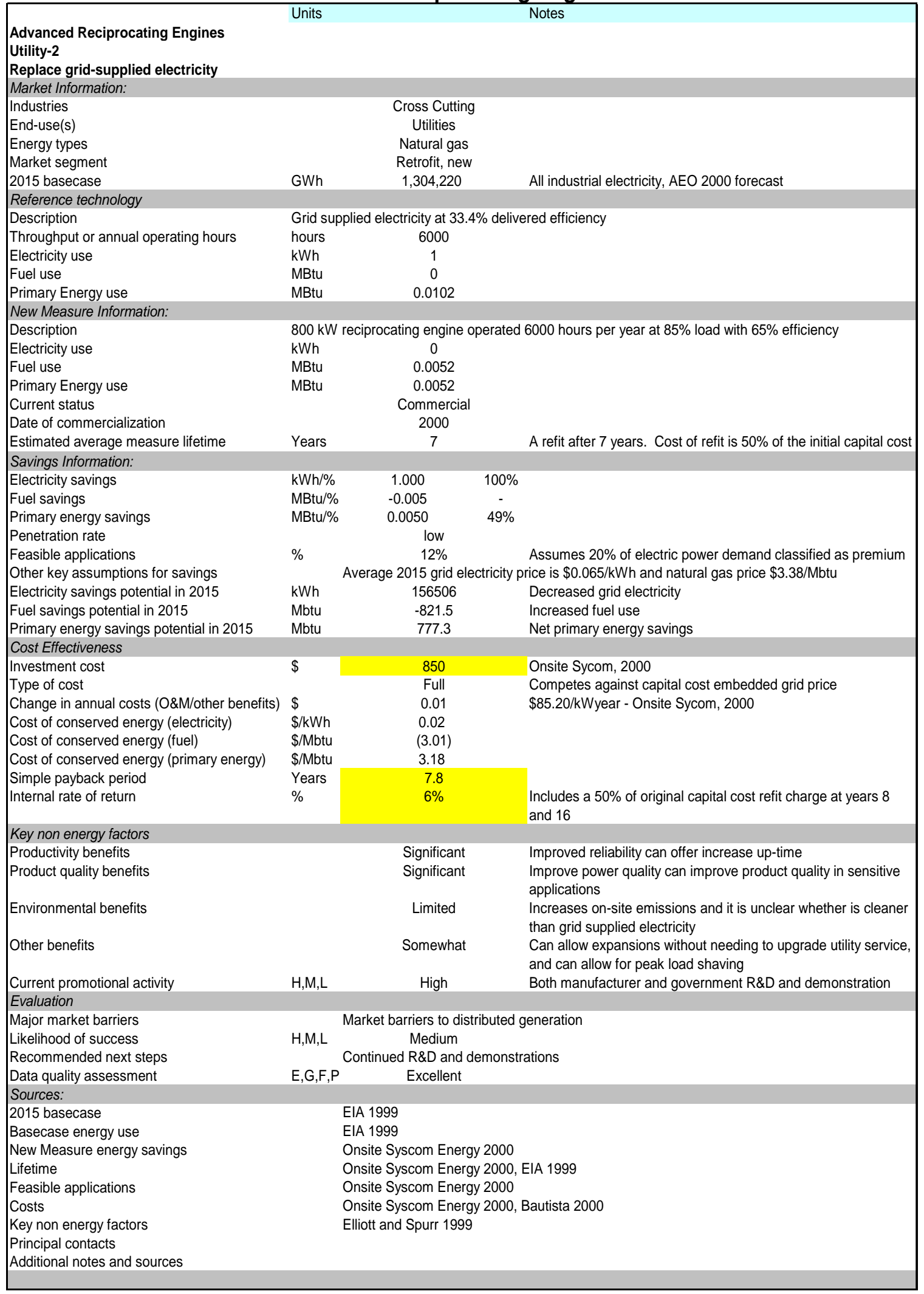




\subsection{Electron Beam Pasteurization (Food-1)}

Radiation pasteurization subjects food to controlled ionizing radiation that has sufficient energy to knock electrons from the outer rings of atoms of the foods to create free radicals and ions, resulting in the destruction of bacteria and pathogens. The radiation used does not have sufficient energy to split atoms that would cause the exposed objects to become radioactive. The U.S. Food and Drug Administration has approved the following sources of ionizing radiation for the treatment of foods (Wang, 2009):

- Gamma rays produced by the natural decay of radioactive cobalt-60 or cesium-137 isotopes

- X-rays with a maximum energy of five million electron volts (MeV)

- Electrons with a maximum energy of $10 \mathrm{MeV}$

Electron beam technology has perhaps the greatest potential for the safe, effective, and cost-efficient radiation pasteurization of meat, dairy, and canned goods. In electron beam systems, a multi-stage electron accelerator generates a dense beam of high-energy electrons. This beam is magnetically focused and scanned across the target, providing saturation of the food product with electrons that deposit their energy while breaking the chemical bonds of its atoms. Electron beam sterilization has been used in medical devices for more than 40 years, but only in recent years have the problems of relatively low penetration ability and device complexity been solved.

In the previous report, an example of milk pasteurization was used for the construction of the old Data Table (Martin et al. 2000). However, milk irradiation does not appear to be allowed by the Food and Drug Administration currently ([FDA], 2008). Only meat, spices, shell eggs and some fruit and produce was allowed in 2008 (Wang, 2009).

In the Data Table, a comparison is made with regard to processed meats and its disinfection. It is estimated that $10 \%$ of the fuel costs during meat processing is used for disinfecting (Ramírez, Patel, \& Blok, 2006). This corresponds with about 0.4 MBtu per metric ton (Wang, 2009). Compared with the electricity consumption for food irradiation of refrigerated processed meat (25 kWh per metric ton) (Wang, 2009), this results in energy savings of $43 \%$. However, food irradiation installations are expensive (4-10 M\$) and have high operation costs ( 100 \$ per metric ton) (Lawless, 2007). Because the costs of previous disinfecting methods are unknown, it is not possible to establish a payback period.

During the 1970's, several companies, including Varian Associates, Proctor and Gamble, and Siemens began renewed research in the application of x-ray technology for medical equipment and their involvement in the improvement of accelerated electron technology raised performance parameters to a new level. The major disadvantage of electron beams has been that the electrons don't penetrate more than an inch and a half into an organic object (Wang, 2009).

The greatest advantage of electron beam pasteurization is that it is quite versatile. The technology can be utilized to treat products that would normally undergo thermal treatment as well as products that cannot withstand the high temperatures of traditional pasteurization. Meat products and fresh fruits and vegetables can be irradiated in order to kill bacteria and molds. One of the largest market barriers against this technology is the stigma that is associated with irradiated foods. None of the country's major food 
companies will publicly acknowledge interest in food irradiation (Skerrett, 1997).

Economics will play a large role in determining which of the alternative approaches to thermal pasteurization may become widely used in food processing. Food is a relatively inexpensive commodity; therefore, even slight decreases in processing costs can have a big impact on consumer prices. In 1997, electron beam processing was expected to add an additional ten cents or so per pound of product (http://www.technologyreview.com/biomedicine/11621/).

Electron beam pasteurization techniques can be a viable option for foods that cannot withstand high temperatures, such as meats, cheeses, fruits, and vegetables. In order for this technology to truly enter the marketplace, the initial capital and installation costs will need to come down, in all but the more expensive specialty food markets. 
Table 6. Electron Beam Pasteurization Data Table

\begin{tabular}{|c|c|c|c|}
\hline & Units & & Notes \\
\hline \multicolumn{4}{|l|}{$\begin{array}{l}\text { Electron Beam Pasteurization } \\
\text { Food-1 } \\
\text { Replace thermal pasteurization }\end{array}$} \\
\hline \multicolumn{4}{|l|}{ Market Information: } \\
\hline Industries & & Food & NAICS 311 \\
\hline End-use(s) & \multirow{4}{*}{\multicolumn{2}{|c|}{$\begin{array}{c}\text { Process heating, other } \\
\text { Natural gas, electricity, coe } \\
\text { New, replace on failure }\end{array}$}} & \\
\hline Energy types & & & \\
\hline Market segment & & & \\
\hline 2015 basecase & & & Same level AMI 2009 \\
\hline \multicolumn{4}{|l|}{ Reference technology } \\
\hline Description & \multicolumn{2}{|c|}{ disinfection of processed meat } & \\
\hline Throughput or annual operating hours & tons & 1.00 & \\
\hline Electricity use & $\mathrm{kWh}$ & & \\
\hline Fuel use & MBtu & 0.38 & Ramirez 2006; Wang 2009 \\
\hline Primary Energy use & MBtu & 0.38 & Ramirez 2006; Wang 2009 \\
\hline \multicolumn{4}{|l|}{ New Measure Information: } \\
\hline Description & \multicolumn{3}{|c|}{ electron beam pasteurization of refrigerated meat $(25 \mathrm{kWh} / \mathrm{t})$} \\
\hline Electricity use & kWh & 25.00 & Wang, 2009 \\
\hline Fuel use & MBtu & 0.00 & \\
\hline Primary Energy use & MBtu & 0.21 & Wang, 2009 \\
\hline Current status & & Commercialized & \\
\hline Date of commercialization & & 1995 & \\
\hline Estimated average measure lifetime & Years & 10 & \\
\hline \multicolumn{4}{|l|}{ Savings Information: } \\
\hline Electricity savings & $\mathrm{kWh} / \%$ & -25.00 & \\
\hline Fuel savings & MBtu/\% & $100 \%$ & \\
\hline Primary energy savings & MBtu/\% & $43 \%$ & \\
\hline Penetration rate & & low & Industry must overcome negative stigma of irradiated foods \\
\hline Feasible applications & $\%$ & $10 \%$ & \\
\hline \multicolumn{4}{|l|}{ Other key assumptions for savings } \\
\hline Electricity savings potential in 2015 & GWh & -99.00 & \\
\hline Fuel savings potential in 2015 & Tbtu & 1.49 & \\
\hline Primary energy savings potential in 2015 & 5 Tbtu & 0.64 & \\
\hline \multicolumn{4}{|c|}{ Cost Effectiveness } \\
\hline Investment cost & $\$$ & 700 & Implementing electron beam is capital intensive \\
\hline Type of cost & & Full & \\
\hline Change in annual costs (O\&M/other ben & e\$its) & 100 & Disinfection costs reference technology unknown \\
\hline Cost of conserved energy (electricity) & $\$ / k W h$ & -9.58 & \\
\hline Cost of conserved energy (fuel) & $\$ / \mathrm{Mbtu}$ & 638.18 & \\
\hline Cost of conserved energy (primary eners & g\$s)/Mbtu & 1478.25 & \\
\hline Simple payback period & Years & Unknown & \\
\hline Internal rate of return & $\%$ & Unknown & \\
\hline \multicolumn{4}{|l|}{ Key non energy factors } \\
\hline Productivity benefits & & Significant & Electron beam pasteurizes in a few seconds and does not require he \\
\hline Product quality benefits & & Significant & Does not alter the taste or quality of the food \\
\hline Environmental benefits & & None & \\
\hline Other benefits & & & \\
\hline Current promotional activity & $\mathrm{H}, \mathrm{M}, \mathrm{L}$ & Medium & Several companies are involved in promoting the technology \\
\hline \multicolumn{4}{|l|}{ Evaluation } \\
\hline Major market barriers & & Public perception & Negative publicity involving irradiated food. Banned in EU \\
\hline Likelihood of success & $H, M, L$ & Low & \\
\hline Recommended next steps & & Testing on safety, $\mathrm{PR}$ & Testing for safety must be done to allay fears of public \\
\hline Data quality assessment & $E, G, F, P$ & Fair & \\
\hline \multicolumn{4}{|l|}{ Sources: } \\
\hline 2015 basecase & & & AMI 2009 \\
\hline Basecase energy use & & & Ramirez 2006; Wang 2009 \\
\hline New Measure energy savings & & & Wang 2009 \\
\hline Lifetime & & & Thayer, et al. 1996 \\
\hline \multicolumn{4}{|l|}{ Feasible applications } \\
\hline \multicolumn{4}{|l|}{ Costs } \\
\hline \multicolumn{4}{|l|}{ Key non energy factors } \\
\hline Principal contacts & & & \\
\hline Additional notes and sources & & & \\
\hline
\end{tabular}




\subsection{High-Efficiency/Low $\mathrm{NO}_{x}$-Burners (Other-2)}

Industrial combustion technologies can contribute to large energy efficiency increases. However, better efficiency might lead to unwanted processes as well. One such example is preheating combustion air, which might result in a more efficient process, but also in higher $\mathrm{NO}_{\mathrm{x}}$ emissions. Since air quality regulations have become stricter, these emissions should be lowered. In burner technology there are two approached to achieve this: reducing $\mathrm{NO}_{x}$ formation in the combustion process or end-of-pipe catalytic removal (SCR; Selective Catalytic Reduction). As the costs of flue-gas removal are high and can reduce efficiency (Chambers \& Trottier, 2007), integrated solutions in the combustion process are preferred.

$\mathrm{NO}_{\mathrm{x}}$ formation in the combustion process can be limited by reducing the amount of nitrogen in contact with oxygen at high flame temperatures. Available methods to realize nitrogen reduction in combustion air are oxy-fuel combustion (e.g. in glass, metals industry), improved mixing of combustion air and fuel, near stoichiometric conditions through staged combustion and flue gas recirculation (FGR) (Berntsson, Franck, \& Asblad, 1997). FGR is relatively expensive and may also reduce efficiency (Chambers \& Trottier, 2007). Oxy-fuel burners have been discussed for the steel industry in the previous report (Martin et al., 2000) and are not taken into account in this update. Here, we focus on high-efficiency low $\mathrm{NO}_{x}$ burner designs using air as oxidant. We discuss burners for boilers, furnaces and direct heating. Note that the performance of a burner depends on the configuration of the boiler or furnace in which it is used. Hence, the savings may vary widely, depending on the specific situation. In this description, we try to separate the effects of improved burner design from furnace/boiler design.

Boilers are used throughout industry and consume about 6.47 Quads (6.83 EJ) of fuels, or 37 percent of total industrial fuel use (Energy and Environmental Analysis, 2005). Because of their widespread use, air quality regulation has historically been aimed at boilers. By-products, biomass and waste are currently the dominant boiler fuels (50 percent), followed by natural gas (32 percent) (Energy and Environmental Analysis, 2005). In 2000 natural gas was mostly used with 40 percent of boiler fuel use, but was closely followed by the by-products, biomass and waste fuels (38 percent).

Research in low or even ultralow NOx-burners is ongoing in many parts of the world. In the U.S., DOE's Office of Industrial Technologies (OIT) has sponsored several combustion research projects. Research on low NOx-combustion is done at research institutes (e.g., Gas Research Institute, Gas Technology Institute), national laboratories (e.g., Lawrence Berkeley National Laboratory) and universities (e.g., University of California at Irvine), as well as manufacturers. Most burner manufacturers also supply low NOx-burners, e.g., Alzeta, Bloom Engineering, COEN, Detroit Stoker, Hauck, John Zink and Maxon.

Heat distribution and flux are important design features of furnaces to improve the efficiency. Burner concepts are developed that aim at improving the heat distribution by impulse firing (for heat treatment and intermittent kilns) and high velocity burners (as discussed in the roller kiln for ceramic products). In furnaces recuperators and regenerators are used to improve efficiency. A recuperator is a heat exchanger that 
extracts heat from the furnace waste gases to pre-heat incoming combustion air. Compared to furnaces without air preheating energy savings of 30 percent can be reached (Flanagan, 1993). Regenerative burners are operated in pairs. While one is used to burn the fuel, another burner uses a porous ceramic bed to store heat. After a few minutes the process is reversed, and the heat stored in the ceramic bed is used to preheat the combustion air. In this way about 85 percent of the heat in the flue gases is recovered, and the combustion air can be pre-heated to temperatures of only $150 \mathrm{oC}$ less than the furnace operating temperature (Flanagan, 1993). Compared with cold air burners, regenerative burners can achieve fuel savings in excess of 50 percent (Flanagan, 1993). However, potential high NOx-emissions may limit preheat temperatures and hence energy savings. Also, the full benefit of the burners depends on the integration in the furnace. For low to medium-temperature applications, we concentrate on burner designs that achieve low-NOx $(<20 \mathrm{ppm})$ while improving energy efficiency.

For example, the Pyrocore ceramic burner marketed by Alzeta Corp. (after development with the Gas Research Institute, US EPA and Southern California Gas Company) is used for direct firing applications in the food industry (with extremely low emissions) ([CADDET], 2000a) and for process heaters in the oil industry ([CADDET], 1989). Energy savings were not specified in either application.

At Lawrence Berkeley National Laboratory another type of burner was developed: a low-swirl burner (LSB) (Yegian \& Cheng, 1998). In the last decade, the burner has been commercialized by Maxon Corporation and produces burners with $\mathrm{NO}_{\mathrm{x}}$ emissions lower than 9 ppm (corrected to $3 \%$ oxygen).

From natural gas boilers, $\mathrm{NO}_{\mathbf{x}}$ is mainly generated through thermal processes. Advanced burner designs can reduce $\mathrm{NO}_{x}$ emissions, while maintaining or improving efficiency. $\mathrm{NO}_{x}$ emissions from standard industrial gas boilers can be between 60 and $200 \mathrm{ppm}$. Low $\mathrm{NO}_{\mathrm{x}}$ burners can reduce emissions to 20-30 ppm, while ultra-low $\mathrm{NO}_{\mathrm{x}}$ burners (also used for direct heating applications) can reduce emissions to 5-9 ppm. COEN has installed low- $\mathrm{NO}_{x}$ burners that comply with California air quality standards in the oil industry (Bakersfield, CA), textile plant (Vernon, CA), as well as heating plants (Sacramento, CA). In these plants $\mathrm{NO}_{x}$ emissions between 9 and $26 \mathrm{ppm}$ have been achieved, at high efficiencies. Efficiency gains are not always specified. In the case of a heating plant in Sacramento (CA), an efficiency gain of 3 percent was achieved (COEN, 2000). We assume fuel savings of 5 percent for using high-efficiency (ultra) low- $\mathrm{NO}_{x}$ burners. While the capital costs of the burner are comparable to those of standard burners, the total system costs would be lower, if SCR NO $\mathrm{N}_{x}$-removal would need to be installed. Implementation of high-efficiency Low- $\mathrm{NO}_{x}$ burners will be primarily driven by air quality regulations. 
Table 7. High-Efficiency Low NOx Burners Data Table

High-Efficiency Low-NOx Burners Units Notes

\section{other-2}

Low-NOx High Efficiency Burners Market Information:

Industries

End-use(s)

Energy types

Market segment

2015 basecase use

Reference technology

Description

Throughput or annual op. hrs.

Electricity use

Fuel use

Primary energy use

New Measure Information:

Description

Electricity use

Fuel use

Primary Energy use

Current status

Date of commercialization

Est. avg. measure life

(1)

Savings Information:

Electricity savings

Fuel savings

Primary energy savings

Penetration rate

Feasible applications

Other key assumptions

Elec svgs potential in 2015

Fuel svgs potential in 2015

Primary energy svgs potential in 2015

Cost Effectiveness

Investment cost

Type of cost

Change in other costs

Cost of saved energy (elec)

Cost of saved energy (fuel)

Cost of saved energy (primary)

Simple payback period

Internal rate of return

Key non energy factors

Boilers, Process Heating

Natural Gas

Retrofit

Tbtu $\quad 6470 \quad$ Same level 2005 use (slow growth, efficiency

Conventional burners in existing boilers or furnaces

$1 \quad$ Boilers and furnaces are available in any

kWh $\quad 0$

TBtu 6470

TBtu $\quad 6470.0$

Low-NOx High Efficiency Burners

kWh 0

TBtu $\quad 6146.5 \quad 5 \%$ fuel savings

TBtu $\quad 6146.5$

Commercial

1996

Years 20

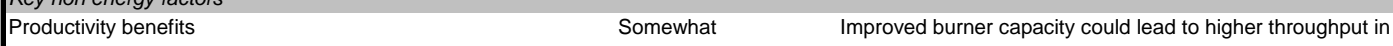

Environmental benefits

Other benefits

$\begin{array}{lll}\mathrm{kWh} / \% & 0 & 0 \%\end{array}$

$\begin{array}{lll}\text { MBtu/\% } & 323.5 & 5 \%\end{array}$

MBtu/\% $\quad 323.5 \quad 5 \%$

$\% \quad$ Low

$10 \%$ of industrial natural gas use is in non-attainment

GWh 0

Tbtu 32.4

Current promotional activity

Evaluation

Major market barriers

Likelihood of success

Recommended next steps

Data quality assessment

Sources:

2015 basecase

Basecase energy use

New measure energy savings

Lifetime

Feasible applications

Costs

Key non energy factors

\$/MBtu $\quad 0.78 \quad$ Canadian Study $(\$ 9.5 / \mathrm{kW})$

$\begin{array}{lll} & \text { Full } & \\ \$ / \mathrm{MBtu} & -0.35 & 5 \% \text { saving gas bill (gas price } \$ 7 /\end{array}$

$\$ / \mathrm{kWh} \quad \mathrm{N} / \mathrm{A}$

\$Mbtu $\quad-0.23$

\$Mbtu $\quad-0.23$

Years 2.2

$\%$

Discount rate for all CCE calculations is

Principal contacts

Additional notes and sources

For high-temperature applications, $\mathrm{NO}_{\mathrm{x}}$-emission reductions are limited because of the high flame temperatures required. Still, modern burners designed to mix the combustion air and fuel well, reducing $\mathrm{NO}_{x}$-emissions. The Gyro-Therm burner 
developed in Australia for the cement industry achieves reductions in $\mathrm{NO}_{\mathrm{x}}$-emissions of 30 to 70 percent, while saving 5 percent on fuels in a clinker kiln in the cement industry. The stable flame reduced refractory wear. The technology has been applied in several cement plants around the world including the U.S. (e.g. Ash Grove, Durkee, OR). The payback period is around 2 years ([CADDET], 1997). Stordy Combustion Engineering (United Kingdom) has developed a low- $\mathrm{NO}_{x}$ regenerative burner that can achieve $\mathrm{NO}_{x}$ emissions of 100-125 ppm at air-preheat temperatures of $1000^{\circ} \mathrm{C}$ (CADDET Newsletter, 1999), resulting in fuel savings of 40 percent compared to conventional burners at nearstoichiometric conditions (Flanagan, 1993). Potential applications are found in the metals industry, e.g. reheating furnaces, aluminum smelting, and copper smelting.

There is a lack of data on the burner market, the penetration of new burner technologies and most DOE-OIT combustion projects have been concluded currently (2010). Therefore, this update uses the same evaluation factors in the data table as in the previous Emerging Technologies report. However, for the calculation of energy savings potential, we assume that the technology can be used in 10 percent of natural gas fired heating applications and yields 5\% energy savings on average. The estimation of natural gas use for process heating is derived from the most recent U.S. energy outlook for 2010 ([AEO], 2010) and the U.S. industrial boiler inventarization (Energy and Environmental Analysis, 2005). This corresponds with $37 \%$ of total industrial energy consumption and is $6470 \mathrm{TBtu}$.

The costs will depend on the individual applications of the burners. The costs of next generation $\mathrm{NO}_{x}$-burners are updated to $9.5 \$ / \mathrm{kW}$ (Chambers \& Trottier, 2007).

Operation and management costs are estimated to be similar to the older burners. These assumptions result in a payback period of two years for retrofit-situations. The reduced use of FGR in existing boilers may lead to reduced operating costs, and reductions in $\mathrm{NO}_{x}$ emissions offsets. It is estimated that FGR/Low NOx costs have capital costs of 14.6 $\$ / \mathrm{kW}$, with increasing operating costs. However, these cost-savings will be highly sitedependent.

The main driving force for Low $\mathrm{NO}_{x}$-burners is air quality regulation. The relative low cost compared to options like SCR or FGR makes them attractive options. However, in the design of Low $\mathrm{NO}_{x}$ burners, energy efficiency should be an integrated part of the design. Future steps include the dissemination of information on Low-NO $\mathrm{N}_{x}$ burner technology to potential users and air quality regulators, as well as demonstration of burners in different applications, especially with respect to furnace applications. This update cannot establish significant changes in this respect for the last ten years.

\subsection{Pump System Efficiency Improvements (Motorsystems-6)}

Pumps consume approximately 17 percent of industrial electricity (Tutterow, Casada, \& McKaine, 2002). The selection of a pump for a given application requires the consideration of the flow requirements, required delivered pressure, and the system effects. While most engineers are trained to select pumps to meet requirements as specified in a design, many motor selection decisions are based upon estimates of operating conditions that may not even be close to the true operating conditions. Once a system is placed in operation, the operation conditions may deviate further, moving the 
pump into a range of operation that is not only inefficient, but also potentially destructive. These changes result from changes in application, such as increases, or more frequently, decreases in flow rate requirements. In addition, system resistance can increase as a result of fouling and/or scaling. The pump impeller can erode - changing its effective system curve. Many of these changes are gradual and so may not be evident (Nadel et al., 2000).

To bring a pump system back into acceptable operation, an engineer needs to first assess what the process requirements are. This task can be as simple as taking some measurements, or as complex as performing a systems optimization analysis. Once the pumping requirements are determined, an analysis needs to be performed to determine if the existing pump can meet the current operating characteristics. Among the options available are slowing the pump, trimming or replacing the impeller, and replacing the pump. Frequently, the initial reaction is to slow the pump. This may not be a good choice if the pump is significantly oversized. If the pump is slowed dramatically from its design speed, its system curve will change and may have a very limited range of operation. In many cases it may be much better to select another pump ([DOE], 1999; Hovstadius, Erickson, \& V., 2000; Nadel et al., 2000).

The savings from right-sizing a pump can be significant. The 17 percent savings in the example used in the Data Table is reflective of the savings that are achievable ([DOE], 1999). The system analysis is perhaps the most difficult and costly portion of a project. However, payback periods of 3 years are typical ([DOE], 1999; Hovstadius et al., 2000; Nadel et al., 2000). Also, in large systems major energy savings are possible. At the Texan Decker Creek Generation station a pump improvement program was installed during 2004 for its $405 \mathrm{MW}$ gas turbine. This improved pump efficiency from $59 \%$ to $85 \%$, reducing energy consumption by $220,000 \mathrm{MMBtu}$ annually and having a payback period of less than one year ([DOE-ITP], 2005).

Because large pumps frequently require the large motors at a facility, downsizing the pump may also achieve significant savings in electricity demand, thus reducing demand charges paid by the facility. In addition to the electricity savings, right-sizing pumps can lead to more stable system operation. Pulsation and flow variations that often result from pumps operated outside of their system curve can be disruptive to processes. Correction of these problems can improve production quality, and in some cases increase the capacity of systems that depend upon the pump. Sometimes the downsizing of a pump can also free up spaces that can offer additional options for process improvements. Frequently, these benefits will be the driving motivation for project implementation (Hovstadius et al., 2000; Nadel et al., 2000).

While the engineering associated with pump systems is well understood, many engineers are not experienced in conducting these analyses. Software tools, such as the pump system assessment tool (PSAT) developed by DOE and the Hydraulic Institute ([DOE-OIT], U.S. Department of Energy, Office of Industrial Technologies, 2000), provide a means of addressing this issue. Engineers need to be made aware of this and similar tools, and receive training in its application. Unfortunately a trained and equipped consulting community does not create demand for the service by users. The end-user community must be made aware of the opportunity and must be encouraged 
to seek out these services. However, there is a delicate balance between creating market demand, and developing the capability to deliver services in the marketplace. Both demand and supply need to grow in parallel.

Since the previous report was published (Martin et al., 2000), little has changed with regard to pump system efficiency improvements. There is no indication that these improvements have aided a large share of industrial companies. However, there is no reason to say pump efficiency improvements have not occurred at all. In 2006 a second version of an industrial guidebook for pump performance was released by the Department of Energy ([DOE-ITP], 2006), so improvements are still seen as necessary. 
Table 8. Pump Efficiency Improvement Data Table

Pump efficiency improvement

Motorsys-6

Appropriate selection of pump system components to optimize system operation and minimize system losses

Market Information:

Industries

End-use(s)

Energy types

Market segment

2015 basecase

Units

Notes

Reference technology

Description

Throughput or annual operating hours

Electricity use

Fuel use

Primary Energy use

New Measure Information:

Description

Electricity use

Fuel use

Primary Energy use

Current status

Date of commercialization

Cross cutting

Motors and drives

Electric

Retrofit

GWh $\quad 142,000 \quad$ pump systems are $17 \%$ of industrial electricity

Estimated average measure lifetime

$200 \mathrm{HP}$ pump rated at $4650 \mathrm{gpm}$ at $114 \mathrm{ft}$ of head, but operating at $3612 \mathrm{gpm}$ with $107 \mathrm{ft}$ of head

4000

kWh $\quad 128$

MBtu NA

MBtu $\quad 1.096$

Savings Information:

Replaced with smaller pump optimized to process requirements and new 200hp motor

kWh 107

MBtu NA

MBtu $\quad 0.910$

Commercial

$\sim$ Application of standard engineering practice, formalized in early

1980s

Systems tend to fall out of optimization due to facility changes

Electricity savings

Fuel savings

Primary energy savings

Penetration rate

Feasible applications

Other key assumptions for savings

Electricity savings potential in 2015

Fuel savings potential in 2015

Primary energy savings potential in 2015

Cost Effectiveness

Investment cost

\$ 15,693

Change in annual costs (O\&M/other benefits) \$ $\quad-1,800$

Cost of conserved energy (electricity) \$/kWh $\quad$ \$

Cost of conserved energy (fuel) \$/MBtu NA

Cost of conserved energy (primary energy) \$/MBtu

Simple payback period $\quad$ Years $\quad 2.1$

Internal rate of return $\quad \% \quad 48 \%$

Key non energy factors

Productivity benefits

Product quality benefits

Significant

More stable system operation

Environmental benefits

Other benefits

Significant

More consistent flow, allows for more stable process operation

Current promotional activity

None

\section{Evaluation}

Major market barriers

Likelihood of success

Recommended next steps

Data quality assessment

Sources:

2015 basecase

Basecase energy use

New Measure energy savings

Lifetime

Feasible applications

Costs

Key non energy factors

principal contacts

Somewhat

$\mathrm{H}, \mathrm{M}, \mathrm{L} \quad$ Moderate

$17 \%$

NA

$17 \%$

unsure

Feasible in all half of pump systems

22

46

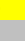

\section{Electric demand savings}

Discount rate for all CCE calculations is 15\%

Abilit

DOE has distributed a design program, and has been working with the Hydraulic Institute to deploy an educational program

Additional notes and sources
Lack of knowledge, reluctance to pay engineering fees, lack of skilled providers

$\mathrm{H}, \mathrm{M}, \mathrm{L} \quad$ Medium

Expanded end-user education, development of engineering training

E,G,F,P Good

MECS 2006, Nadel et al 2000, Xenergy 1998

DOE 1999d

DOE 1999d

Nadel et al 2000, Martin 1999

Nadel et al 2000, Martin 1999

DOE 1999d

Nadel et al 2000

Vern Martin, Flow Care $\quad$ 519-740-8733 


\subsection{Semi-Continuous Melt Silicon Crystal Growth (Electron-1)}

Semiconductor devices are primarily fabricated from monocrystalline silicon, which is produced from polycrystalline silicon. The most common process used to produce single crystals from molten silicon is the Czochralski (CZ) method. In the CZ process, crushed polycrystalline silicon is doped with arsenic, boron, phosphorus, or antimony and melted at high temperatures in a quartz crucible. A pull rod with a small silicon "seed" at the end is lowered into the molten liquid and rotated in a clockwise direction. When the rod is slowly pulled from the melt, a surface tension between the seed and the molten silicon is created, thereby causing a small amount of the liquid to rise with the seed. This liquid cools because of the lower temperature above the melt and forms a single crystal silicon ingot that has the same structural orientation as the seed. The crucible is rotated in a counterclockwise direction to create an eddy current that carries contaminants away from the crystal. The crucible and other components are surrounded by a containment structure that is filled with argon gas. The purpose of the gas is to keep away from oxygen, a contaminant, before it reaches the crystal at the melt surface. The ingot diameter is determined by the temperature of the melt pool and the speed at which the rod is extracted. Most ingots are produced in $150 \mathrm{~mm}$ and $200 \mathrm{~mm}$. The length of the ingot is determined by the amount of molten silicon in the crucible. In 2007 about 10,000 metric tons of CZ-monocrystalline silicon was produced (Mueller, 2007). In the Data Table, this production is estimated to increase by $5 \%$ annually, up to an amount of 160,000 short tons in 2015.

Siemens Solar Industries has been developing a process to improve the production of silicon ingot. The project reduced electricity consumption by 60 percent, improved silicon quality and had cost savings of about 21 percent (Fickett \& Mihalik, 2001). The key changes to the process include additional insulation in the walls of the crucible and at the top of the molten hot zone, the addition of a conical shield above the crucible, and the addition of a continuous recharge system. The additional insulation reduces heat transfer from the melt surface, improves control over the temperature gradients at the melt surface, and allows the rod to be pulled more rapidly. In their setup, they could maintain a semi-continuous $\mathrm{CZ}$ growth process. The main reason for the energy saving was the installed Fluidized Bed Reactor (Fickett \& Mihalik, 2001). With a Fluidized Bed Reactor (FBR) costs can be lowered and such reactors have been commercialized for the production of granular silicon. For example, Peak Sun Silicon uses a FBR in combination with the Schumacher process (which uses bromine, instead of chlorine in regular Siemens processes) and adds that their silicon could be used as a direct feedstock for continuous melt replenishment $\mathrm{CZ}$ processing (http://www.peaksunsilicon.com/schumacher-process/).

All silicon produced for both semiconductor and solar photovoltaic end-uses are produced in batch. A (semi-)continuous recharge system would allow the introduction of material during the run and would permit the growing of longer silicon ingots. The challenges to semi continuous melt growth include maintaining the growing environment, maintaining acceptable temperatures and temperature gradients when introducing materials, insuring the uniformity of the melted material, avoiding disturbance of the melt surface, and avoiding contaminating the silicon being drawn from the melt. 
In 2000 there were seven major manufacturers in the U.S. that produced semiconductor grade silicon: Wacker, SHE, Komatsu, Mitsubishi Silicon America, MEMC, SumitomoSiTiX, and Motorola.

The market for solar photovoltaic silicon represented about 5 percent of the total market for silicon in 2000. The solar industry has been dominated by single crystal silicon, of which Siemens is a major player in the market. The other companies involved in the solar market include Solarex, BP Solar, Evergreen Solar, ASE Americas, Photowatt, Sharp, and Kayocera. Demand for solar products continues to grow and remains significantly larger than supply (Herron, 2010).

This technology update shows that silicon production has increased over the last decade, due to a large extent to the growing solar photovoltaic market. It is estimated that monocrystalline cells represent about $38 \%$ of 2008 solar cell production, while polycrystalline cells account for almost half (Saga, 2010). Virtually all monocrystalline silicon appears to be produced with CZ-technology, but it is unclear to what extent continuous processes are used. 
Table 9. Continuous Melt Silicon Growth Data Table

Continuous Melt Silicon Crystal growth

Electron-1

Replace batch crystal growth - Czochralski (CZ) method

Market Information:

Industries

End-use(s)

Energy types

Market segment

(a)

2015 basecase

Reference technology

Description

Throughput or annual operating hours

Electricity use

Fuel use

Primary Energy use

New Measure Information:

Description

Electricity use

Fuel use

Primary Energy use

Current status

Date of commercialization

Estimated average measure lifetime Units

Notes

Savings Information:

Electricity savings

Fuel savings

Primary energy savings

Penetration rate

Feasible applications

Other key assumptions for savings

Electricity savings potential in 2015

Fuel savings potential in 2015

Primary energy savings potential in 2015

Cost Effectiveness

Investment cost

Type of cost

Change in annual costs (O\&M/other benefits) $\$$

Cost of conserved energy (electricity) \$/kWh

Cost of conserved energy (fuel) \$/Mbtu

Cost of conserved energy (primary energy)

Simple payback period

Internal rate of return

Key non energy factors

Productivity benefits

Product quality benefits

Environmental benefits

Other benefits

Current promotional activity

Evaluation

Major market barriers

Likelihood of success

Recommended next steps

Data quality assessment

Sources:

2015 basecase

Basecase energy use

New Measure energy savings

Lifetime

Feasible applications

Costs

Key non energy factors

Principal contacts

Additional notes and sources

SIC 3674

Semiconductor
Process heating, other

Electricity

New, replace on failure

retrofit

short tor $\quad 16252.01 \quad$ Mueller 2007 (10,000 metric tons in $2007,5 \%$ growth for 8 years)

Czochralski (CZ) method

tons $\quad 1.00$

kWh $\quad 600000 \quad$ Ficket, 2001

MBtu $\quad 0$

$\begin{array}{lll}\text { MBtu } & 5118.0 \quad \text { Ficket, } 2001\end{array}$

Continuous melt silicon crystal growth

kWh $\quad 240000 \quad$ Ficket, 2001

MBtu $\quad 0$

MBtu $2047.2 \quad$ Ficket, 2001

$\begin{array}{ll}2047.2 & \text { Ficket, } 2001 \\ \text { Pilot plant } & \text { Personal com }\end{array}$

Personal communication with Greg Mihalik, 2000

Years $\quad 7 \quad$ Personal communication with Greg Mihalik, 2000

kWh $/ \% \quad 360000 \quad 60 \%$

$\begin{array}{lll}\mathrm{MBtu} / \% & 0.00 & 0.00\end{array}$

$\begin{array}{lll}\mathrm{MBtu} / \% & 3070.8 & 60 \%\end{array}$

$\% \quad$ Medium

GWh -2340.3

Tbtu $\quad 0$

19.96

629076

Full

Cost of modifications to the grower plus cost of recharge system

$-125815$

Estimate 20 percent of incremental cost

\$/Mbtu 8

Years $\quad 4.88$

0.19

$\begin{aligned} & \text { Significant } \\ & \text { Somewhat } \\ & \text { Somewhat }\end{aligned} \quad$ Pot scrap has been reduced from about 8.8 to 2.2 lbs per run

$\mathrm{H}, \mathrm{M}, \mathrm{L} \quad \mathrm{High}$

Dependent on markets

$\mathrm{H}, \mathrm{M}, \mathrm{L} \quad \mathrm{High}$

E,G,F,P $\quad$ Excellent

Testing to create a truly continuous process

Mueller 2007

EIA 1999

Ficket, 2001; Personal communication with Greg Mikalik, 2000

Personal communication with Greg Mikalik, 2000

Reed, et al. 1999

Personal communication with Greg Mikalik, 2000 


\subsection{Cooling and Storage (Food-4)}

Refrigeration in the food sector is a large energy consumer and is mainly used for freezing or cooling of meat, fruit, vegetables, as well as for frozen products (e.g. icecream, juice). Refrigeration in industry is mostly done by means of compression cooling and in some cases by absorption cooling (Mottal, 1995). Electricity use for refrigeration in the food and beverages industry is estimated to be 25 percent of its total electricity use (Okos, Rao, Drecher, Rode, \& Kozak, 1998) at 18.6 TWh. This is 7.5 TWh higher than the estimation of the previous Emerging Technologies report (Martin et al., 2000; Xenergy, 1998).

Many options exist to improve the performance of industrial refrigeration systems. System optimization and control strategies combined show a large potential for energy efficiency improvement of up to 30 percent (Brownell, 1998). Opportunities include system design, component design (e.g., adjustable speed drives), as well as improved operation and maintenance practices. We focus on new system designs. Adjustable speed drives and process control systems have been discussed elsewhere. New system designs include the use of adsorption heat pumps, gas engine driven adsorption cooling, new working fluids (e.g., ammonia, CO2) and alternative approaches (e.g., thermal storage). Due to the wide variety, we focus on selected technology developments in the areas of gas engines, thermal storage and new working fluids.

Gas engines can be applied to drive the compressor instead of an electric motor. A gas engine is used as the direct drive, and the system can follow refrigeration loads by using variable engine speed. The waste heat of the engine can be used to preheat water or for space heating at the plant. GRI has developed a system, marketed by Thermopower Corporation, which has been tested in ice production, food processing, and chemical industries ([GRI], 1997). Other suppliers market similar products. NYSERDA supported an innovative demonstration at a dairy plant with a gas engine with an absorption chiller. Without the absorption sub-cooling, the project would have saved 52 percent on a primary energy basis. With the absorption cooling, the project decreased primary energy use by 77 percent ([CADDET], 1996). The gas engine compressor system (without absorption cooling) has capital costs twice as high as a chiller system, and a payback period of about 2 years. A similar system installed at Pittsburgh (PA) cooling warehouse had a payback period of 1.9 years ([CADDET], 2000b). The gas engine-absorption cooling system has substantially higher capital costs compared to an electric chiller system (almost a factor 3 higher), but the large energy savings and reduced peak energy use result in a payback period of 4 years. The use of a gas engine may result in higher onsite $\mathrm{NO}_{x}$ emissions, although offsetting high peaking power plant emissions. Hence, in non-attainment areas extra $\mathrm{NO}_{x}$-reduction measures need to be installed.

Thermal storage is an "old" technology in the sense that it has been used for several centuries for seasonal cooling. Thermal storage has been re-discovered for applications in the food industry to shave peak loads by using off-peak power to generate ice, which is stored and used for cooling later (Saito, 2002). Several plants operate thermal storage systems in the U.S., combined with innovative cooling concepts, e.g. a fermentation plant in Rochester (NY), a cheese factory in Corfu (NY), a food services company in Clark County (NV) and a vegetable and food processing plant in Placentia (CA). Energy 
savings vary depending on the plant. The fermentation plant in Rochester (NY) reduced cooling energy needs by 80 percent compared to the existing mechanical chiller system. This system had a payback period of up to 4 years ([CADDET], 1993b). In other applications the savings were not always fully documented or are much smaller. The load shift accounts for the productivity increase, as it allows the use of low-priced electricity at the off-peak hours. With peaking power-supply problems not uncommon in California, the Midwest and Texas, peak power is a highly valuable commodity, making this technology economically attractive.

Other major trends are a reduction of refrigerant charges and the development of new working fluids. Traditionally, the most common working fluids for compression heat pumps are ammonia and CFCs or HCFCs. R\&D is directed toward alternative working fluids, especially for the CFCs and HCFCs due to the Montreal Protocol. These alternative working fluids can save energy. Savings of 2 to 20 percent have been reported (Lorentzen, 1993a, 1993b; Trepp, Savoie, \& Kraus, 1992). Recent developments include the use of natural refrigerants such as $\mathrm{CO}_{2}$ (Stene, 1999). $\mathrm{CO}_{2}$ is suitable for cooling of storage facilities. In Japan research has also looked at metal hydride systems for commercial cooling, as well as for small-scale systems. A first working prototype was demonstrated in 1995 at a very small scale (for a vending machine), and the technology has been demonstrated for a warehouse of $1100 \mathrm{ft}^{2}\left(100 \mathrm{~m}^{2}\right)$ at storage temperatures of $40^{\circ} \mathrm{F}\left(-40^{\circ} \mathrm{C}\right)$. The system can be designed in a wide variety of scales $(10-10,000 \mathrm{~kW})$, and reduces power use by approximately 20 percent compared to traditional CFCcontaining systems (JNT 1996). 
Table 10. Cooling and Storage in the Food Industry Data Table

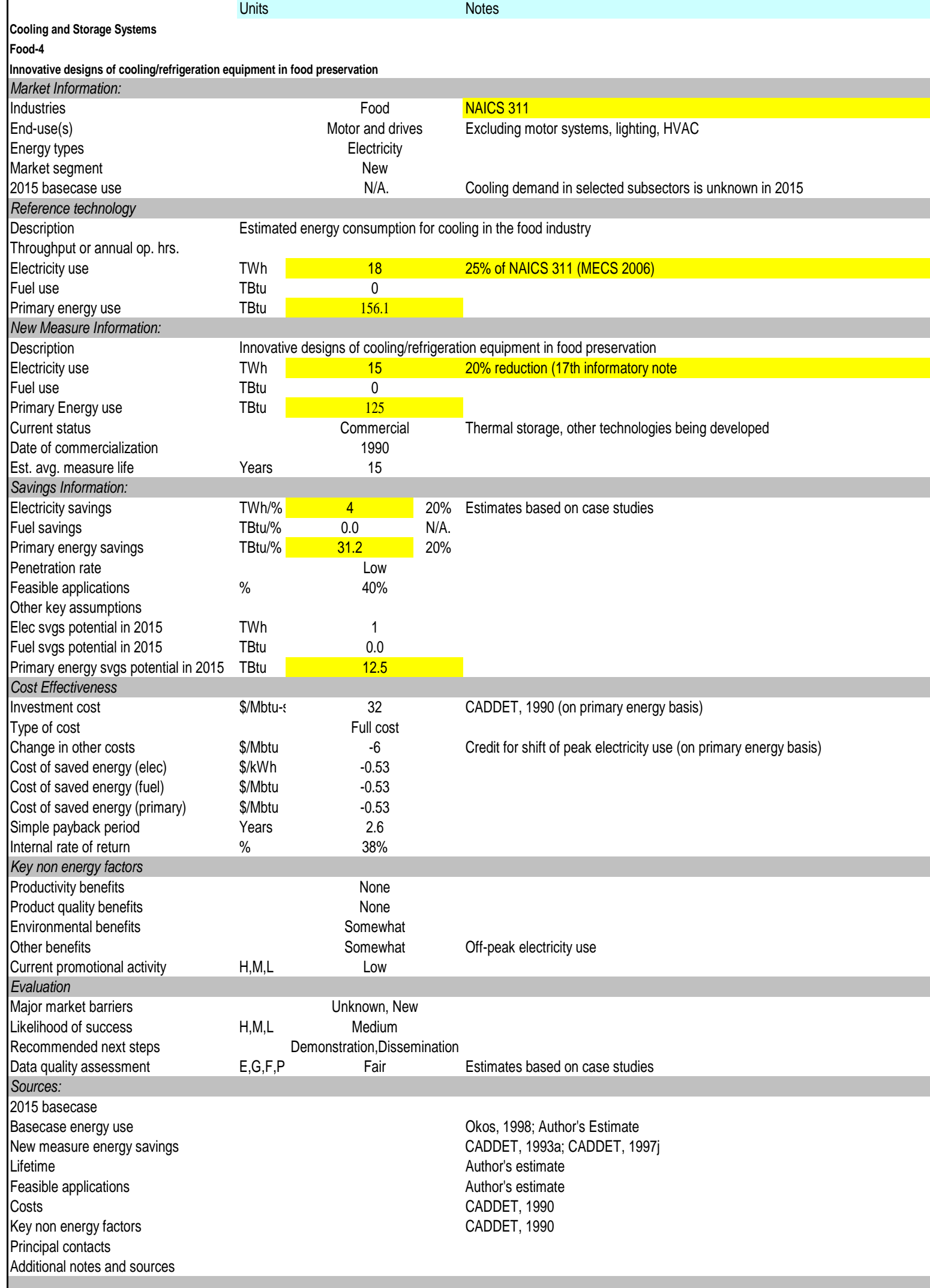


For the technology characterization, we assume a potential for energy efficiency improvement of 20 percent on average, which can be achieved using different technologies, e.g. thermal storage, natural gas engine (not for non-attainment areas) and the use of new refrigerants in small-scale industrial applications. Higher energy savings are possible in specific cases, as outlined above.

Given the incentives for reduction of peak power use and expected peaking-power shortages in important food producing regions, we assume that there is a substantial interest in implementing new refrigeration equipment in the food industry. Hence, we estimate that between 2000 and 2015, 40 percent of the potential may be realized.

Capital costs will depend heavily on the specific site and cooling conditions, as well as technology implemented. Hence, the costs and profitability of the investment will vary widely. We base the cost estimate on the thermal storage system installed at Kirk Produce, Placentia (CA) ([CADDET], 1990). The cost savings because of switching to offpeak hours electricity use have been accounted as a productivity benefit. Other benefits may occur, such as increased product quality ([CADDET], 1990), but have not been taken into account in the cost estimates.

Most technologies, except for the use of selected new refrigerants, have been demonstrated commercially. Hence, dissemination of the results among other potential users is needed, as is demonstration of new concepts or innovative combinations of efficient cooling systems.

The International Institute of Refrigeration has identified potential energy savings of 20 percent in refrigeration systems on the short term and 30-50 percent in 2020, if high efficiency standards are installed ([IIR], 2003). In a study on Californian energy efficiency in fresh fruit and vegetable processing, efficiency measures were described which could have demand savings ranging up to $319 \mathrm{~kW}$, energy savings from 4,000 $1,200,000 \mathrm{kWh}$ per year with payback periods ranging from within a year up to 6.5 years (Hackett, Chow, \& Ganji, 2005). However, no detailed data on the implementation of efficiency measures was found.

\subsection{Biodesulfurization of Gasoline (Refining-1)}

As the overall sulfur content of crude oil has increased over the past decades ([EIA], $2009 \mathrm{~b}$ ) and is likely to increase further in the next years, gasoline manufacturers have had to find better and more efficient ways of desulfurizing their supplies. The average sulfur content of gasoline in the U.S. gasoline pool is limited to $30 \mathrm{ppm}$, while diesel sulfur content should currently be $15 \mathrm{ppm}$ on average. Biodesulfurization (BDS) is a process in which live microorganisms selectively remove sulfur from fuel and could deliver low-sulfur gasoline economically and with fewer environmental emissions.

In the past the Merox process was the primary technology employed for the removal of sulfur in gasoline, but nowadays treatment with hydrogen (Hydrodesulfurization, HDS) is the main technology (Mohebali \& Ball, 2008; Soleimani, Bassi, \& Margaritis, 2007; Sullivan, 2004; Xu, Feng, Yu, Li, \& Ma, 2009). This catalytic process occurs at high temperatures $\left(200-450{ }^{\circ} \mathrm{C}\right.$ ) and high pressure (30-100 bar $\mathrm{H}_{2}$ pressure) (Seeberger \& Jess, 2010). 
The advantage of oxidative biodesulfurization processes is that the reaction takes place at ambient conditions and produces non-toxic by-products, eliminating the need for collateral processing of hydrogen sulfide. The biocatalytic process may be designed as a batch process in which the reactants and biocatalyst are maintained in a reaction vessel for a period of time. Alternatively, the bioprocess can be designed as a continuous flow process in which the reactants are only brought into contact with the biocatalyst for a limited period of time.

In 2000, initial capital investment for a biodesulfurization unit was expected to be around \$18 million for a 25,000 barrel per day facility in 2015 ([ANL], 1998; [DOE-OIT], U.S. Department of Energy, Office of Industrial Technologies, 1999c). This would be half the capital cost of a standard desulfurization facility, which was estimated at \$36 million. The yearly operating and maintenance costs were expected to run a bit higher for a biodesulfurization unit - about an additional $\$ 620,000$ annually. With its unit savings enough energy would be saved to deflect these costs however and result in a payback of just less than two years. In 2010 no recent capital and O\&M costs for BDS could be found online.

Motor gasoline production in 2015 was estimated to be 11.73 million barrels per day, according to the Annual Energy Outlook 2000 ([AEO], 1999). The Annual Energy Outlook of 2010 currently predicts a production of 9.37 million barrels of motor gasoline for 2015 ([AEO], 2010). In the next decades this number is declining in favor of diesel production. However, also diesel production would benefit from a successful biodesulfurization process.

Nevertheless, the biotechnology is still in the bench-scale test state as it was in 2000. Future developments for this technology include: elucidation of the desulfurization pathway including the isolation, identification, and quantification of the pathway intermediates; enhancement of solvent tolerance of the catalyst; definition of the basis for the required genetic improvements of the organisms; and determination of the rate and extent of gasoline desulfurization. These issues are still preventing BDS from becoming a feasible technology (Xu et al., 2009). Therefore, we have assumed 5\% application in 2015 in the data table.

Most refineries and gasoline processing facilities operate continuous reactions. It is relatively easy to maintain and operate a batch bioreactor, but it requires significant startup time to initiate the microbial activity and allow products to accumulate. Future research is needed to develop continuous flow reactions since these processes are more prone to contamination with undesired microorganisms, making quality control difficult to maintain.

Currently, it is thought that two major steps should be made soon to make BDS worthwhile: a rapid progress in understanding and finding optimal ways to implement biotechnology in refineries (Mohebali \& Ball, 2008). At the moment the process is still too slow, too expensive and not suited for large-scale implementation. It might be used in an additional refinery step (Soleimani et al., 2007), but further development of hydrodesulfurization and newer processes like ionic liquid extraction (Seeberger \& Jess, 2010) might limit its future. 
Table 11. Biodesulfurization Data table

\begin{tabular}{|c|c|c|c|}
\hline & Units & & Notes \\
\hline \multicolumn{4}{|l|}{$\begin{array}{l}\text { Biodesulfurization of Gasoline } \\
\text { Refin-1 } \\
\text { Replace hydrodesulfurization }\end{array}$} \\
\hline \multicolumn{4}{|l|}{ Market Information: } \\
\hline Industries & & Petroleum refineries & NEICS 324110 \\
\hline End-use(s) & & Process heating, other & \\
\hline Energy types & & Electricity & DOE-OIT 1998a \\
\hline Market segment & & New, replace on failure & \\
\hline 2015 basecase & $\begin{array}{l}\text { million } \\
\text { barrels }\end{array}$ & 3,420 & 9.37 Mbarrels / day. Prediction Energy Outlook 2010 \\
\hline \multicolumn{4}{|l|}{ Reference technology } \\
\hline Description & \multicolumn{3}{|c|}{ Hydrodesulfurization } \\
\hline Throughput or annual operating hours & barrels & 1.0 & \\
\hline Electricity use & kWh & 11.14 & DOE-OIT 1998a \\
\hline Fuel use & MBtu & 0 & DOE-OIT 1998a \\
\hline Primary Energy use & MBtu & 0.09 & DOE-OIT 1998a \\
\hline \multicolumn{4}{|l|}{ New Measure Information: } \\
\hline Description & \multicolumn{3}{|c|}{ Biocatalytic removal of sulfur from gasoline } \\
\hline Electricity use & kWh & 9.99 & Assumed $10 \%$ savings over conventional technology \\
\hline Fuel use & MBtu & 0 & \\
\hline Primary Energy use & MBtu & 0.09 & \\
\hline Current status & & Bench scale trials & Xu 2009, Mohebali 2008, Soleimani, 2007 \\
\hline Date of commercialization & & N/A & \\
\hline Estimated average measure lifetime & Years & 15 & \\
\hline \multicolumn{4}{|l|}{ Savings Information: } \\
\hline Electricity savings & $\mathrm{kWh} / \%$ & $10 \%$ & \\
\hline Fuel savings & MBtu/\% & $0 \%$ & \\
\hline Primary energy savings & MBtu/\% & $10 \%$ & \\
\hline Penetration rate & & Medium & \\
\hline Feasible applications & $\%$ & $5 \%$ & Application in 2015 seems very limited \\
\hline \multicolumn{4}{|l|}{ Other key assumptions for savings } \\
\hline Electricity savings potential in 2015 & GWh & 196 & \\
\hline Fuel savings potential in 2015 & Tbtu & 0 & \\
\hline Primary energy savings potential in 2015 & Tbtu & 1.67 & \\
\hline \multicolumn{4}{|l|}{ Cost Effectiveness } \\
\hline Investment cost & $\$$ & $\mathrm{~N} / \mathrm{A}$ & ANL 1998 Based on 25,000 bbl/day facility $18 \mathrm{M}$ for biodesulf vs. $36 \mathrm{M}$ for hydro \\
\hline \multicolumn{4}{|l|}{ Type of cost } \\
\hline Change in annual costs (O\&M/other benefits) & $\$$ & $\mathrm{~N} / \mathrm{A}$ & O\&M costs are higher for biodesulfurization units \\
\hline Cost of conserved energy (electricity) & $\$ / k W h$ & $\mathrm{~N} / \mathrm{A}$ & \\
\hline Cost of conserved energy (fuel) & $\$ / M b t u$ & $\mathrm{~N} / \mathrm{A}$ & \\
\hline Cost of conserved energy (primary energy) & \$/Mbtu & $\mathrm{N} / \mathrm{A}$ & \\
\hline Simple payback period & Years & $\mathrm{N} / \mathrm{A}$ & \\
\hline Internal rate of return & $\%$ & $\mathrm{~N} / \mathrm{A}$ & \\
\hline \multicolumn{4}{|l|}{ Key non energy factors } \\
\hline \multicolumn{4}{|l|}{ Productivity benefits } \\
\hline Product quality benefits & & Significant & Biodesulfurization does not reduce octane the way hydrodesulfurization does \\
\hline Environmental benefits & & None & \\
\hline Other benefits & & & \\
\hline Current promotional activity & $\mathrm{H}, \mathrm{M}, \mathrm{L}$ & Medium & \\
\hline \multicolumn{4}{|l|}{ Evaluation } \\
\hline Major market barriers & & $\begin{array}{l}\text { Capital and equipment } \\
\text { intensive, small steps }\end{array}$ & No large breakthroughs have been discovered in the last decade \\
\hline Likelihood of success & $\mathrm{H}, \mathrm{M}, \mathrm{L}$ & Low & \\
\hline Recommended next steps & & Research, scale-up & $\begin{array}{l}\text { Improve biocatalyst stability, faster kinetics, broader substrate specificity, } \\
\text { industrial integration }\end{array}$ \\
\hline Data quality assessment & $E, G, F, P$ & Good & \\
\hline \multicolumn{4}{|l|}{ Sources: } \\
\hline 2015 basecase & & & Energy Outlook 2010 \\
\hline Basecase energy use & & & DOE-OIT 1998 \\
\hline New Measure energy savings & & & DOE-OIT 1998, Xu 2009, Mohebali 2008, Soleimani 2007 \\
\hline Lifetime & & & Argonne National Laboratory 1998 \\
\hline Feasible applications & & & Author's estimate \\
\hline \multicolumn{4}{|l|}{ Costs } \\
\hline \multicolumn{4}{|l|}{ Key non energy factors } \\
\hline Principal contacts & & & \\
\hline Additional notes and sources & & & \\
\hline
\end{tabular}




\subsection{Fouling Minimization (Refining-2)}

The petroleum refining industry is one of the largest energy consumers in the manufacturing sector. Primary energy consumption in 1994 was 3,230 TBtu (3,424 PJ), or 20.5 percent of total manufacturing energy consumption. Modern refineries are complex integrated systems that transform crude oil into transport fuels, residual fuel oil, and other products. The energy required for processing a unit of crude oil input in a complex refinery is roughly equal to about 10 percent of the energy content of the input crude, although this can vary ([EIA], 2010; [WEC], 1995). The main processes in refining involve crude distillation (the separation of crude oil into various distillate products through pyro-processing and fractionation), conversion (the addition of hydrogen into hydrocarbon chains to produce higher quality products), reforming (the "reorganization" of hydrocarbon molecules to increase the octane) and finishing or treating processes (removal of sulfur and other impurities) ([WEC], 1995). Crude distillation alone consumes about 4-5 percent of the energy content of the oil (Worrell, 1994).

In a complex refinery, most processes occur under high temperature and pressure conditions; the management and optimization of heat transfer among processes is therefore important for increasing overall energy efficiency. Fouling, a deposit buildup in units and piping which impede heat transfer, require the combustion of additional fuel. For example, the processing of many heavy crude oils in the U.S. increases the likelihood of localized coking deposits in the heating furnaces, thereby reducing furnace efficiency and creating potential equipment failure. An estimate by the Office of Industrial Technology at the U.S. Department of Energy noted that the cost penalty for fouling could be as much as $\$ 2$ billion annually in material and energy costs ([DOE-OIT], U.S. Department of Energy, Office of Industrial Technologies, 1999a).

Several methods of investigation have been underway to attempt to reduce fouling including the use of sensors to detect early fouling, physical and chemical methods to create high temperature coatings (without equipment modification), the use of ultrasound, as well as the improved long term design and operation of facilities. The U.S. Department of Energy initially funded preliminary research into this area, but funding has been discontinued (Bott, 2000; Huangfu, 2000). Recent scientific papers dealt with issues like heat exchanger monitoring, prediction of fouling rates, fouling impacts and optimal cleaning schedules (de Oliveira Filho, Liporace, Queiroz, \& Costa, 2009)

Initial analysis on fouling effects of a 100,000 bbl/day crude distillation unit found an additional heating load of $12.3 \mathrm{kBtu} /$ barrel (13.0 MJ/barrel) processes (Panchal \& Huangfu, 2000). Reducing this additional heating load could results in significant cost and energy savings. Indeed, it is estimated that a 1 Kelvin drop in heating temperature in a 100,000 bbl/day plant might cost $\$ 40,000$ (Yeap, Wilson, Polley, \& Pugh, 2001). In an energy assessment of the Californian Martinez Refinery ([DOE-OIT], U.S. Department of Energy, Office of Industrial Technologies, 2002), expenditures in the maintenance area like heat exchanger cleaning would cost about $\$ 10$ million, but would save over \$ 14 million on energy costs. This would result in a payback period of less than a year. However, it is unsure what the life time of this technology is before new 
investments have to be made. We use the 8 percent reduction in energy costs of this plant as representative for the calculations in the data tale.

It is likely that a well-designed heat exchange network would have fewer cleaning requirements, thereby saving in operations and maintenance costs. While the issue of fouling can now be found in scientific papers and engineering conferences, it is currently unknown to what extent fouling has become a potential energy and cost saver for refineries. Some sources believe that the future development of in this area is expected to be in the area of Condition-Based Maintenance of Heat-Transfer Equipment that will be based on Knowledge-Based and Monitoring -Based Mitigation of Fouling/Corrosion (Panchal, 2000). With current developments in fouling modeling and its potential savings, it appears likely to be implemented in refineries in some way. 
Table 12. Fouling Minimization Data Table

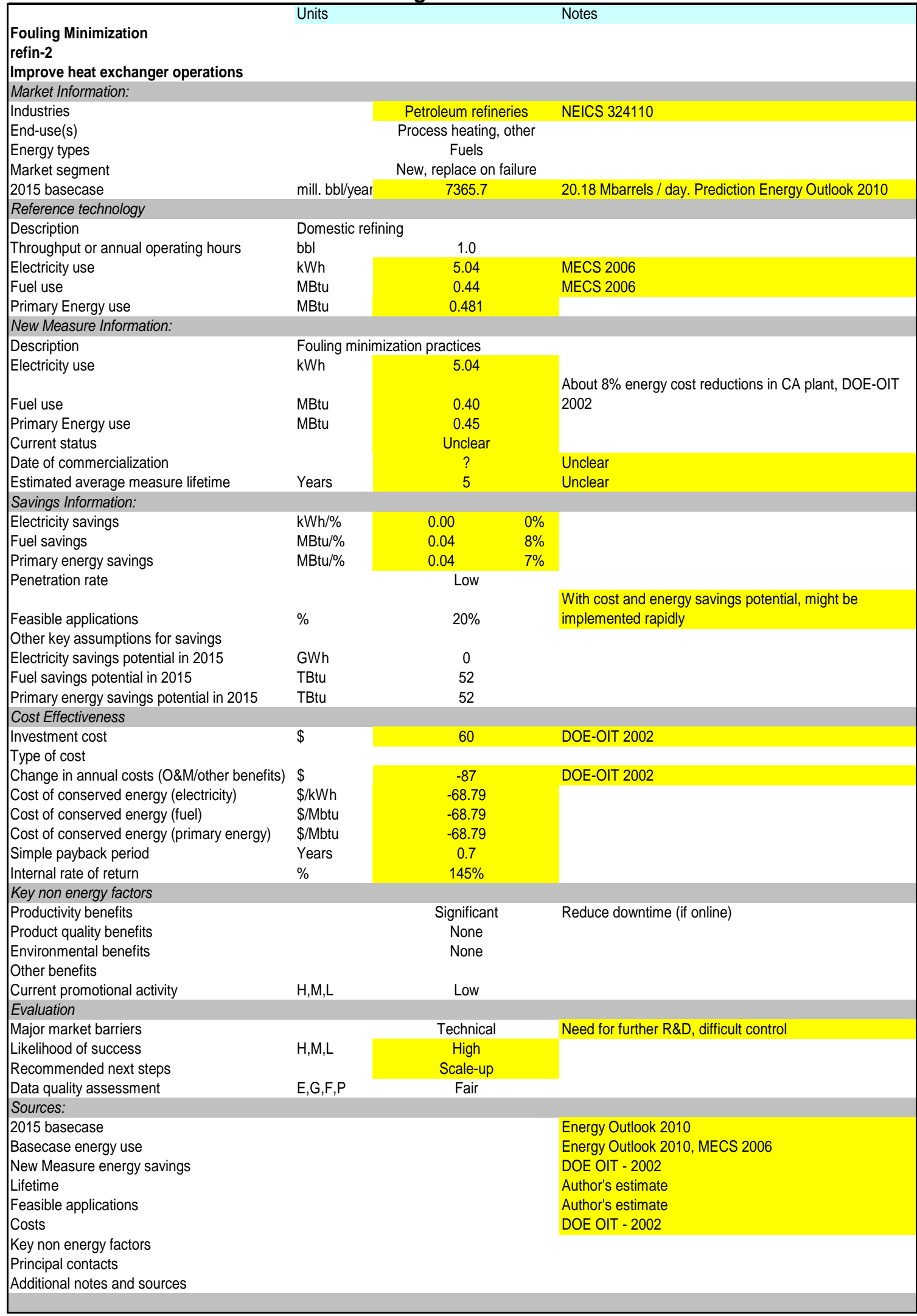




\subsection{Plastics Recovery (Chemicals-8)}

In the United States, plastics production has grown significantly between 1980 and 2000 at rates of 3-8 percent annually with total plastics production of 29 million tons (26 Mt) in 1996 ([Anon], 1997). Some of the main plastic products include low-density polyethylene (LDPE), high-density polyethylene (HDPE), polyethylene teraftalate (PET), polystyrene, and polyvinyl chloride (PVC). The markets have experienced particularly strong growth in PVC, polypropylene, and HDPE. While not as energy-intensive as the production of bulk chemicals, the production of plastic materials in NAICS 325211 and 325212 accounts for an important share of chemical energy use due to the large volume of production. Primary energy consumption for plastics and resins production in 2006 was 603 TBtu (639 PJ) or 4 percent of manufacturing energy consumption.

In recent years, recycling in the U.S. has grown to about 33\% of municipal solid waste (MSW). However, if one compares the weight of produced plastics with the weight of recovered plastics, the result is a low recovery rate of 7 percent ([EPA], 2008). While some progress has been made in recovering plastics from some waste streams, the overall recovery rate for post-consumer waste in the U.S. is low - about 9 percent (Denison, 1996). There are still large opportunities to greatly increase recycling in the U.S. In many cases, economics prevent the increase in recycling since the cost of collecting and processing post-consumer plastics is higher than the cost of producing virgin materials (Kobler, 2000).

Complex or mixed waste streams are particularly challenging to separate and purify to a useful level. Aside from the PET and HDPE bottle markets, one of the single largest concentrated supplies can be found in automobile shredder residue (ASR). ASR includes plastics, rubber, glass, fibers and amounts for 5 million tons $(4.5 \mathrm{Mt})$ of U.S. landfill waste annually ([DOE-VTP], 2009). It is estimated that 20-31 percent of this is 20 different types of plastic materials; however, the two major types of plastic are polypropylene and ABS (acrylonitrile butadiene styrene) (Kobler, 2000). Currently, virtually no post-consumer plastics are used in today's new vehicles ([USCAR], 1998; Kobler, 2000; Salyp Elv Center). Of these plastics, thermoplastics such as polypropylene, polyethylene, polycarbonate, nylon, and polyurethane can potentially be melted and reused while thermosets do not re-melt and are more challenging to recycle (Betts, 1999; Kobler, 2000).

Various technologies have been developed to recover and reuse plastics in ASR. MBA Polymers developed a mechanical separation process that allows plastics of similar densities to be separated for reuse. This has been used to separate and recover different plastics from computer housings. Early development of this process was partially supported by the U.S. Department of Energy's NICE³ program, the Vehicle Recycling Partnership (VRP), and the American Plastics Council (APC) ([DOE-OIT], U.S. Department of Energy, Office of Industrial Technologies, 1999b; Biddle, 2000; Yester, 2000). In 2010 MBA Polymers will have recovery plants in Richmond, CA, Germany, China and the United Kingdom with a total capacity of over 150,000 tons per year (Deligio, 2010; Pelsoci, 2007). 
Argonne National Laboratory has developed a separation technology called froth flotation to separate and recover ABS and HIPS from appliance wastes ([DOE-VTP], 2009; Daniels, 2000; DeGaspari, 1999; Kobler, 2000; Yester, 2000). This technology has received developmental support from the U.S. Department of Energy's Office of Industrial Technology in collaboration with the VRP and the American Plastics Council ([DOE-OIT], U.S. Department of Energy, Office of Industrial Technologies, 1999b) and could be applied to ASR in the future. A small-scale trial using appliance waste streams was conducted at the Appliance Recycling Centers of America with support from the VRP but no pilot plant had been constructed in 2000 (Daniels, 2000; Yester, 2000). More recently plans unfolded for a 20-ton-per-hour pilot plant ([DOE-VTP], 2009).

Recovery Plastics International (RPI) has developed a skin flotation technology that recovers about 80 percent of the plastic stream from ASR (Kobler, 2000). This technology has also received R\&D funding support from VRP and a Salt Lake City plant has been operating since 2000. Currently the company specializes in recovering electronics plastic (Ashpole, 2009).

In the froth flotation technology, plastics of similar densities are placed in an aqueous solution, and the wetting characteristics of various plastic types are selectively adjusted. This preparation allows for small gas bubbles to attach to particular plastics thereby allowing for separation in the solution ([USCAR], 1998; DeGaspari, 1999). The skin flotation technique at RPI puts on a skin of plasticizer on the plastic surface selectively, which makes it hydrophobic. That targeted plastic type, which preferentially absorbed the plasticizer, is the only one to float (Kobler, 2000). Only with skin flotation technology has raw ASR been used as the primary feedstock material, and also is able to separate out plastics from rubbers improving the quality of the separated product (Kobler, 2000).

Energy savings from this system can be significant. Including the embodied energy in plastics, savings estimates range from 50-75 MBtu/ton (58-87 GJ/t) material recycled (Daniels, 2000). (M. Fisher \& Mark, 1999) note that the plastics content of ASR is about 13 percent by weight. Based on this analysis we estimate a savings of $13 \mathrm{MBtu} /$ ton (15 GJ/t) (M. Fisher \& Mark, 1999; Lipinsky \& Wesson, 1995).

Aside from energy savings, the environmental implications of recycling technologies are significant. Roughly 25 percent of the weight of the vehicles is currently landfilled, which includes plastics, foam, copper, trace metals, rubber, and fluff. ASR recycling is estimated to divert at least 40 percent of this currently land-filled materials (Kobler, 2000).

Installation cost estimates for plastics separations technologies vary in range from $\$ 100$ $350 /$ ton ( $\$ 110-390 / t)$ recovered material based on annual recovery capacity (Daniels, 2000; Kobler, 2000). Operations costs are claimed to be competitive or lower than existing virgin plastics and estimates have been given of 15-20 cents/pound for the RPI process and 50-75 cents/pound for the ANL process (Daniels, 2000; Kobler, 2000). The relative payback will also depend on the market price for the various recovered materials, assuming they meet market specifications.

Apart from technical and economic feasibility, the full commercialization of this technology is dependent on changes in U.S. environmental regulations. Existing 
regulations promulgated in 1976 under the Toxic Substances Control Act are unclear but apparently do not allow the reintroduction of any product containing more than 2 parts per million of toxic Polychlorinated Biphenyls (PCBs) ([EPA], 2000; [USCAR], 1998; Kobler, 2000)1. Shredder residue on average has concentrations of 10-30 ppm PCBs, however this residue is primarily on the surface of the plastics and generally not embedded in the plastic material itself (Kobler, 2000). ASR technologies that wash the plastic surfaces are able to remove the PCBs and produce products below the $2 \mathrm{ppm}$ PCBs level. Clarification in the regulations to account for this will help to stimulate the ASR plastics recovery market (Kobler, 2000). R\&D support by the VRP was curtailed because of this issue but there is optimism that this could be remedied and the EPA was looking into modification possibilities (Fisher, M. (American Plastics Council), 2000; Yester, 2000). MBA Polymers has called for U.S. legislation of plastic waste to create a domestic plastic recycling market like Europe and Canada have (Deligio, 2010).

Other key issues in the development of large-scale recovery facilities include ensuring access to a consistent source and volume of ASR streams so that recovered plastics customers such as auto manufacturers can be ensured of continued uninterrupted supply. Since the previous report (Martin et al., 2000), the technology to recover plastics from car residues has been developed progressively (now in commercial application stage) and especially MBA polymers has become a major company with significant capacity increases in recent years. Its future application can be very large due to the number of cars in the United States. However, the right economic and legislative incentives are not in place yet.

\footnotetext{
1 The original legislation states that "no person may manufacture, process, or distribute in commerce or use any polychlorinated biphenyl in any manner other than in a totally enclosed manner" (i.e. any manner that would expose human beings to PCBs) (EPA 2000).
} 
Table 13. Plastics Recovery Data Table

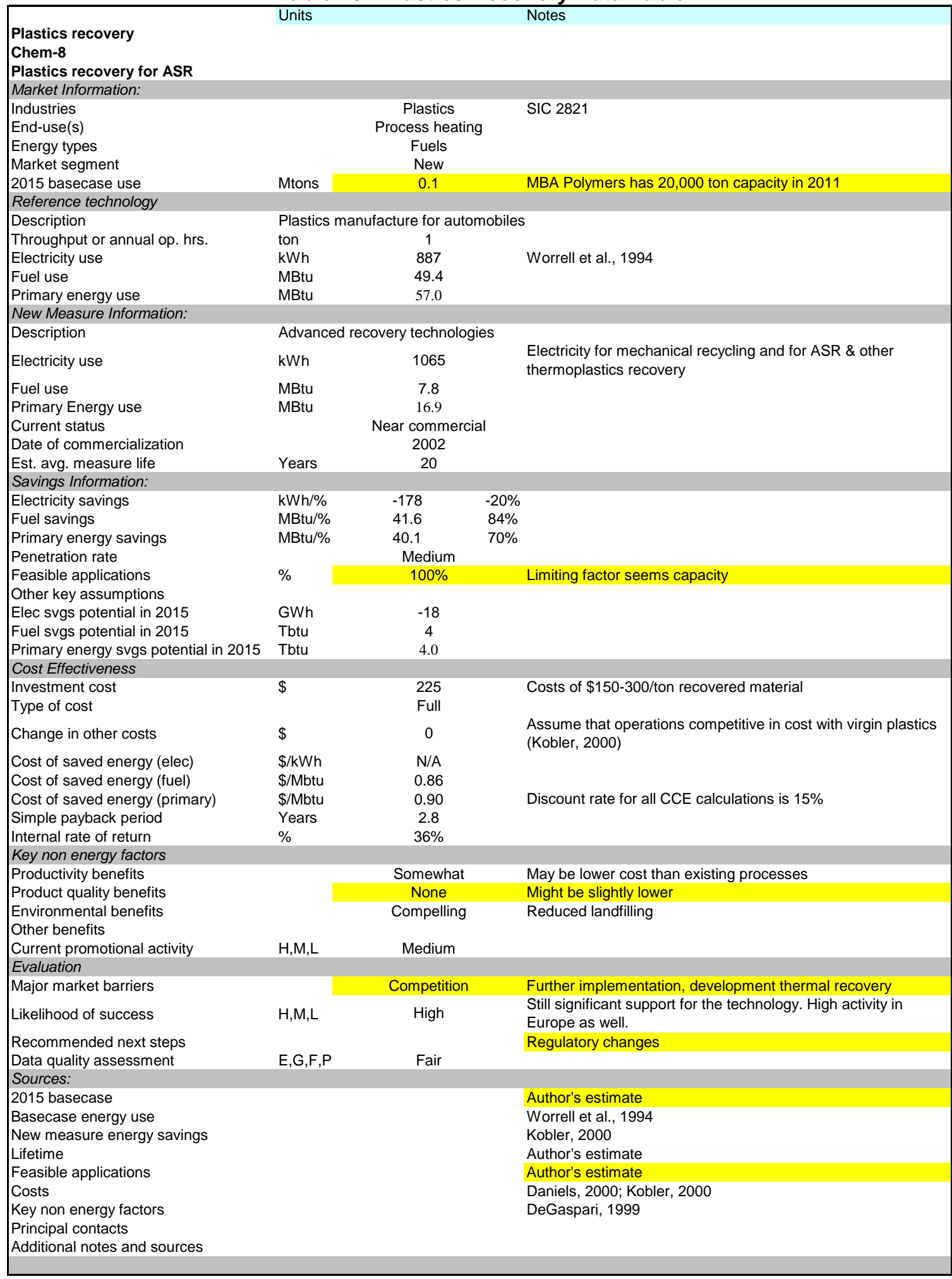




\subsection{Condensing Belt Drying (Paper-2)}

The pulp and paper industry is a large industrial energy user, with an estimated primary energy consumption of 2,354 TBtu (2495 PJ) in 2006 ([EIA], 2009a). Since 1994, energy consumption has declined by about 20\% (2,970 TBtu, or 3133 PJ) (EIA, 1997). Paper and paperboard production has remained constant since 1995 at about 85 Mton per year, most likely due to declining newspaper markets (Kramer, Masanet, Xu, \& Worrell, 2010). In the data table, we estimate paper and paperboard production at 90 Mton per year. Papermaking (as opposed to pulp production) is usually divided into four basic steps: 1) stock formation and forming, 2) pressing (mechanical dewatering), 3) evaporative drying, and 4) finishing. Of these steps, the drying is the most energyintensive since it requires evaporation of the water on the web.

In current drying practices, after the paper sheet is formed and pressed to remove excess water and promote bonding of fibers, and no more water can be removed mechanically, the sheet moves through a series of 40-50 steam heated cylinders, with the final consistency being about 90-95 percent solids content. With the Condensing Belt (or Condebelt) drying technology being developed by a Finnish company called Valmet (Metso nowadays), the paper is dried in a drying chamber by contact with a continuous hot steel band, heated either by steam or hot gas, rather than being run through the steam-heated cylinders. On the other side of the sheet are three layers: fine-wire gauze, coarse-wire gauze, and an externally cooled steel band. The evaporated water passes through the wire gauze and condenses on the steel band. The condensate is removed by pressure and suction (de Beer, 1998). The benefit of the Condebelt technology is that it has the potential to completely replace the drying section of a conventional paper machine, and has a drying rate 5-15 times higher than conventional methods (Lehtinen, 1995).

Based on results from pilot plant tests performed by Valmet, (de Beer, 1998) estimated that for larger drying machines where losses through the seals of the drying chamber can be better controlled, steam savings are 10 to 20 percent of existing processes, while electricity consumption is expected to remain equal.

The first commercial installations of the Condebelt technology were in Finland (1996) and South Korea (1999). These two plants produce industrial and packaging paper grades, and this technology may be applicable initially to continuous paperboard production (Dimond, 2000; Ojala, 2000). Because the Condebelt has a higher drying rate than standard drying machines, the size of the Condebelt dryer can be reduced. The two plants have been constructed as add-on technologies to existing facilities, with minimal energy savings. However, larger savings are possible if the Condebelt were constructed as a full replacement. Currently it appears that only one other South Korean plant has implemented condebelt technology in 2003 (Huovila, 2001).

As the technology has remained in an early commercialization stage, it assumed that costs have not changed significantly since 2000. Total costs for the installation of a paper machine including the forming and pressing can range from \$850-1,300/ton (Hekkert \& Worrell, 1997). Initial cost for the demonstration facility were $\$ 260 /$ ton paper (de Beer, 1998). One estimate suggests that the cost of installing Condebelt for a greenfield (or 
newly constructed) plant would run up to double the cost of an existing cylinder machine (Ojala, 2000; Ronkainen, 2000). Other estimates suggest that the cost would be roughly the same (Hekkert \& Worrell, 1997; Worrell, Bode, \& de Beer, 1997). We assume a 25 percent increase from existing costs. Operations and maintenance costs are not expected to change significantly from current practice.

Installation of Condebelt technology is expected to result in increased productivity (increased throughput, less capital expenditure) while also allowing for some improvement in product quality (de Beer, 1998; Retulainen \& Hämäläinen, 1999). There do not appear to be any significant technical barriers although no full-scale large commercial operations have been installed in the U.S. There are, however, other competing commercial and emerging drying technologies that may limit rapid uptake by the U.S. market.

While there appear to be limited technical barriers for this technology, it remains to be proven for a variety of paper grades (aside from linerboard) and has yet to make headway in the U.S. market and the world. We believe that the market penetration for this technology by 2015 will be low, and that several demonstration projects would probably be necessary to see how the technology fares under U.S. conditions. 
Table 14. Condensing Belt Drying Data Table

\begin{tabular}{|c|c|c|c|c|}
\hline & \multicolumn{3}{|l|}{ Units } & \multirow[t]{2}{*}{ Notes } \\
\hline Condebelt drying & 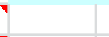 & & & \\
\hline Paper-2JW & 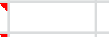 & & & \\
\hline Condensing belt drying & 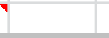 & & & \\
\hline \multicolumn{5}{|l|}{ Market Information: } \\
\hline Industries & \multicolumn{3}{|c|}{ Pulp and Paper } & NAICS 322 \\
\hline End-use(s) & 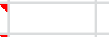 & \multicolumn{2}{|l|}{ Process heating } & \\
\hline Energy types & ' & \multicolumn{2}{|l|}{ Fuels, electricity } & \\
\hline Market segment & $\checkmark$ & \multicolumn{2}{|l|}{ New, retrofit } & \\
\hline 2015 basecase use & Mton & \multicolumn{2}{|l|}{90.0} & Extrapolation Kramer 2009 \\
\hline \multicolumn{5}{|l|}{ Reference technology } \\
\hline Description & \multicolumn{4}{|c|}{ Drying section, paper production } \\
\hline Throughput or annual op. hrs. & tons & \multicolumn{2}{|c|}{1} & \\
\hline Electricity use & kWh & \multicolumn{2}{|l|}{19} & Motor drive for machine rollers \\
\hline Fuel use & MBtu & \multicolumn{2}{|l|}{8.6} & Steam use in drying cylinders \\
\hline Primary energy use & MBtu & \multicolumn{2}{|l|}{8.7} & \\
\hline \multicolumn{5}{|l|}{ New Measure Information: } \\
\hline Description & Condensi & belt drying systen & & \\
\hline Electricity use & kWh & 19 & & De Beer, 1998b \\
\hline Fuel use & MBtu & 7.3 & & De Beer, 1998b \\
\hline Primary Energy use & MBtu & 7.5 & & \\
\hline Current status & 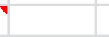 & Commercial & & \\
\hline Date of commercialization & ' & 1996 & & \\
\hline Est. avg. measure life & Years & 20 & & Worrell et al., 1997a \\
\hline Savings Information: & & & & \\
\hline Electricity savings & $\mathrm{kWh} / \%$ & 0 & $0 \%$ & De Beer, 1998b \\
\hline Fuel savings & MBtu/\% & 1.3 & $15 \%$ & De Beer, 1998b \\
\hline Primary energy savings & MBtu/\% & 1.3 & $15 \%$ & \\
\hline Penetration rate & Y & Medium & & \\
\hline Feasible applications & $\%$ & $20 \%$ & & Applicable to most paper grades. Demo currently w/ linerboard \\
\hline Other key assumptions & & & & \\
\hline Elec svgs potential in 2015 & GWh & 0 & & \\
\hline Fuel svgs potential in 2015 & Tbtu & 23 & & \\
\hline Primary energy svgs potential in $2015^{\circ}$ & Tbtu & 23.2 & & \\
\hline Cost Effectiveness & & & & \\
\hline Investment cost & $\$$ & 260 & & $\begin{array}{l}\text { Assume full paper machine costs of } \$ 1000 / \text { ton. Assume } 50 \% \text { drying } \\
\text { end. } \$ 600 / \text { ton full investment cost. (De Beer, 1998; Worrell et al. } \\
\text { 1997) }\end{array}$ \\
\hline Type of cost & & Incremental & & \\
\hline Change in other costs & $\$$ & 0 & & \\
\hline Cost of saved energy (elec) & $\$ / k W h$ & $\mathrm{~N} / \mathrm{A}$ & & \\
\hline Cost of saved energy (fuel) & $\$ / M b t u$ & 32.24 & & \\
\hline Cost of saved energy (primary) & $\$ / M b t u$ & 32.24 & & Discount rate for all CCE calculations is $15 \%$ \\
\hline Simple payback period & Years & 65.2 & & \\
\hline Internal rate of return & $\%$ & $-9 \%$ & & \\
\hline Key non energy factors & & & & \\
\hline Productivity benefits & & Significant & & Reduced capital expenditure (small machines), higher production rate \\
\hline Product quality benefits & & Somewhat & & Improvement in strength properties \\
\hline Environmental benefits & & None & & \\
\hline Other benefits & & & & \\
\hline Current promotional activity & $\mathrm{H}, \mathrm{M}, \mathrm{L}$ & Low & & One major supplier, non-US \\
\hline Evaluation & & & & \\
\hline Major market barriers & & Marketing, cost & & \\
\hline Likelihood of success & $\mathrm{H}, \mathrm{M}, \mathrm{L}$ & Low & & \\
\hline Recommended next steps & & & & US demonstration at commercial scale, global commercialization \\
\hline Data quality assessment & $E, G, F, P$ & Good & & \\
\hline Sources: & & & & \\
\hline 2015 basecase & 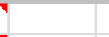 & & & Kramer et al. 2010 \\
\hline Basecase energy use & & & & $\begin{array}{l}\text { Elaahi \& Lowitt, 1988; Nilsson et al, 1995; Giraldo \& Hyman, 1994; } \\
\text { Jaccard \& Willis, } 1996\end{array}$ \\
\hline New measure energy savings & 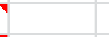 & & & De Beer, 1998b \\
\hline Lifetime & 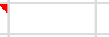 & & & Worrell et al., 1997a \\
\hline Feasible applications & & & & Retulainen, E., Hämäläinen, A. 1999 \\
\hline Costs & 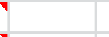 & & & De Beer, 1998b \\
\hline Key non energy factors & 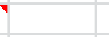 & & & Retulainen, E., Hämäläinen, A. 1999 \\
\hline Principal contacts & & & & \\
\hline Additional notes and sources & & & & \\
\hline
\end{tabular}




\subsection{Dry Sheet Forming (Paper-4)}

The pulp and paper industry is a large industrial energy user, with an estimated primary energy consumption of 2,354 TBtu (2495 PJ) in 2006 ([EIA], 2009a). Since 1994 energy consumption has declined by about 20\% (2,970 TBtu, or 3133 PJ) (EIA, 1997)). Paper and paperboard production has remained constant since 1995 at about 85 Mton per year, most likely due to declining newspaper markets (Kramer et al., 2010). In the data table we estimate paper and paperboard production at 90 Mton per year. Papermaking (as opposed to pulp production) is usually divided into four basic steps: 1) stock formation and forming, 2) pressing (mechanical dewatering), 3) evaporative drying, and 4) finishing. Of these steps, the drying is the most energy-intensive since it requires evaporation of the water on the web.

In the forming step, the continuous slurry that has been prepared is formed into a uniform web. The most common forming machines are twin wire formers (for thin and multi-layered sheets). Both machines deposit low consistency wood-pulp (less than 1 percent wood-pulp) onto a moving wire mesh, which allows water to drain away.

While originally conceived as a paper technology, dry web forming has developed into its own industry niche of non-woven, which involves the production of light absorbent paper-like materials used in personal hygiene products. In dry web forming, the nonwoven is produced without the addition of water. The fibers can be disbursed either through a carding technique or through an air layering technique. In the former, the fibers are disbursed mechanically while in the latter, fibers are suspended in air and paper is formed from this suspension. Fiber-to-fiber bonding is obtained by adding resins to the fibers or by spraying a polymer-latex onto the web formed. The air laying technique allows for a higher production rate and better control and most dry forming is done through this technique (de Beer, Blok, \& Worrell, 1998; Pivko, 1999b).

The advantage of dry sheet forming is the significant savings in energy requirements for evaporating water from the sheet in the later drying stage. (de Beer et al., 1998) estimates a savings of 50 percent in drying fuel requirements and an increase in electricity consumption in an air layering plant of $150-250 \mathrm{kWh} /$ ton paper to maintain the air stream and motor drive for the equipment.

Air laid drying/dry sheet forming technology was invented simultaneously by a Danish inventor named Karl Kroyer and by the Japanese at Honshu paper company (Pivko, 1999b). Early conception of the technology occurred in the 1940s, but commercialization of today's processes took place in the early 1980s through Moeller and Jochumsen (M\&J), a Danish firm (Pivko, 1999b). Today, other producers of dry formed technology include Dan Web (Denmark) and Honshu Paper Co. (Japan) (de Beer, 1998; Pivko, 1999b). United Paper Mills-kymmene had originally licensed the Dan-Web technology (used at Walkisoft, Finland) but is now not a manufacturer of this technology (Pivko, $1999 \mathrm{~b}$ ). Worldwide, installed capacity with this technology is about $350 \mathrm{ktons}$, and is growing rapidly. New capacity additions expected over the next couple of years are 120 ktons, mostly in North America (Pivko, 2000). Current installed capacity in North America is estimated to be only 0.1 percent of total paper production in this region 
([FAO], 2000; Pivko, 1999a). The largest capacity plant is being constructed in North Carolina (Ward, 2000).

The primary products currently being produced with this technology are personal hygiene products (diapers, feminine hygiene, adult incontinence, training pants for babies, baby wipes), and some specialty areas (tableware, medical products, hot towels in restaurants). This is a small percentage of the overall paper tissue market as production has already shifted into the non-woven. It was estimated that the market replacement potential is 5 percent of U.S. paper production (Kincaid, 1998).

If this technology becomes applicable to the paper industry, direct investment costs could be one-third to one-half a conventional non-integrated paper mill (de Beer, 1998). Operation and maintenance costs are also expected to be lower (de Beer, 1998). However, the technology does not have the same type of machine speed as paper producers $(1,500 \mathrm{~m} / \mathrm{min}$ as compared to up to $6000 \mathrm{~m} / \mathrm{min}$ on conventional paper machines) (Pivko, 2000).

Total costs for the installation of a paper machine (including the forming and pressing) can range from $\$ 850-1,300 /$ ton (Hekkert \& Worrell, 1997). Air-laid technologies are slightly more expensive. A 55,115 ton (50,000 tonne) state-of-the-art plant in North Carolina under construction is being built at an estimated cost of $\$ 1,500 /$ ton, the first project where costs have dropped below $\$ 2,000 /$ ton (Pivko, 2000). These lower costs may expand the potential market opportunities for this type of material. Aside from potential cost efficiencies that are associated with this technology, wastewater pollutants are eliminated thereby allowing a more flexible location of paper mills closer to demand centers.

It appears that dry sheet forming technology was not developed further for paper production by checking online sources in July 2010. Therefore, the only change in this update is the new base case in the data table. If this technology does progress, it is most likely because of specialty applications and not for standard paper grades. 
Table 15. Dry Sheet Forming Data

\begin{tabular}{|c|c|c|c|c|}
\hline & \multicolumn{3}{|l|}{ Units } & Notes \\
\hline \multicolumn{5}{|l|}{ Dry sheet forming } \\
\hline \multicolumn{5}{|l|}{ Paper-4JW } \\
\hline \multicolumn{5}{|l|}{ Dry sheet forming } \\
\hline \multicolumn{5}{|l|}{ Market Information: } \\
\hline Industries & \multicolumn{3}{|c|}{ Pulp and Paper } & NAICS 322 \\
\hline End-use(s) & Y & \multicolumn{2}{|l|}{ Process heating } & \\
\hline Energy types & 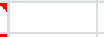 & \multicolumn{2}{|l|}{ Fuels, electricity } & \\
\hline Market segment & 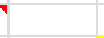 & \multicolumn{2}{|l|}{ New, retrofit } & \\
\hline 2015 basecase use & Mton & 90.0 & & Extrapolation Kramer 2009 \\
\hline \multicolumn{5}{|l|}{ Reference technology } \\
\hline Description & \multicolumn{4}{|c|}{ Paper drying } \\
\hline Throughput or annual op. hrs. & tons & \multicolumn{2}{|l|}{1} & \\
\hline Electricity use & kWh & \multicolumn{2}{|l|}{480} & Martin et al., 2000 \\
\hline Fuel use & MBtu & \multicolumn{2}{|l|}{9.2} & Fuel use primarily in drying, not forming stage; Martin et al.,2000 \\
\hline Primary energy use & MBtu & \multicolumn{2}{|l|}{13.3} & \\
\hline New Measure Information: & & & & \\
\hline Description & Dry shee & ming & & \\
\hline Electricity use & kWh & 710 & & De Beer, 1998b \\
\hline Fuel use & MBtu & 4.6 & & De Beer, 1998b \\
\hline Primary Energy use & MBtu & 10.6 & & \\
\hline Current status & & Commercial & & \\
\hline Date of commercialization & & 1985 & & \\
\hline Est. avg. measure life & Years & 20 & & Worrell et al., 1997 \\
\hline Savings Information: & & & & \\
\hline Electricity savings & kWh/\% & -230 & $-48 \%$ & \\
\hline Fuel savings & MBtu/\% & 4.3 & $47 \%$ & \\
\hline Primary energy savings & MBtu/\% & 2.3 & $18 \%$ & \\
\hline Penetration rate & & Medium & & \\
\hline Feasible applications & $\%$ & $5 \%$ & & Currently applied only to specialty products; Pivko, 1999 \\
\hline Other key assumptions & & & & \\
\hline Elec svgs potential in 2015 & GWh & -1033 & & \\
\hline Fuel svgs potential in 2015 & Tbtu & 19 & & \\
\hline Primary energy svgs potential in 2015 & Tbtu & 10.5 & & \\
\hline Cost Effectiveness & & & & \\
\hline Investment cost & $\$$ & 350 & & Cost ranges from $\$ 1,500$ to $\$ 2000 /$ tonne (Pivko, 1999) \\
\hline Type of cost & & Incremental & & \\
\hline Change in other costs & $\$$ & 0 & & \\
\hline Cost of saved energy (elec) & $\$ / k W h$ & -0.24 & & \\
\hline Cost of saved energy (fuel) & $\$ / M b t u$ & 13.02 & & \\
\hline Cost of saved energy (primary) & $\$ / M b t u$ & 23.87 & & Discount rate for all CCE calculations is $15 \%$ \\
\hline Simple payback period & Years & 48.3 & & \\
\hline Internal rate of return & $\%$ & N/A. & & \\
\hline Key non energy factors & & & & \\
\hline Productivity benefits & & None & & \\
\hline Product quality benefits & & Significant & & Improved product quality for personal hygiene products \\
\hline Environmental benefits & & Somewhat & & Reduction in water waste \\
\hline Other benefits & & & & \\
\hline Current promotional activity & $\mathrm{H}, \mathrm{M}, \mathrm{L}$ & & & Technology already in the marketplace \\
\hline Evaluation & & & & \\
\hline Major market barriers & & Technical & & $\begin{array}{l}\text { In niche market. Technology not likely applicable for broader } \\
\text { application }\end{array}$ \\
\hline Likelihood of success & $\mathrm{H}, \mathrm{M}, \mathrm{L}$ & Low & & For the niche market, but does not appear to be developed. \\
\hline Recommended next steps & & & & Research/demonstration on applicability to other grades \\
\hline Data quality assessment & $E, G, F, P$ & Good & & \\
\hline Sources: & & & & \\
\hline 2015 basecase & & & & Kramer et al., 2010 \\
\hline Basecase energy use & & & & Elahi \& Lowitt, 1998; Nillson et al., 1995; Jaccard \& Willis, 1996 \\
\hline New measure energy savings & & & & De Beer, 1998 \\
\hline Lifetime & ' & & & Worrell et al., $1997 a$ \\
\hline Feasible applications & & & & Pivko, 1999 \\
\hline Costs & 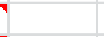 & & & Pivko, 1999 \\
\hline Key non energy factors & & & & De Beer, 1998; Pivko, 1999 \\
\hline Principal contacts & & & & \\
\hline Additional notes and sources & & & & \\
\hline
\end{tabular}




\subsection{Heat Recovery Paper-Enclosing Hoods (Paper-5)}

The pulp and paper industry is a large industrial energy user, with an estimated primary energy consumption of 2,354 TBtu (2495 PJ) in 2006 ([EIA], 2009a). Since 1994 energy consumption has declined by about 20\% (2,970 TBtu, or 3133 PJ) (EIA, 1997)). Paper and paperboard production has remained constant since 1995 at about 85 Mton per year, most likely due to declining newspaper markets (Kramer et al., 2010). In the data table we estimate paper and paperboard production at 90 Mton per year.

Papermaking (as opposed to pulp production) is usually divided into four basic steps: 1) stock formation and forming, 2) pressing (mechanical dewatering), 3) evaporative drying, and 4) finishing. Of these steps, the drying is the most energy-intensive since it requires evaporation of the water on the web.

In the drying section, steam filled rollers dry paper through the evaporation of water in the web. A typical drying machine may have up to 40-50 steam heated drying cylinders (de Beer, 1998; Elaahi \& Lowitt, 1988). Heat recovery technologies are primarily directed at this initial stage of the drying section. In the middle of this section is the size press, which can apply coating to the paper. The size press must be placed so that the paper can continue drying after coating because the coating itself must also dry. The last stage in the papermaking process is the Calendar stack, which is a series of carefully spaced rollers that control the thickness and smoothness of the final paper.

There is a strong link between pulp consistency and steam demand on the drying section. Here, pulp enters with a consistency of 40-45 percent and paper exits the machine with a consistency of 90-95 percent (Abrahamsson, Aly, Jernquist, \& Stenstrom, 1997; de Beer, 1998). Typically $2 \mathrm{~kg}$ water are evaporated per $\mathrm{kg}$ of paper and $6.7 \mathrm{~kg}$ of air is required to remove $1 \mathrm{~kg}$ of water vapor (de Beer, 1998). In the paper making process, the heat, which is mainly required in form of low-pressure steam, is transferred to the web via the steam-injected cylinders. As the water vapor exits the web, carried away by pre-heated air, and the web is dried, saturated low-pressure steam is released. The goal of more advanced waste heat recovery systems is to convert this lower quality steam into more useful heat. Existing equipment based on canopy air-to-air heat recovery systems recover about 15 percent of the energy contained in the hood exhaust air.

There are several systems for heat recovery that can improve energy efficiency. One new system involves the installation of enclosed hoods and sensors on the drying section of the paper machine. Paper machines with enclosed hoods can require up to one-half the amount of air per ton of water evaporated than paper machines with canopy hoods. Thermal energy demands are reduced since a smaller volume of air is heated. Electricity requirements in the exhaust fan are also reduced optimizing drying efficiency ([CADDET], 1994; Elaahi \& Lowitt, 1988). Another promising system further upgrades this waste heat by means of heat pumps and mechanical vapor recompression (MVR) (Abrahamsson et al., 1997; van Deventer, 1997). A different technology approach, which involves the heating provided to the cylinders, is to use stationary siphons to better extract the exhausted steam from the cylinders (Morris, 1998). The heat can also be recuperated from the ventilation air of the drying section and used for heating of the facilities (de Beer, Blok, van Wees, \& Worrell, 1994). 
U.S. paper drying consumption lies between 6-9 MBtu/ton (7-10.5 GJ/t) (Kramer et al., 2010). Roughly 20 percent of the heat is required for air heating. With enclosing hoods, air-heating requirements are minimized because of higher rates of heat recovery from the captured steam. Optimizing ventilation and using sensors control on the machine allows steam savings of $0.65 \mathrm{MBtu} /$ ton $(0.75 \mathrm{GJ} / \mathrm{t})$ paper and electricity savings of 5.7 $\mathrm{kWh} /$ ton $(6.3 \mathrm{kWh} / \mathrm{t})$ paper ([CADDET], 1994). (Conchie, 1993) claims further savings of $0.86 \mathrm{MBtu} /$ ton $(1 \mathrm{GJ} / \mathrm{t})$ in an UK tissue mill. These were achieved by replacing the worn out Yankee hood and adding two novel features to the machine: the counter current series air flow (mainly of interest to tissue and machine-glazed papers manufacturers) and humidity sensors (of general relevance to all papermakers). By using MVR to produce superheated steam from the water vapor extracts from the web, (van Deventer, 1997) estimated steam savings of 50 percent and an increase in electricity consumption of $145 \mathrm{kWh} /$ ton $(159 \mathrm{kWh} / \mathrm{t})$. Improved siphon technology can achieve savings up to $0.76 \mathrm{MBtu} /$ ton $(0.88 \mathrm{GJ} / \mathrm{t})$.

([CADDET], 1994) noted the cost of $\$ 9.5 /$ ton paper and additional O\&M costs of $\$ 0.07 /$ ton paper for the installation of a closed hood system that optimizes ventilation ([CADDET], 1994; Conchie, 1993). The addition of technologies to upgrade the heat (e.g. MVR and heat pumps) is estimated to be more expensive, $\$ 17.6 /$ ton paper (de Beer et al., 1994). Because the heat exchangers require frequent cleaning, the additional O\&M costs will amount to $\$ 1.6 /$ ton paper. In addition to energy savings, enclosing hoods and optimizing ventilation can also increase productivity. In one installation, the payback from increased material throughput (an additional 5,500 tons) was less than 1.5 years ([CADDET], 1994).

Enclosing hoods and optimizing ventilation can be a successful technology in the marketplace for all paper grades, and there might be a likelihood of achieving significant market penetration for the future. It is most likely that this technology would be installed for larger newer machines, so rapid market penetration is limited. Since 2000 little development has been identified from online searches. 
Table 16. Heat Recovery Paper Data Table

\begin{tabular}{|c|c|c|c|c|}
\hline & \multicolumn{3}{|l|}{ Units } & Notes \\
\hline \multicolumn{5}{|c|}{ Heat Recovery Paper (Enclosing hood) } \\
\hline \multicolumn{5}{|l|}{ Paper-5JW } \\
\hline \multicolumn{5}{|l|}{ Heat recovery in paper drying } \\
\hline \multicolumn{5}{|l|}{ Market Information: } \\
\hline Industries & \multicolumn{3}{|c|}{ Pulp and Paper } & NAICS 322 \\
\hline End-use(s) & ' & \multicolumn{2}{|l|}{ Process heating } & \\
\hline Energy types & ' & \multicolumn{2}{|l|}{ Fuels, electricity } & \\
\hline Market segment & I & \multicolumn{2}{|l|}{ New, retrofit } & \\
\hline 2015 basecase use & Mton & 90.0 & & Extrapolation Kramer 2009 \\
\hline \multicolumn{5}{|l|}{ Reference technology } \\
\hline Description & \multicolumn{4}{|c|}{ Drying section paper production } \\
\hline Throughput & tons & \multicolumn{2}{|l|}{1} & \\
\hline Electricity use & kWh & \multicolumn{2}{|l|}{18} & Martin et al., 2000 (electricity share for the whole drying section) \\
\hline Fuel use & MBtu & \multicolumn{2}{|l|}{1.8} & $20 \%$ of Fuel use in drying is for air heating; de Beer, 1998 \\
\hline Primary energy use & MBtu & \multicolumn{2}{|l|}{2.0} & \\
\hline New Measure Information: & & & & \\
\hline Description & Enclosing & $n$ the drying sect & ion of $p$ & Iapermaking allows to recover the heat necessary for air heating \\
\hline Electricity use & kWh & 12 & & CADDET, 1994; Van Deventer, 1997 \\
\hline Fuel use & MBtu & 1.1 & & CADDET, 1994; Van Deventer, 1998 \\
\hline Primary Energy use & MBtu & 1.2 & & \\
\hline Current status & ' & Commercial & & \\
\hline Date of commercialization & ' & & & \\
\hline Est. avg. measure life & Years & 20 & & Based on lifetime of other drying technologies \\
\hline Savings Information: & & & & \\
\hline Electricity savings & kWh/\% & 6.30 & $35 \%$ & \\
\hline Fuel savings & MBtu/\% & 0.76 & $41 \%$ & \\
\hline Primary energy savings & MBtu/\% & 0.81 & $41 \%$ & \\
\hline Penetration rate & & Medium & & \\
\hline Feasible applications & $\%$ & $20 \%$ & & Author estimate, based on stock turnover of larger machines \\
\hline Other key assumptions & & & & \\
\hline Elec svgs potential in 2015 & 'GWh & 113.4 & & \\
\hline Fuel svgs potential in 2015 & 'Tbtu & 13.7 & & \\
\hline Primary energy svgs potential in 2015 & Tbtu & 14.6 & & \\
\hline Cost Effectiveness & & & & \\
\hline Investment cost & $\$$ & 9.5 & & CADDET 1994; Conchie, 1993 \\
\hline Type of cost & 7 & Full cost & & \\
\hline Change in other costs & $\$$ & 0.07 & & O\&M costs CADDET (1994f) \\
\hline Cost of saved energy (elec) & $\$ / k W h$ & 0.25 & & \\
\hline Cost of saved energy (fuel) & $\$ /$ Mbtu & 2.09 & & \\
\hline Cost of saved energy (primary) & $\$ / M b t u$ & 1.95 & & Discount rate for all CCE calculations is $15 \%$ \\
\hline Simple payback period & Years & 3.9 & & \\
\hline Internal rate of return & $\%$ & $25 \%$ & & \\
\hline Key non energy factors & & & & \\
\hline Productivity benefits & & Somewhat & & Increased throughput \\
\hline Product quality benefits & & None & & \\
\hline Environmental benefits & & Somewhat & & Reduced emissions \\
\hline Other benefits & & Somewhat & & Safety. The steam is not discharged indoor \\
\hline Current promotional activity & $H, M, L$ & Medium & & Installations do already exist in EU \\
\hline Evaluation & & & & \\
\hline Major market barriers & & & & Information \\
\hline Likelihood of success & 'H,M,L & Medium & & \\
\hline Recommended next steps & & & & Continued demonstration \\
\hline Data quality assessment & $E, G, F, P$ & Good & & \\
\hline Sources: & & & & \\
\hline 2015 basecase & 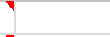 & & & Kramer et al., 2010 \\
\hline Basecase energy use & 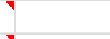 & & & Martin et al., 2000 \\
\hline New measure energy savings & ' & & & (CADDET 1994f) (Conchie 1993). \\
\hline Lifetime & ' & & & De Beer 1998; Martin et al. 2000 \\
\hline Feasible applications & & & & Both paper mills and waste paper mills \\
\hline Costs & ' & & & (CADDET 1994f) (Conchie 1993). \\
\hline Key non energy factors & V & & & (CADDET 1994f) (Conchie 1993). \\
\hline Principal contacts & & & & \\
\hline Additional notes and sources & & & & \\
\hline
\end{tabular}




\subsection{Impulse Drying (Paper-7)}

The pulp and paper industry is a large industrial energy user, with an estimated primary energy consumption of 2,354 TBtu (2495 PJ) in 2006 ([EIA], 2009a). Since 1994 energy consumption has declined by about 20\% (2,970 TBtu or 3133 PJ) (EIA, 1997)). Paper and paperboard production has remained constant since 1995 at about 85 Mton per year, most likely due to declining newspaper markets (Kramer et al., 2010). In the data table we estimate paper and paperboard production at 90 Mton per year. Papermaking (as opposed to pulp production) is usually divided into four basic steps: 1) stock formation and forming, 2) pressing (mechanical dewatering), 3) evaporative drying, and 4) finishing. Of these steps, the drying is the most energy-intensive since it requires evaporation of the water on the web.

In current drying practices, after the paper sheet is formed and pressed and no more water can be removed mechanically, the sheet moves through a series of 40-50 steam heated cylinders, with the final consistency being about 90-95 percent solids content. In conventional papermaking the web has moisture content of 45-50 percent before entering the drying section. Impulse drying is a technology that improves the mechanical dewatering of paper and reduces the amount of water that needs to be removed in the drying section. In impulse drying the paper web is subjected to very high temperatures at the press nip in order to drive moisture out of the web so that the moisture content is significantly reduced (to 38 percent or less) before entering the drying phase (US DOE (U. S. D. o. E. [DOE-OIT], Office of Industrial Technologies, 1998). The technology involves pressing the paper between one very hot rotating roll $\left(300-900^{\circ} \mathrm{F}\right)$ and a static concave a conventional shoe press. The pressure is about ten times higher than that in press and Condebelt drying (Boerner \& Orloff, 1994; de Beer et al., 1998). Ultimately, consistencies of the sheet can be increased to 55 percent for board and 78 percent for lightweight paper using impulse drying, but the paper still needs to be fed through a conventional drying system after this stage (de Beer, 1998). The impulse dryer can be retrofitted into an existing machine or incorporated into new models. For new machines, the size and costs of the paper machine can be reduced compared to existing processes, thereby making it more cost-effective. Also the drying rate can be significantly increased (50-500 times).

This technology was first developed in 1980 at the Institute of Paper Science and Technology in the U.S. with the collaboration of Beloit (de Beer, 1998). The patents for this technology were originally licensed to Beloit and are now owned by Metso, a Finnish company.

While impulse drying is applicable to many grades of paper, initial U.S. efforts were directed toward the drying of newsprint and linerboard (de Beer, 1998). Successful production of reeled impulse dried linerboard took place in September, 1998 when an impulse dryer was tested on a Beloit paper machine (Orloff, Phelan, \& Asensio, 1999; Orloff, Phelan, \& Crouse, 1999). Beloit research facilities tested a variety of pilot scale configurations, including the addition of a short and regular shoe press and hover press, to eliminate delamination problems (Orloff \& Crouse, 1999). Most recent, test trials have documented an increase in speed and an increase in speed, press dryness, and strength 
characteristics compared to existing technology (Larsson \& Orloff, 2000; Orloff, Phelan, \& Asensio, 1999; Orloff, Phelan, \& Crouse, 1999).

Given the higher consistencies of the paper or board entering the conventional drying section, drying energy consumption is significantly reduced. (de Beer, 1998) assumes potential steam consumption reductions of 40-50 percent with a small increase in electricity consumption of 5-10 percent (de Beer, 1998). However, these estimates assume that the rotating roll is heated by fuel. Both the Canadian and U.S. pilot tests were based on electric induction heating of the rotating roll which reduces primary energy savings to closer to 15 percent ([CADDET], 1995; Orloff, Phelan, \& Asensio, 1999; Orloff, Phelan, \& Crouse, 1999).

In a recent (2008) publication of Natural Resources Canada on electrical impulse drying, costs of installing the technology for a 180,000 ton per year machine is estimated at $\$ 17.5$ million (Guérette, 2008). This would result in incremental installation costs of $\$ 97 /$ ton paper. Operation and maintenance costs are estimated to be $\$ 10$ lower.

Impulse drying has been shown to produce paper which is thinner, smoother and stronger than that yielded by the conventional drying process ([CADDET], 1995; Orloff \& Crouse, 1999; Orloff, Phelan, \& Asensio, 2000). Trials with a South African furnish demonstrated increased production speeds by 14 percent and reduced basis weight (i.e. increased strength) by 2.5-5 percent, with an overall 20 percent improvement in productivity (Orloff et al., 2000). The drying section can also be reduced, resulting in lower capital costs. It allows an existing paper mill to operate at increased speeds (thus increasing production capacity), and allows for a new paper machine to significantly reduce the number of conventional drying rollers.

While the technology is promising, there were problems initially with the paper delaminating or sticking to the roll (Boerner \& Orloff, 1994; Orloff \& Crouse, 1999). Research has focused on inhibiting sheet delamination through impulse drying at elevated ambient nip-opening pressures or through controlled depressurization (Orloff \& Crouse, 1999; Orloff et al., 2000). These methods may actually improve the operational flexibility of the technology. Still, there is concern that technical obstacles for commercialization might be insurmountable (Ronkainen, 2000).

The creation of a commercial market for impulse drying has not yet become a reality and the development of full-scale commercial demonstration units will still be needed to help transition this technology to market. There does not yet appear to be significant backing for a large scale U.S. demonstration project and researchers at the Swedish pulp and paper research institute have stated that there is lot of work to be done before commercial application will be reality (Luiten, 2000). In more recent years only Canada appears to be busy with further development (Guérette, 2008). 
Table 17. Impulse Drying Data Table

\begin{tabular}{|c|c|c|c|c|}
\hline \multicolumn{4}{|c|}{ Units } & \multirow[t]{2}{*}{ Notes } \\
\hline \multirow{2}{*}{\multicolumn{5}{|c|}{$\begin{array}{l}\text { Impulse drying } \\
\text { Paper-7JW }\end{array}$}} \\
\hline & & & & \\
\hline \multicolumn{5}{|l|}{ Impulse drying } \\
\hline \multicolumn{5}{|l|}{ Market Information: } \\
\hline Industries & \multicolumn{3}{|c|}{ Pulp and Paper } & NAICS 322 \\
\hline End-use(s) & & \multicolumn{2}{|l|}{ Process heating } & \\
\hline Energy types & & \multicolumn{2}{|l|}{ Fuels, electricity } & \\
\hline Market segment & & \multicolumn{2}{|l|}{ New, retrofit } & \\
\hline 2015 basecase use & Mton & \multicolumn{2}{|l|}{90.0} & Extrapolation Kramer et al. 2010 \\
\hline \multicolumn{5}{|l|}{ Reference technology } \\
\hline Description & \multicolumn{4}{|c|}{ Drying section, paper production } \\
\hline Throughput or annual op. hrs. & tons & \multicolumn{2}{|c|}{1} & \\
\hline Electricity use & kWh & \multicolumn{2}{|l|}{19} & Motor drive for machine rollers \\
\hline Fuel use & MBtu & \multicolumn{2}{|l|}{8.6} & Steam use in drying cylinders \\
\hline Primary energy use & MBtu & 8.7 & & \\
\hline New Measure Information: & & & & \\
\hline Description & Impulse o & g system & & \\
\hline Electricity use & kWh & 170 & & Orloff et al., 1999 \\
\hline Fuel use & MBtu & 6.2 & & Orloff et al., 1999 \\
\hline Primary Energy use & MBtu & 7.6 & & \\
\hline Current status & & Commercial & & \\
\hline Date of commercialization & & 1996 & & \\
\hline Est. avg. measure life & Years & 20 & & Worrell et al., 1997a, Atlas project \\
\hline Savings Information: & & & & \\
\hline Electricity savings & $\mathrm{kWh} / \%$ & -151 & $-810 \%$ & \\
\hline Fuel savings & MBtu/\% & 2.4 & $28 \%$ & \\
\hline Primary energy savings & MBtu/\% & 1.1 & $13 \%$ & \\
\hline Penetration rate & & Medium & & \\
\hline Feasible applications & $\%$ & $20 \%$ & & Initial penetration in newsprint and linerboard \\
\hline Other key assumptions & & & & \\
\hline Elec svgs potential in 2015 & GWh & -2724 & & \\
\hline Fuel svgs potential in 2015 & Tbtu & 43 & & \\
\hline Primary energy svgs potential in $2015^{3}$ & Tbtu & 20.0 & & \\
\hline Cost Effectiveness & & & & \\
\hline Investment cost & $\$$ & 97 & & Typical cost: $\$ 17.5$ million for 180,000 ton/year machine \\
\hline Type of cost & & Incremental & & \\
\hline Change in other costs & $\$$ & -10 & & $\$ 1 /$ ton higher productivity, $\$ 9 /$ ton gas savings \\
\hline Cost of saved energy (elec) & $\$ / \mathrm{kWh}$ & -0.04 & & \\
\hline Cost of saved energy (fuel) & $\$ / \mathrm{Mbtu}$ & 2.31 & & \\
\hline Cost of saved energy (primary) & $\$ /$ Mbtu & 4.97 & & Discount rate for all CCE calculations is $15 \%$ \\
\hline Simple payback period & Years & 7.2 & & \\
\hline Internal rate of return & $\%$ & $13 \%$ & & \\
\hline Key non energy factors & & & & \\
\hline Productivity benefits & & Significant & & $\begin{array}{l}\text { Reduced capital expenditure (small machines), higher } \\
\text { production rate }\end{array}$ \\
\hline Product quality benefits & & Somewhat & & Improvement in strength properties \\
\hline Environmental benefits & & None & & \\
\hline Other benefits & & & & \\
\hline Current promotional activity & $\mathrm{H}, \mathrm{M}, \mathrm{L}$ & Low & & One major supplier, non-US \\
\hline Evaluation & & & & \\
\hline Major market barriers & & Marketing & & \\
\hline Likelihood of success & $\mathrm{H}, \mathrm{M}, \mathrm{L}$ & Medium & & \\
\hline Recommended next steps & & & & US demonstration at commercial scale \\
\hline Data quality assessment & $E, G, F, P$ & Fair & & \\
\hline Sources: & & & & \\
\hline 2015 basecase & & & & Kramer et al., 2010 \\
\hline Basecase energy use & & & & $\begin{array}{l}\text { Elaahi \& Lowitt, 1988; Nilsson et al, 1995; Giraldo \& Hyman, } \\
\text { 1994; Jaccard \& Willis, } 1996\end{array}$ \\
\hline New measure energy savings & & & & De Beer, 1998 \\
\hline Lifetime & & & & Worrell et al., 1997a \\
\hline Feasible applications & & & & Martin et al., 2000 \\
\hline Costs & & & & Guérette 2008 \\
\hline Key non energy factors & & & & \\
\hline Principal contacts & & & & \\
\hline Additional notes and sources & & & & \\
\hline
\end{tabular}




\section{References}

[AEO], Energy Information Administration, U.S. Department of Energy. (1999). Energy Outlook 2000 (No. DOE/EIA-0383(2000)). Washington, DC: U.S.

Department of Energy, Energy Information Administration.

[AEO], Energy Information Administration, U.S. Department of Energy. (2010). Energy Outlook 2010 (No. DOE/EIA-0383(2010)). Washington, DC: U.S.

Department of Energy, Energy Information Administration.

[ANL], Argonne National Laboratory. (1998). Biodesulfurization of Gasoline - A Technology Roadmap. Argonne, IL: Argonne National Laboratory.

[Anon]. (1997). Chemical and Engineering News Production Statistics. Chemical and Engineering News, 72(27).

[CADDET], Centre for the Analysis and Dissemination of Demonstrated Energy Technologies. (1989). The Pyrocore ceramic fiber-matrix burner - Technical Brochedure 38.

[CADDET], Centre for the Analysis and Dissemination of Demonstrated Energy Technologies. (1990). Cooling system for fruit and vegetable storage plant - Technical Brochedure R061.

[CADDET], Centre for the Analysis and Dissemination of Demonstrated Energy Technologies. (1993a). Energy-saving roller kiln - Technical Brochedure R132.

[CADDET], Centre for the Analysis and Dissemination of Demonstrated Energy Technologies. (1993b). An ice pond system for industrial process cooling - Technical Brochedure R135.

[CADDET], Centre for the Analysis and Dissemination of Demonstrated Energy Technologies. (1994). Optimisation of drying-hood ventilation in the paper industry Project No. NL-94-541.

[CADDET], Centre for the Analysis and Dissemination of Demonstrated Energy Technologies. (1995). Electrical impulse drying in the paper and pulp industry Canadian Register, CA-95-503.

[CADDET], Centre for the Analysis and Dissemination of Demonstrated Energy Technologies. (1996). Retrofit cogeneration system at milk processing plant - Technical Brochedure R257.

[CADDET], Centre for the Analysis and Dissemination of Demonstrated Energy Technologies. (1997). Revolutionary low-NOx high efficiency gas burner - Technical Brochedure R284.

[CADDET], Centre for the Analysis and Dissemination of Demonstrated Energy Technologies. (2000a). Industrial hot air burner - Project No. US-97-502. 
[CADDET], Centre for the Analysis and Dissemination of Demonstrated Energy Technologies. (2000b). Natural gas engine-driven low temperature NH3 refrigeration Project No. US-93-535.

[DOE-ITP], U.S. Department of Energy Industrial Technologies Program. (2005). Austin Energy: Pumping System Improvement Project Saves Energy and Improves Performance at a Power Plant Project Summary. Washington, DC: U.S. Department of Energy.

[DOE-ITP], U.S. Department of Energy Industrial Technologies Program. (2006). Improving Pumping System Performance: A Sourcebook for Industry. Washington, DC: U.S. Department of Energy.

[DOE-OIT], U.S. Department of Energy, Office of Industrial Technologies. (1999a). Fouling Minimization. Washington, DC: Office of Industrial Technologies.

[DOE-OIT], U.S. Department of Energy, Office of Industrial Technologies. (1999b). Fractionation of Corn Fibers for Production of Polyols. Chemicals Project Fact Sheet (February).

[DOE-OIT], U.S. Department of Energy, Office of Industrial Technologies. (1999c). Gasoline Biodesulfurization. Washington, DC: Office of Industrial Technologies.

[DOE-OIT], U.S. Department of Energy, Office of Industrial Technologies. (2000). "Decision Tools for Industry." PSAT (Pumping System Assessment Tool) CDROM. Washington, DC: U.S. Department of Energy and ORC Macro.

[DOE-OIT], U.S. Department of Energy, Office of Industrial Technologies. (2002). Martinez Refinery Completes Plant-Wide Energy Assessment (No. DOE/GO-1020021618). Washington, DC: U.S. Department of Energy, Office of Industrial Technologies.

[DOE-OIT], U. S. D. o. E., Office of Industrial Technologies. (1998). Characterization and Conditioning of Tars Produced During Black Liquor Gasification. Washington, DC: U.S. Department of Energy.

[DOE-VTP], U.S. Department of Energy Vehicle Technologies Program. (2009). Recovering Plastics from Retired Vehicles. Washington DC: U.S Department of Energy.

[DOE], U.S. Department of Energy. (1999). "Optimized Pump Systems Save Coal Preparation Plant Money and Energy." Motor Challenge Technical Case Study. Washington, DC: U.S. Department of Energy, Office of Industrial Technologies.

[EIA], U.S. Energy Information Administration. (2009a). 2006 Manufacturing Energy Consumption Survey. Washington, DC: U.S. Energy Information Administration.

[EIA], U.S. Energy Information Administration. (2009b). Annual U.S. Sulfur Content (Weighted Average) of Crude Oil Input to Refineries. In MCRS1US2a.jpg (Ed.). Washington, DC: U.S. Energy Information Administration. 
[EIA], U.S. Energy Information Administration. (2010). Gasoline Components History. Retrieved 7/19/10, from http://tonto.eia.doe.gov/oog/info/gdu/gaspump.html

[EPA], U.S. Environmental Protection Agency. (2000). EPA website at www.epa.gov.

[EPA], U.S. Environmental Protection Agency. (2008). Municipal Solid Waste Generation, Recycling, and Disposal in the United States: Facts and Figures for 2008 (No. EPA-530-F-009-021). Washington, DC: United States Environmental Protection Agency.

[FAO], Food and Agricultural Organization, United Nations. (2000). Statistical database online at: http://www.fao.org.

[FDA], U.S. Food and Drug Administration. (2008). Irradiation in the Production, Processing and Handling of Food (Vol. E8-19573, pp. 49593-49603): U.S. Food and Drug Administration.

[GRI], Gas Research Institute. (1997). Gas Engine-Driven Refrigeration System Reduces Energy Costs - September - GRI Periodical Article. Chicago, IL: Gas Technology Institute.

[IIR], International Institut of Refrigeration. (2003). 17th Informatory Note on Refrigerating Technologies: How to improve energy efficiency in refrigerating equipment. Paris, France: International Institut of Refrigeration.

[USCAR], United States Council for Automotive Research. (1998). USCAR 'Bubbling' About Plastics Separation for Recycling. USCAR Newsletter (fall).

[WEC], World Energy Council. (1995). Efficient Use of Energy Utilizing High Technology: An Assessment of Energy Use in Industry and Buildings. London, UK: World Energy Council.

Abrahamsson, K., Aly, G., Jernquist, A., \& Stenstrom, S. (1997). Application of Heat Pump Systems for Energy Conservation in Paper Drying. International Journal of Energy Research, 21, 631-642.

Ashpole, S. (2009). Recycle bale wire scrap at point of generation. American Recycler, 12, A14-A15.

Berntsson, T., Franck, P.-A., \& Asblad, A. (1997). Process Heating in the Low and Medium Temperature Ranges (No. 22). Sittard, the Netherlands: IEA-CADDET.

Betts, K. (1999). Ford Opens Door to Plastics Recycling. Environmental Science and Technology News.

Biddle, M. (MBA Polymers). (2000). In N. Martin (Ed.)

Boerner, J., \& Orloff, D. (1994). Effects of Basis Weight and Freeness on Sheet Permeability and Critical Impulse-Drying Temperature. Tappi Journal, 77(2), 163168. 
Bott, T. R. (2000). Biofouling Control with Ultrasound. Heat Transfer Engineering, 21(3).

Brownell, K. A. (1998). "Investigation of the Field Performance for Industrial Refrigeration Systems." M.Sc. Thesis. University of Wisconsin, Madison, WI.

CADDET Newsletter. (1999). 21st Century combustion technology now available. 1(March), 7-8.

Callahan, T. J. (2003). Advanced Reciprocating Engine Systems, Distributed Energy Road Show. San Antonio, TX.

Chambers, A., \& Trottier, S. (2007). Technologies for Reducing NOx Emissions from Gas-Fired Stationary Combustion Sources (No. CEM 10685-2007). Edmonton, Canada: Alberta Research Council: Carbon and Energy Management.

COEN. (2000). http://www.coen.com.

Conchie, S. (1993). Dryer hood optimization at Scott Northfleet (Cinderella comes of age!). Paper Technology, 39-42.

Daniels, E. (Argonne National Laboratory). (2000). Froth Flotation. In N. Martin (Ed.).

de Beer, J. (1998). Potential for Industrial Energy Efficiency Improvement in the Long Term. Utrecht University, Utrecht, Netherlands.

de Beer, J., Blok, K., van Wees, M. T., \& Worrell, E. (1994). Icarus-3. The Potential of Energy Efficiency Improvement in The Netherlands up to 2000 and 2015. Utrecht, Netherlands: Utrecht University.

de Beer, J., Blok, K., \& Worrell, E. (1998). Long-term energy efficiency improvements in the paper and board industry. Energy, 23(1), 21-42.

de Oliveira Filho, L. O., Liporace, F. S., Queiroz, E. M., \& Costa, A. L. H. (2009). Investigation of an alternative operating procedure for fouling management in refinery crude preheat trains. Applied Thermal Engineering, 29(14-15), 3073.

DeGaspari, J. (1999). From Trash to Cash. Mechanical Engineering Magazine (June).

Deligio, T. (2010). MBA Polymers to double recycling capacity pushes for US reclaim legislation. Retrieved 21 July, 2010, from http:// www.plasticstoday.com/articles/plastics-recycling-mba-polymers-doublescapacity-pushes-legislation

Denison, R. A. (1996). Environmental Life-Cycle Comparisons of Recycling, Landfilling, and Incineration: A Review of Recent Studies. Annual Review of Energy and the Environment, 21, 191-237.

Diesel \& Gas Turbine Worldwide. (2006). 2006 Annual Mechanical Drive: Order Survey. 
Diesel \& Gas Turbine Worldwide. (2007). 2007 Annual Mechanical Drive: Order Survey.

Diesel \& Gas Turbine Worldwide. (2008). 2008 Annual Mechanical Drive: Order Survey.

Diesel \& Gas Turbine Worldwide. (2009). 2009 Annual Mechanical Drive: Order Survey.

Diesel \& Gas Turbine Worldwide. (2010). 2010 Annual Mechanical Drive: Order Survey.

Dimond, P. (Weyerhauser Corporation). (2000). In N. Martin (Ed.).

EIA. (1997). Manufacturing Consumption of Energy 1994 (No. DOE/EIA-0512(94)). Washington, DC: U.S. Department of Energy, Energy Information Administration.

Elaahi, A., \& Lowitt, H. E. (1988). The US Pulp and Paper Industry: An Energy Perspective. Washington, DC: U.S. Department of Energy.

Elliott, R. N., \& Spurr, M. (1999). Combined Heat and Power: Capturing Wasted Energy. Washington, DC: American Council for an Energy Efficient Economy.

Elmi, G. (1993). Fast Firing Technology in the Brick and Tile Industry - A Technical Evaluation. Ziegelindustrie (3).

Energy and Environmental Analysis, Inc. (2005). Characterization of the U.S. Industrial Commercial Boiler Population.

Fickett, B., \& Mihalik, G. (2001). Multiple batch recharging for industrial CZ silicon growth. Journal of Crystal Growth, 225(2-4), 580.

Fisher, M. (American Plastics Council). (2000). In N. Martin (Ed.).

Fisher, M., \& Mark, F. (1999, SAE Technical Paper Series 1999-01-0664). The Role of Plastics in Automotive Shredder Residue (ASR): Characterization and Environmental Assessment. Paper presented at the Society of Automotive Engineers (SAE) International Congress and Exhibition.

Flanagan, J. M. (1993). Learning from Experiences with the Process Heating in the Metals Industry (No. 11). Sittard, the Netherlands: IEA-CADDET.

Gas Research Institute and National Renewable Energy Laboratory. (2003). GasFired Distributed Energy Resource Technology Characterizations. Oak Ridge, TN: U.S. Department of Energy.

Guérette, J. (2008). Electrical Impulse Drying. Ottawa, Canada: CanmetENERGY, Natural Resources Canada.

Hackett, B., Chow, S., \& Ganji, A. (2005, July 19-22). Energy Efficiency Opportunities in Fresh Fruit and Vegetable Processing/Cold Storage Facilities. Paper presented the 2005 ACEEE Summer Study on Energy Efficiency in Industry, West Point, NY. 
Hedman, B. (2009). CHP: The State of the Market.

Hekkert, M. P., \& Worrell, E. (1997). Technology Characterisation for Natural Organic Materials (No. 98002). Utrecht, Netherlands: Utrecht University.

Herron, J. (2010, April). Silicon future remains in Siemens process. Photon International.

Hovstadius, G., Erickson, R. B., \& V., T. (2000). Pumping System Life Cycle Costs, an Overlooked Opportunity? PumpLines, 10-12.

Huangfu, E. (2000). In N. Martin (Ed.): U.S. Department of Energy.

Huovila, V. (2001). Metso Paper receives repeat Condebelt dryer order from Wolsan Paper Co.: Metso.

ICF: EEA. (2008). Technology Characterization: Gas Turbines. Arlington, VA: ICF: Energy and Environmental Analysis.

Kerr, T. (2008). CHP/DGC Country Scorecard: United States. Paris, France: International Energy Agency.

Kincaid, J. (Ed.). (1998). 1998 North American Pulp and Paper Fact Book. San Francisco, CA: Miller Freeman Publications.

Kobler, R. (Recovery Plastics International). (2000). In N. Martin (Ed.).

Kramer, K. J., Masanet, E., Xu, T., \& Worrell, E. (2010). Energy Efficiency Improvement and Cost Saving Opportunities for the Pulp and Paper Industry (No. LBNL-2268E). Berkeley, CA: Lawrence Berkeley National Laboratory.

Larsson, H., \& Orloff, D. (2000). Lab-scale Impulse Drying Experiments with Extension to Higher Impulse, 12th International Drying Symposium.

Noordwijkerhout, Netherlands.

Lawless, A. (2007). Food Irradiation - What's the big deal? , Michigan State University, East Lansing, MI.

Lehtinen, J. (1995). Condebelt Drying of Paper and Paperboard for Optimizing Quality and Production for Many Grades. Drying Technology, 13(8-9), 2049-2068.

Lipinsky, E., \& Wesson, R. (1995). Characterization of the Top12 U.S. Commodity Polymers. Washington, DC: U.S. Department of Energy, Biological and Chemical Technology Research Program.

Lorentzen, G. (1993a). Application of 'natural' refrigerants. IIF/IIR Energy Efficiency in Refrigeration and Global Warming Impact - Proceedings of meetings of Commissions B1/2 of the International Institute for Refrigeration(IIR)/Institut International de Froide (IIF).

Lorentzen, G. (1993b). Large heat pumps using CO2 refrigerant. IIF/IIR Energy Efficiency in Refrigeration and Global Warming Impact - Proceedings of meetings of 
Commissions B1/2 of the International Institute for Refrigeration(IIR)/Institut International de Froide (IIF).

Luiten, E. (2000). In N. Martin (Ed.): Utrecht University.

Martin, N., Worrell, E., Ruth, M., Price, L., Elliott, R. N., Shipley, A. M., et al. (2000). Emerging Energy-Efficient Industrial Technologies (No. LBNL 46990).

Berkeley, CA: Lawrence Berkeley National Laboratory.

Marvin, D. (2009, 1 August). Sustainability Defined. Ceramic Industry.

Mckinley, S. (2001). California: A Gold Rush for Reciprocating Engine Generators Sustainable Facility.

McKinsey. (2009). Unlocking Energy Efficiency in the U.S. Economy.

Mohebali, G., \& Ball, A. S. (2008). Biocatalytic desulfurization (BDS) of petrodiesel fuels. Microbiology-Sgm, 154, 2169-2183.

Montgomery, D. (2006). High Efficiency, Low Emissions Gas Engine Technology Implementation at Caterpillar, 3rd Annual Advanced Stationary Reciprocating Engines Meeting.

Morris, K. L. (1998). Dryer Section Rebuild at Bowater Calhoun Lowers Stem Use, Ups Machine Speed. Pulp and Paper Magazine (October).

Mottal, R. (1995). Heat pump technology and working fluids. In Conference Proceedings of the 19th International Congress of Refrigeration. Part IVb. The Hague, Netherlands: IIR/IIF.

Mueller, G. (2007). The Czochralski method - where we are 90 years after Jan Czochralski's invention. Crystal Research and Technology, 42(12), 1150-1161.

Nadel, S., Elliott, R. N., Shepard, M., Greenberg, S., Katz, G., \& de Almeida, A. T. (2000). Energy-Efficient Motor Systems (2nd Ed.). Washington, DC: American Council for an Energy-Efficient Economy.

Ojala, T. (Valmet Corporation). (2000). In N. Martin (Ed.).

Okos, M., Rao, N., Drecher, S., Rode, M., \& Kozak, J. (1998). Energy Usage in the Food Industry: American Council for an Energy-Efficient Economy.

Onsite Sycom Energy Corporation. (2000). The Market and Technical Potential for the Combined Heat and Power in the Industrial Sector. Washington, DC: Department of Energy: Energy Information Administration.

Orloff, D., \& Crouse, J. (1999). Impulse drying: Status of the Pilot Scale Research Program. Tappi Journal, 82(9).

Orloff, D., Phelan, P., \& Asensio, C. (1999, September 12-16). Impulse Drying of Board Grades: Converting Trials. Paper presented at the 1999 TAPPI Engineering/Process and Product Quality Conference and Trade Fair. 
Orloff, D., Phelan, P., \& Asensio, C. (2000, September 17-21). Impulse Drying of South African Furnish. Paper presented at the 2000 TAPPI Engineering Conference.

Orloff, D., Phelan, P., \& Crouse, J. (1999, September 12-16). Impulse Drying of Board Grades: Pilot Production Trials. Paper presented at the 1999 TAPPI

Engineering/Process and Product Quality Conference and Trade Fair.

Panchal, C. B. (2000). Fouling Minimization. In N. Martin (Ed.). Annapolis, MD: Energy Concepts Company.

Panchal, C. B., \& Huangfu, E. (2000). Effects of Mitigating Fouling on the Energy Efficiency of Crude-Oil Distillation. Heat Transfer Engineering, 21(3).

Pelsoci, T. (2007). ATP-Funded Green Process Technologies: Improving U.S. Industrial Competitiveness with Applications in Packaging, Metals Recycling, Energy, and Water Treatment (No. GCR 06-897). Washington, DC: U.S. Department of Commerce, National Institute of Standards and Technology.

Pivko, I. (1999a). Technology in Search of Markets. Nonwovens Industry Story.

Pivko, I. (1999b). Technology in Search of Markets. Longboat Key, FL: Notabene Associates.

Pivko, I. (2000). Dry forming technology. In N. Martin (Ed.), Nonwovens Industry Story.

Pöhlmann, H. (2009). The HOB CerTec 6-m Roller: Fresh Impetus for Roller Kiln Engineering. Cfi-Berichte der DGK, 86(2), E19.

Ramírez, C. A., Patel, M., \& Blok, K. (2006). How much energy to process one pound of meat? A comparison of energy use and specific energy consumption in the meat industry of four European countries. Energy, 31(12), 2047.

Retulainen, E., \& Hämäläinen. (1999, September 12-16). Three Years of Condebelt Drying at Stora Enso Pankakoski Mill in Finland. Paper presented at the 1999 TAPPI Engineering/Process and Product Quality Conference and Trade Fair.

Ronkainen, P. (Valmet Corporation). (2000). In N. Martin (Ed.).

SACMI. (2008). FBS Double Channel Roller Kiln - Brochure FBS 260 - 285.

Saga, T. (2010). Advances in crystalline silicon solar cell technology for industrial mass production. NPG Asia Materials, 2(3), 96-102.

Saito, A. (2002). Recent advances in research on cold thermal energy storage. International Journal of Refrigeration-Revue Internationale Du Froid, 25(2), 177-189.

Salyp Elv Center. Website. www.salyp.com. Details on auto shredder residue.

Schwob, M. R. V., Henriques Jr, M., \& Szklo, A. (2009). Technical potential for developing natural gas use in the Brazilian red ceramic industry. Applied Energy, 86(9), 1524. 
Seeberger, A., \& Jess, A. (2010). Desulfurization of diesel oil by selective oxidation and extraction of sulfur compounds by ionic liquids-a contribution to a competitive process design. Green Chemistry, 12(4), 602-608.

Skerrett, P. J. (1997). Food Irradiation: Will It Keep the Doctor Away. Technology Review (November/December).

Soleimani, M., Bassi, A., \& Margaritis, A. (2007). Biodesulfurization of refractory organic sulfur compounds in fossil fuels. Biotechnology Advances, 25(6), 570-596.

Stene, J. (1999). Natural Working Fluids - A Safe and Energy-Efficient Alternative in Compression Heat Pumping Systems. IEA Heat Pump Centre Newsletter, 17(3), 24-26.

Sullivan, D. (2004). The Role of the Merox ${ }^{\mathrm{TM}}$ Process in the Era of Ultra Low Sulfur Transportation Fuels, 5th EMEA Catalyst Technology Conference. Cannes, France.

Tomasseti, G. (1995). The Manufacture of Bricks and Ceramic Tiles in Italy: Two Innovative Production Processes. In Energy Improvement Utilising High Technology. London, UK: World Energy Council.

Trepp, C., Savoie, P., \& Kraus, W. E. (1992). Investigation of the Performance Behaviour of a Compression Refrigerating Unit with Halogen Refrigerant Mixtures R22/R142b, R22/R114 and R22/R12. International Journal of Refrigeration, 14(2), 101-111.

Tutterow, V., Casada, D., \& McKaine, A. (2002). Pumping System Efficiency Improvements Flow Straight to the Bottom Line (No. LBNL-51043). Washington, DC: Lawrence Berkeley National Laboratory.

van Deventer, H. C. (1997). Feasibility of Energy-Efficient Steam Drying of Paper and Textile Including Process Integration. Applied Thermal Engineering, 8(10351041).

Virta, R. L. (1998). Clays and Shale. In Minerals Yearbook 1998. Washington, DC: United States Geological Survey.

Virta, R. L. (2007). Clays and Shale. In Minerals Yearbook 2007. Washington, DC: United States Geological Survey.

Wang, L. (2009). Energy Efficiency and Management in Food Processing Facilities. Boca Raton, FL: CRC Press.

Ward, D. T. (2000). Growth of Nonwovens Shows No Signs of Slowing. International Fiber Journal, 15(1).

Wei, Z., Chen, J., Li, J., Xu, G., Lang, J., \& Huang, B. (2008). Research on temperature control system of ceramic roller kiln based on FCS. 2008 Pacific-Asia Workshop on Computational Intelligence and Industrial Application. PACIIA 2008, 412-415. 
Whittemore, O. J. (1999). Energy Use and Efficiencies in Firing Ceramics, Melting Glass. American Ceramic Society Bulletin, 69-71.

Worrell, E. (1994). Potential for Improved Use of Industrial Energy and Materials. Utrecht University, Utrecht, Netherlands.

Worrell, E., Bode, J. W., \& de Beer, J. (1997). Analysing Research and Technology Development Strategies: The ATLAS Project, Energy Efficient Technologies in Industry. Utrecht, Netherlands: Utrecht University.

Xenergy. (1998). United States Industrial Electric Motor Systems Market Opportunities Assessment. Burlington, MA: Office of Energy Efficiency and Renewable Energy.

Xu, P., Feng, J. H., Yu, B., Li, F. L., \& Ma, C. Q. (2009). Recent Developments in Biodesulfurization of Fossil Fuels. In Biotechnology in China I (Vol. 113, pp. 255274).

Yeap, B. L., Wilson, D. I., Polley, G. T., \& Pugh, S. J. (2001). Incorporation of Fouling Models into the Design of Heat Transfer Networks. In H. MüllerSetinhagen (Ed.), Heat Exchanger Fouling: Fundamental Approaches and Technical Solutions (pp. 243-248). Germnay: Publico Publications.

Yegian, D. T., \& Cheng, R. K. (1998). Development of a lean premixed low-swirl burner for low NOx practical applications. Combustion Science and Technology, 139(1-6), 207-227.

Yester, S. (USCAR). (2000). U.S. car research consortium. In N. Martin (Ed.). 